\title{
Barriers and facilitators to the implementation of lay health worker programmes to improve access to maternal and child health: a qualitative evidence synthesis (Review)
}

Glenton C, Colvin CJ, Carlsen B, Swartz A, Lewin S, Noyes J, Rashidian A

Glenton C, Colvin CJ, Carlsen B, Swartz A, Lewin S, Noyes J, Rashidian A.

Barriers and facilitators to the implementation of lay health worker programmes to improve access to maternal and child health: a qualitative evidence synthesis.

Cochrane Database of Systematic Reviews 2013, Issue 10. Art. No.: CD010414.

DOI: 10.1002/14651858.CD010414.pub2.

www.cochranelibrary.com

Barriers and facilitators to the implementation of lay health worker programmes to improve access to maternal and child health: a qualitative evidence synthesis (Review) 
TABLE OF CONTENTS

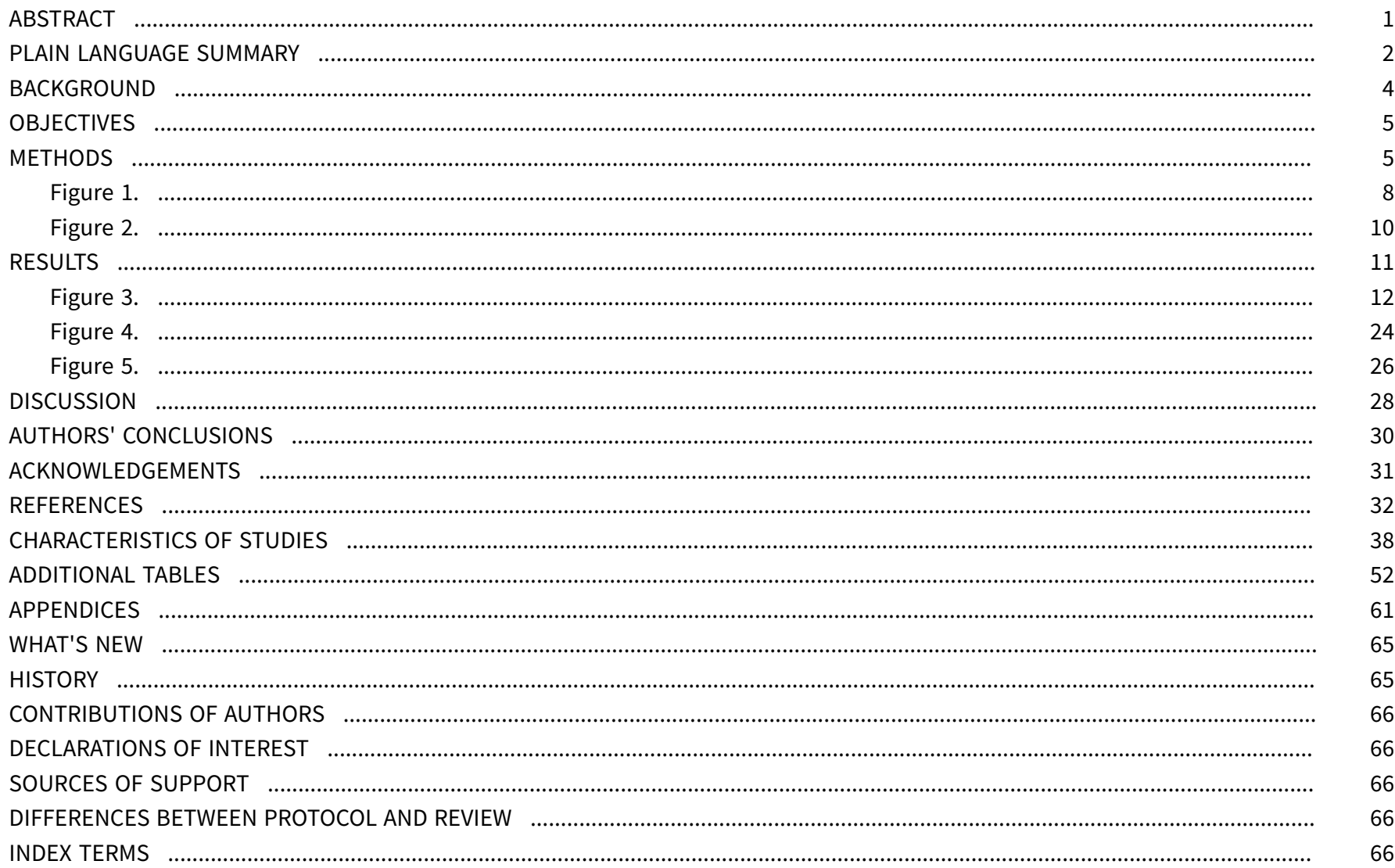


[Qualitative Review]

\title{
Barriers and facilitators to the implementation of lay health worker programmes to improve access to maternal and child health: a qualitative evidence synthesis
}

\author{
Claire Glenton ${ }^{1}$, Christopher J Colvin² ${ }^{2}$ Benedicte Carlsen ${ }^{3}$, Alison Swartz ${ }^{4}$, Simon Lewin ${ }^{1,5}$, Jane Noyes ${ }^{6}$, Arash Rashidian ${ }^{7}$
}

${ }^{1}$ Norwegian Institute of Public Health, Oslo, Norway. ${ }^{2}$ Centre for Infectious Disease Epidemiology and Research (CIDER), School of Public Health and Family Medicine, University of Cape Town, Cape Town, South Africa. ${ }^{3}$ Uni Rokkan Centre, Bergen, Norway. ${ }^{4}$ Primary Health Care Directorate, University of Cape Town Health Sciences, Cape Town, South Africa. ${ }^{5}$ Health Systems Research Unit, South African Medical Research Council, Tygerberg, South Africa. ${ }^{6}$ Centre for Health-Related Research, Fron Heulog, Bangor University, Bangor, UK. ${ }^{7}$ Department of Health Management and Economics, School of Public Health, Tehran University of Medical Sciences, Tehran, Iran

Contact: Claire Glenton, Norwegian Institute of Public Health, PO Box 7004 St Olavs plass, Oslo, N-0130, Norway. claire.glenton@fhi.no.

Editorial group: Cochrane Effective Practice and Organisation of Care Group.

Publication status and date: Edited (no change to conclusions), published in Issue 3, 2019.

Citation: Glenton C, Colvin CJ, Carlsen B, Swartz A, Lewin S, Noyes J, Rashidian A. Barriers and facilitators to the implementation of lay health worker programmes to improve access to maternal and child health: a qualitative evidence synthesis. Cochrane Database of Systematic Reviews 2013, Issue 10. Art. No.: CD010414. DOI: 10.1002/14651858.CD010414.pub2.

Copyright @ 2019 The Cochrane Collaboration. Published by John Wiley \& Sons, Ltd.

\section{A B S T R A C T}

\section{Background}

Lay health workers (LHWs) perform functions related to healthcare delivery, receive some level of training, but have no formal professional or paraprofessional certificate or tertiary education degree. They provide care for a range of issues, including maternal and child health. For LHW programmes to be effective, we need a better understanding of the factors that influence their success and sustainability. This review addresses these issues through a synthesis of qualitative evidence and was carried out alongside the Cochrane review of the effectiveness of LHWs for maternal and child health.

\section{Objectives}

The overall aim of the review is to explore factors affecting the implementation of LHW programmes for maternal and child health.

\section{Search methods}

We searched MEDLINE, OvidSP (searched 21 December 2011); MEDLINE Ovid In-Process \& Other Non-Indexed Citations, OvidSP (searched 21 December 2011); CINAHL, EBSCO (searched 21 December 2011); British Nursing Index and Archive, OvidSP (searched 13 May 2011 ). We searched reference lists of included studies, contacted experts in the field, and included studies that were carried out alongside the trials from the LHW effectiveness review.

\section{Selection criteria}

Studies that used qualitative methods for data collection and analysis and that focused on the experiences and attitudes of stakeholders regarding LHW programmes for maternal or child health in a primary or community healthcare setting.

\section{Data collection and analysis}

We identified barriers and facilitators to LHW programme implementation using the framework thematic synthesis approach. Two review authors independently assessed study quality using a standard tool. We assessed the certainty of the review findings using the CerQual approach, an approach that we developed alongside this and related qualitative syntheses. We integrated our findings with the outcome 
measures included in the review of LHW programme effectiveness in a logic model. Finally, we identified hypotheses for subgroup analyses in future updates of the review of effectiveness.

\section{Main results}

We included 53 studies primarily describing the experiences of LHWs, programme recipients, and other health workers. LHWs in high income countries mainly offered promotion, counselling and support. In low and middle income countries, LHWs offered similar services but sometimes also distributed supplements, contraceptives and other products, and diagnosed and treated children with common childhood diseases. Some LHWs were trained to manage uncomplicated labour and to refer women with pregnancy or labour complications.

Many of the findings were based on studies from multiple settings, but with some methodological limitations. These findings were assessed as being of moderate certainty. Some findings were based on one or two studies and had some methodological limitations. These were assessed have low certainty.

Barriers and facilitators were mainly tied to programme acceptability, appropriateness and credibility; and health system constraints. Programme recipients were generally positive to the programmes, appreciating the LHWs' skills and the similarities they saw between themselves and the LHWs. However, some recipients were concerned about confidentiality when receiving home visits. Others saw LHW services as not relevant or not sufficient, particularly when LHWs only offered promotional services. LHWs and recipients emphasised the importance of trust, respect, kindness and empathy. However, LHWs sometimes found it difficult to manage emotional relationships and boundaries with recipients. Some LHWs feared blame if care was not successful. Others felt demotivated when their services were not appreciated. Support from health systems and community leaders could give LHWs credibility, at least if the health systems and community leaders had authority and respect. Active support from family members was also important.

Health professionals often appreciated the LHWs' contributions in reducing their workload and for their communication skills and commitment. However, some health professionals thought that LHWs added to their workload and feared a loss of authority.

LHWs were motivated by factors including altruism, social recognition, knowledge gain and career development. Some unsalaried LHWs wanted regular payment, while others were concerned that payment might threaten their social status or lead recipients to question their motives. Some salaried LHWs were dissatisfied with their pay levels. Others were frustrated when payment differed across regions or institutions. Some LHWs stated that they had few opportunities to voice complaints.

LHWs described insufficient, poor quality, irrelevant and inflexible training programmes, calling for more training in counselling and communication and in topics outside their current role, including common health problems and domestic problems. LHWs and supervisors complained about supervisors' lack of skills, time and transportation. Some LHWs appreciated the opportunity to share experiences with fellow LHWs.

In some studies, LHWs were traditional birth attendants who had received additional training. Some health professionals were concerned that these LHWs were over-confident about their ability to manage danger signs. LHWs and recipients pointed to other problems, including women's reluctance to be referred after bad experiences with health professionals, fear of caesarean sections, lack of transport, and cost. Some LHWs were reluctant to refer women on because of poor co-operation with health professionals.

We organised these findings and the outcome measures included in the review of LHW programme effectiveness in a logic model. Here we proposed six chains of events where specific programme components lead to specific intermediate or long-term outcomes, and where specific moderators positively or negatively affect this process. We suggest how future updates of the LHW effectiveness review could explore whether the presence of these components influences programme success.

\section{Authors' conclusions}

Rather than being seen as a lesser trained health worker, LHWs may represent a different and sometimes preferred type of health worker. The close relationship between LHWs and recipients is a programme strength. However, programme planners must consider how to achieve the benefits of closeness while minimizing the potential drawbacks. Other important facilitators may include the development of services that recipients perceive as relevant; regular and visible support from the health system and the community; and appropriate training, supervision and incentives.

\section{PLAIN LANGUAGE SUMMARY}

\section{Factors that can influence the success of lay health worker programmes for maternal and child health}

This review was carried out by researchers in The Cochrane Collaboration. It summarises the findings of 53 studies that explore factors influencing the success of lay health worker (LHW) programmes for mothers and child health. This review was carried out alongside the Cochrane review assessing the effectiveness of LHW programmes on maternal and child health.

\section{What is a lay health worker?}


A LHW is a lay person who has received some training to deliver healthcare services but is not a health professional. In most of the studies in this review, LHWs offered health care to people who were on low incomes living in wealthy countries or to people living in poor countries. The LHWs in wealthy countries offered health promotion, counselling and support. The LHWs in poor countries offered similar services but they sometimes also distributed food supplements, contraceptives and other products, treated children with common childhood diseases, or managed women in uncomplicated labour.

\section{What the research says}

The studies described the experiences of LHWs, mothers, programme managers, and other health workers with LHW programmes. Many of our findings were based on studies from different settings and had some methodological problems. We judged these findings to have moderate certainty. Some findings were only based on one or two studies that had some methodological problems and were judged to be of low certainty.

Mothers were generally positive about the programmes. They appreciated the LHWs' skills and the similarities they saw between themselves and the LHWs. However, some mothers were concerned about confidentiality when receiving home visits. Others saw LHW services as not relevant or not sufficient, particularly when LHWs only offered promotional services. LHWs and mothers emphasised the importance of trust, respect, kindness and empathy. However, LHWs sometimes found it difficult to manage emotional relationships and boundaries with mothers. Some LHWs feared blame if health care was not successful. Others felt demotivated when their services were not appreciated. Support from health systems and community leaders could give LHWs credibility if these health systems and community leaders had authority and respect. Active support from family members was also important.

Health professionals often appreciated the LHWs' contributions to reducing their workload, and their communication skills and commitment. However, some health professionals thought that LHWs added to their own workloads and feared a loss of authority.

LHWs were motivated by altruism, social recognition, knowledge gain and career development. Some unsalaried LHWs wanted regular payment. Others were concerned that payment might threaten their social status or lead people to question their motives. Some salaried LHWs were dissatisfied with their pay levels. Others were frustrated when other LHWs had higher salaries. Some LHWs said that they had few opportunities to voice complaints.

Some LHWs described insufficient, poor quality and irrelevant training programmes. They called for more training in counselling and communication and in topics outside their current role, including common health problems and domestic problems. LHWs and supervisors complained about supervisors' lack of skills, time and transportation. Some LHWs appreciated the opportunity to share experiences with other LHWs.

Some LHWs were traditional birth attendants who had received additional training. Some health professionals were concerned that these LHWs were over-confident about their ability to manage danger signs. LHWs and mothers identified women's reluctance to be referred after bad experiences with health professionals, fear of caesarean sections, lack of transport, and costs. Some LHWs were also reluctant to refer women on because of poor co-operation with health professionals.

We organized these findings into chains of events where we have proposed how certain LHW programme elements might lead to greater programme success.

\section{Authors' conclusions}

Rather than being seen as a lesser trained health worker, LHWs represent a different and sometimes preferred type of health worker. The often close relationship between LHWs and their recipients is a strength of such programmes. However, programme planners must consider how to achieve the benefits of closeness while avoiding the problems. It may also be important to offer services that recipients perceive as relevant; to ensure regular and visible support from other health workers and community leaders; and to offer appropriate training, supervision and incentives. 


\section{B A C K G R O U N D}

The Millennium Development Goals 4, 5 and 6 aim to reduce child mortality, improve maternal health, and combat HIV/AIDS, malaria and other diseases. A key obstacle to the achievement of these goals is the chronic shortage and poor distribution of health workers in many countries (WHO 2010). One important approach to this problem is the moving of tasks to health workers with less training, or 'task-shifting' (sometimes referred to as 'optimising') for instance by transferring certain tasks from doctors to nurses, midwives, or lay health workers. By re-organising the health workforce in this way, policy makers hope to make more efficient use of the human resources already available and thereby expand and strengthen coverage of key health interventions (WHO 2012; WHO/PEPFAR/UNAIDS 2007).

\section{Description of the intervention}

Lay health workers (LHWs) perform diverse functions related to healthcare delivery. While LHWs are usually provided with job-related training they have no formal professional or paraprofessional tertiary education, and can be involved in either paid or voluntary care (Lewin 2005). The term 'lay health worker' is thus broad in scope and includes, for example, community health workers, village health workers, treatment supporters and birth attendants.

The primary healthcare approach adopted by the World Health Organization (WHO) at Alma-Ata promoted the initiation and rapid expansion of LHW programmes in low and middle income country settings, including a number of large national programmes, in the 1970s (Walt 1990). However, the effectiveness and costs of such programmes came to be questioned in the following decade, particularly at national level. Several evaluations were conducted and these indicated difficulties in the scaling up of LHW programmes as a consequence of a range of factors. Important constraints included inadequate training and ongoing supervision; insecure funding for incentives, equipment and drugs; failure to integrate LHW initiatives with the formal health system; poor planning; and opposition from health professionals (Frankel 1992; Walt 1990). These constraints led to poor quality care and difficulties in retaining trained LHWs in many of the programmes.

The 1990s saw renewed interest in community or LHW programmes in low and middle income countries. This was prompted by a number of factors including the growing AIDS epidemic; the resurgence of other infectious diseases; and the failure of the formal health system to provide adequate care for people with chronic illnesses (Hadley 2000; Maher 1999). The growing emphasis on decentralisation and partnership with communitybased organisations also contributed to this renewed interest. In high income country settings, a perceived need for mechanisms to deliver health care to minority communities and to support people with a wide range of health issues (Hesselink 2009; Witmer 1995) led to further growth in a variety of LHW interventions.

More recently, the growing focus on the human resource crisis in health care in many low and middle income countries has re-energised debates regarding the roles that LHWs may play in extending services to 'hard to reach' groups and areas, and in substituting for health professionals for a range of tasks (Chopra 2008; WHO 2005; WHO 2006; WHO 2007). Task shifting is not a new concept. However, it has been given particular prominence and urgency in the face of the demands placed on health systems, in a number of settings, by the increased need for treatment of HIV/AIDS (Hermann 2009; Lehmann 2009; Schneider 2008; Zachariah 2009). Within this context, it is thought that LHWs may be able to play an important role in helping to achieve the Millennium Development Goals for health, particularly for child survival and treatment of tuberculosis (TB) and HIV/AIDS (Chen 2004; Filippi 2006; Haines 2007; Lewin 2008). For example, LHWs may be one route to expanding the coverage of effective neonatal and child health interventions, such as exclusive breastfeeding and communitybased case management of pneumonia, which remain under $50 \%$ in many low and middle income countries (Darmstadt 2005).

In contrast to earlier initiatives that tended to focus on generalist LHWs delivering a range of services within communities, more recent programmes have often been vertical in their approaches. In these programmes LHWs deliver a single or a small number of focused interventions addressing a particular health issue, such as promotion of vaccination; or one aspect of treatment care, such as supporting treatment adherence for people with tuberculosis (TB) (Lehmann 2007; Schneider 2008).

\section{Why it is important to do this review}

The Cochrane review on the effectiveness of LHW programmes for maternal and child health and infectious diseases (Lewin 2010) identified a total of 82 randomised trials, representing a substantial body of evidence regarding the effectiveness of these types of programmes. In these trials, LHWs received a small amount of training to perform a range of health services, often targeting common causes of childhood mortality and morbidity. The review concluded that these types of programmes can effectively deliver key maternal and child health interventions in primary and community health care, including interventions to increase childhood immunisation rates and breastfeeding rates.

While the review concluded that this approach is promising, the results of these trials were heterogeneous, which, given the complexity of these types of interventions, was not unexpected. In addition, the level of organisation and support used for these interventions may have been higher than in real-life settings. If these types of interventions are to be successfully implemented and scaled up, we need a greater understanding of the factors that may influence their success and sustainability. These include the values, preferences, knowledge and skills of stakeholders, and the feasibility and applicability of the intervention for particular settings and healthcare systems (see Table 1 for an overview of factors affecting implementation). While Cochrane reviews of effectiveness are not designed to answer these types of questions, there is growing acknowledgement that syntheses of qualitative research can address questions such as these.

It is also increasingly recognised that bringing together qualitative studies in one synthesis can add value by allowing us to see both similarities and differences that exist across various contexts. As with systematic reviews of effectiveness, syntheses of qualitative data should be carried out in a systematic and transparent way. The last few years have seen strong development in the methodology for synthesising data from multiple qualitative studies, including within The Cochrane Collaboration (Noyes 2009), and the Cochrane Qualitative Research Methods Group has identified around 500 such syntheses. 
While high quality syntheses of qualitative evidence can on their own prove valuable to researchers and policymakers, pairing qualitative syntheses with systematic reviews of (quantitative) effectiveness data allows for even more comprehensive insights into single topic areas. At least one Cochrane review has previously prompted a 'matching' synthesis of qualitative data. The Cochrane review of directly observed therapy (DOT) versus self-administered treatment for adherence to TB treatment showed that DOT, despite its widespread use, does not achieve better outcomes (Volmink 2007). Two parallel reviews, both co-authored by members of the current research team (Munro 2007; Noyes 2007), searched for qualitative studies on factors explaining non-adherence to TB treatment. Together, these syntheses of qualitative research not only provided supporting evidence regarding the intervention's lack of effect but also helped explain this lack of effect and informed policy and the design of more appropriate interventions (Garner 2007). Qualitative evidence also helped to clarify the many often context-specific barriers and facilitators to accessing and complying with complex interventions to promote medicines management and treatment.

Pairing reviews of effectiveness with reviews of qualitative studies is equally relevant in the field of health workforce interventions, and a large body of relevant qualitative research exists. This research has described barriers and facilitators to the success of interventions targeting different aspects of human resources for health. These barriers and facilitators include the attitudes and experience of the health workers themselves and also those of other stakeholders such as the health professionals they work with or whose tasks they have taken over, and the communities they serve. On the one hand, health workers taking on new tasks may appreciate the opportunity to be more useful as well as to gain increased salaries and public recognition (De Brouwere 2009). On the other hand, task shifting may not be accompanied by sufficient supervision or compensation and can create confusion, role conflicts and competition between health worker groups (De Brouwere 2009; Yakan 2009).

Previously we had attempted to identify all qualitative studies that were carried out alongside the 82 trials included in the review of LHW programme effectiveness. We did this by contacting authors of all the included trials, checking papers for references to qualitative research, searching PubMed for related studies, and carrying out citation searches. However, we were only able to find qualitative research that had been done during or after the trial for $14(17 \%)$ of the trials (Glenton 2011). In addition, descriptions of qualitative methods and results were often sparse. Therefore, we decided to look for qualitative studies that explored LHW programmes either alongside or outside a trial context.

This review is one of a series of reviews that aimed to inform the World Health Organization's 'Recommendations for Optimizing Health Worker Roles to Improve Access to key Maternal and Newborn Health Interventions through Task Shifting' (OPTIMIZEMNH) (WHO 2012).

\section{O B JE C T IVES}

The overall aim of the review is to explore factors affecting the implementation of lay health worker (LHW) programmes for maternal and child health.
- to identify, appraise and synthesise qualitative research evidence on the barriers and facilitators to the implementation of LHW programmes for maternal and child health;

- to integrate the findings of this review with the findings of the Cochrane review of effectiveness of LHW programmes (Lewin 2013) so as to enhance and extend our understanding of how these complex interventions work, and how context impacts on implementation;

- to identify hypotheses for undertaking subgroup analyses in future updates of the Cochrane review of the effectiveness of LHW programmes (Lewin 2013).

\section{METHODS}

\section{Criteria for considering studies for this review}

\section{Types of studies}

We included studies that used qualitative study designs such as ethnographic research, case studies, process evaluations and mixed methods designs. We included these studies if they had used qualitative methods for data collection (including focus group and individual interviews, observation, and document analysis) and qualitative methods for data analysis (including thematic analysis or any other appropriate qualitative analysis method that enabled analysis of text and observations and narrative presentation of findings). We therefore excluded studies that had collected data using qualitative methods but had analysed these data using quantitative methods.

\section{Types of participants}

We included studies that focused on the experiences and attitudes of stakeholders about lay health worker programmes in any country. Participants could include lay health workers, patients and their families, policy makers, programme managers, other health workers, or any others involved in or affected by the programmes.

\section{Types of interventions}

We included studies of programmes that were delivered in a primary or community healthcare setting; that intend to improve maternal or child health; and that had used any type of lay health worker, including community health workers, village health workers, birth attendants, peer counsellors, nutrition workers and home visitors.

For the purpose of this review, we defined a lay health worker as any health worker who:

- performs functions related to healthcare delivery,

- is trained in some way in the context of the intervention, but

- has received no formal professional or paraprofessional certificate or tertiary education degree (Lewin 2005).

We defined maternal and child health care as follows:

- child health: health care aimed at improving the health of children aged less than five years

- maternal health: health care aimed at improving reproductive health, ensuring safe motherhood, or directed at women in their role as carers for children aged less than five years (Lewin 2010)

The review has the following objectives:

Barriers and facilitators to the implementation of lay health worker programmes to improve access to maternal and child health: a 
We included studies where services were delivered in a hospital setting if they also included a primary or community health care component.

While the Cochrane intervention review also evaluated the effectiveness of lay health worker programmes on infectious diseases, we decided not to include this topic in the current synthesis of qualitative evidence so as to make it more manageable.

\section{Types of outcome measures}

\section{Phenomena of interest}

We included studies where the primary focus was the experiences and attitudes of stakeholders towards lay health worker programmes.

\section{Search methods for identification of studies}

\section{Electronic searches}

We searched the following electronic databases for eligible studies:

- MEDLINE IN-Process \& Other Non-Indexed Citations December 20, 2011, OvidSP (searched 21.12.11)

- MEDLINE, 1948 to November Week 3 2011, OvidSP (searched 21.12.11)

- British Nursing Index and Archive, 1985 to May 2011, OvidSP (searched 13.05.11)

- CINAHL, 1981 to present, EbscoHost (searched 21.12.11).

A search strategy had previously been developed for the Cochrane review of lay health worker programme effectiveness (Lewin 2010), including a comprehensive list of terms used in the literature to describe lay health worker interventions. We used these terms but removed the methods filter that was used to identify randomised trials. When searching MEDLINE (Appendix 1) and CINAHL (Appendix 2), we instead made use of their filter for qualitative studies, choosing the "specificity" alternative for MEDLINE and the "Qualitative - Best balance" alternative for CINAHL. When searching the British Nursing Index (Appendix 3), we used terms based on the MEDLINE methods filter.

We limited searches to English for feasibility reasons, given that it would be extremely time-consuming and costly to undertake full text translation into English of qualitative papers for inclusion in this synthesis.

\section{Other sources}

In addition to the electronic searches, we contacted experts in the field, and searched reference lists of included studies. We also included studies that we had previously identified as having been carried out alongside the trials from the lay health worker programme effectiveness review (Glenton 2011).

\section{Data collection and analysis}

\section{Selection of studies}

Two review authors independently assessed the titles and abstracts of the identified records to evaluate their eligibility. The full text of all the papers identified as potentially relevant by one or both review authors were retrieved. These papers were then assessed independently by two review authors. Disagreements between the review authors was resolved via discussion or, when required, by seeking a third review author's view. Where appropriate, we contacted the study authors for further information.

While systematic reviews of intervention effectiveness aim to include all relevant trials in order to avoid bias, this is not necessarily the case for syntheses of qualitative studies. In fact, too great a number of included studies can threaten the quality of data analysis, although there are few guidelines as to the ideal number of papers to include. In addition, the purpose of these syntheses is interpretive explanation rather than predictive (Doyle 2003), and "the results of a conceptual synthesis will not change if ten rather than five studies contain the same concept, but will depend on the range of concepts found in the studies, their context, and whether they are in agreement or not" (Thomas 2008). It may therefore be unnecessary to locate every available study and review authors may aim for a sample that is purposive rather than exhaustive (Doyle 2003).

Following from this standpoint, we utilised purposive sampling in order to arrive at a group of studies that provided geographical coverage. By achieving this coverage, we hoped to ensure a greater variation in contexts and thereby greater conceptual diversity. This aim of achieving geographical coverage was also driven by the fact that the review was developed to complement the review of lay health worker programme effectiveness, which included studies from several regions of the world. An additional reason was that the OPTIMIZEMNH guidance that our review aimed to inform was global, and geographical coverage was therefore regarded as helpful. However, we were concerned that our exclusion of studies in languages other than English would negatively affect this goal. After our initial round of study inclusion, we saw that studies from North America and UK were well-represented while we had few studies from Latin America. We therefore decided that when we were in doubt about the inclusion of a particular study, we would be lenient towards studies from Latin America while we would be particularly stringent towards studies from North America and the UK. In most cases, this meant being particularly stringent about our requirement that studies should have as their primary focus the experiences and attitudes of stakeholders towards lay health worker programmes. The same requirement was applied particularly leniently for Latin American studies. In a few cases, we also applied the definition of "healthcare" stringently for studies from North America and the UK, excluding a few studies where lay health workers focused on child accident prevention and on social support, for instance support for parents of children with special needs. Finally, we excluded a small number of studies from the UK because they overlapped greatly with other studies in terms of the topics and settings covered (See Characteristics of excluded studies).

\section{Data extraction and management}

We developed a data extraction form that was informed by the SURE framework (The SURE Collaboration 2011) (See Table 1 for an overview of the key domains of the SURE framework). This framework focuses on barriers to implementing health systems changes and includes the following factors: (a) knowledge and skills; attitudes regarding programme acceptability, appropriateness and credibility; and motivation to change or adopt new behaviours among recipients of care, providers of care, and other stakeholders; (b) health system constraints (including accessibility of care, financial resources, human resources, educational system, clinical supervision, internal 
communication, external communication, allocation of authority, accountability, management or leadership (or both), information systems, facilities, patient flow processes, procurement and distribution systems, incentives, bureaucracy, and relationship with norms and standards); and (c) social and political constraints (including ideology, short-term thinking, contracts, legislation or regulations, donor policies, influential people, corruption, and political stability). In syntheses of qualitative research, the "informants" are the authors of the individual studies rather than the participants in these studies. The authors' interpretations, presented for instance through themes and categories, therefore represent our data. While the authors' interpretations were primarily collected from the results sections of each paper, author interpretations were sometimes also found in the discussion sections, and these were also extracted when relevant and when well-supported by data.

We also extracted information concerning the first author's name; year of publication; language; country of study; clinical area; study setting (primary health centre or community; rural / urban, etc).

\section{Assessment of risk of bias in included studies}

As this is a synthesis of qualitative studies, we did not carry out any assessment of risk of bias for the included studies. Instead, we assessed the quality of the included studies as described below.

\section{Assessment of the quality of the included qualitative studies}

Our inclusion criteria specified that studies needed to use both qualitative data collection and analysis methods. This criterion also constituted a basic quality threshold. In addition, and following Cochrane Qualitative Research Methods Group guidance (Noyes
2011), two researchers independently applied a set of quality criteria to each included study. Disagreements were then resolved by seeking a third review author's view. Appraisal was performed using some of the main elements of the Critical Appraisal Skills Programme (CASP) quality assessment tool for qualitative studies (CASP 2006), as in other syntheses of qualitative evidence (Carlsen 2007; Munro 2007). See Table 2 for an overview of the quality criteria used.

We included studies that met our inclusion criteria regardless of study quality. We used the quality assessment when judging the relative contribution of each study to the development of explanations and relationships, as described in more detail below. It has been noted that poorer quality studies tend to contribute less to the synthesis (Atkins 2008). Therefore, the synthesis becomes "weighted" towards the findings of the better quality studies. Also, there is currently no consensus among qualitative researchers on the role of quality criteria and how they should be applied, and there is ongoing debate about how study quality should be assessed for the purposes of systematic reviews (Atkins 2008).

\section{Appraisal of certainty of review findings}

GRADE is now an accepted approach to assessing the certainty of findings from reviews of effectiveness (Guyatt 2011). However, few methods for assessing the certainty of findings drawn from syntheses of qualitative evidence have been developed. In connection with the development this synthesis and other syntheses of qualitative research (Colvin 2013; Rashidian 2013) carried out to inform the WHO OPTIMIZEMNH recommendations, we therefore chose to develop a system which we refer to as the CerQual (certainty of the qualitative evidence) approach (Figure 1). 
Figure 1. The CerQual approach

Overall aim of the system:

To assess the degree of CERTAINTY of the review finding

This is based on an assessment of

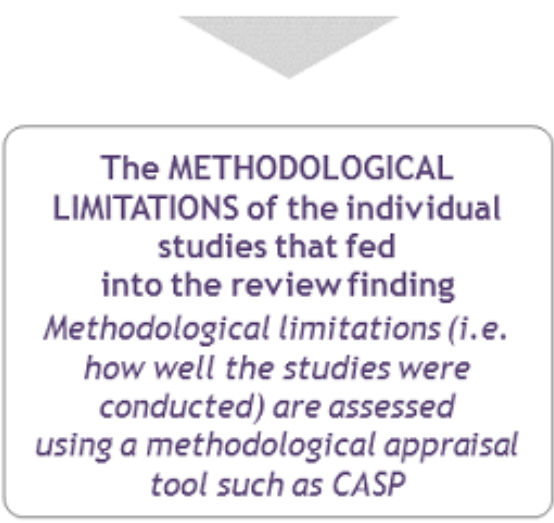

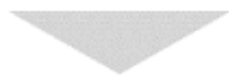

$$
\begin{gathered}
\text { The COHERENCE } \\
\text { of the } \\
\text { review finding }
\end{gathered}
$$

Coherence is assessed by the extent to which we are able to identify a clear pattern across the individual study data
In the CerQual approach our assessment of certainty is based on two factors: the methodological limitations of the individual studies contributing to a review finding and the coherence of each review finding.

Assessing methodological limitations: Findings that are drawn from well-conducted studies can be regarded as more dependable (Lincoln 1985). We therefore appraised how well the individual studies which contributed to the evidence of a review finding were conducted, using an adaptation of the Critical Appraisal Skills Programme (CASP) quality-assessment tool for qualitative studies (CASP 2006), as described above. When several studies with varied methodological limitations contributed to a finding, we made an overall judgment about the distribution of strengths and weaknesses in the studies to come to an assessment of the overall methodological limitations.

Assessing coherence: We assessed the coherence of each review finding by looking at the extent to which we were able to identify a clear pattern across the data contributed by each of the individual studies. This pattern could be assessed as clear in circumstances where the review finding was consistent across multiple contexts or where the review finding incorporated explanations for any variations across individual studies. The coherence of the review findings could be further strengthened where the individual studies contributing to the finding were drawn from a wide range of settings.

We assessed the certainty of each review finding as either high, moderate or low. A review finding drawn from generally wellconducted studies with few methodological limitations - and showing high levels of coherence - was rated as high certainty. A review finding where there were concerns regarding either the methodological limitations of the studies or the coherence of the finding was assessed as moderate certainty. Where the studies had important methodological limitations and where there were concerns regarding the coherence of the review finding, this finding was assessed as being of low certainty.

CerQual is similar to GRADE (Guyatt 2011) in that both approaches aim to assess the certainty of (or confidence in) the evidence, and both also rate this certainty for each finding across studies rather than for each individual study. GRADE also bases its assessment on a combination of the quality of the evidence and other factors, including consistency across studies. However, GRADE is designed to assess the certainty of evidence regarding the effectiveness of an intervention, and is not suitable when appraising the certainty of qualitative evidence. The CerQual approach is also similar to an approach used by Goldsmith et al (Goldsmith 2007). In their synthesis of qualitative research, they assess the overall quality of the evidence for each individual finding by evaluating the quality,

Barriers and facilitators to the implementation of lay health worker programmes to improve access to maternal and child health: a 
consistency and directness of the evidence. We have chosen not to refer to the directness of the evidence as it can be argued that, in the context of qualitative evidence syntheses, this dimension needs to be assessed by the end-user of the evidence.

\section{Data synthesis}

We analysed and synthesised qualitative evidence using the framework thematic synthesis approach (Booth 2012). Thematic synthesis is one of several approaches recommended by the Cochrane Qualitative Review Methods Group (Noyes 2011) and may be particularly appropriate where evidence is likely to offer only thin description and is likely to be largely descriptive as opposed to highly theorised or conceptual. In the framework approach, the thematic synthesis is guided by an a priori theoretical framework. Framework synthesis has five stages:

- Familiarisation: immersion in the included studies with the aims and objectives of the review.

- Identifying a thematic framework: Rather than develop our own a priori framework after reading the included studies, we opted to use the SURE framework described above (The SURE Collaboration 2011) as an a priori framework of themes and categories. We used this framework to guide our analysis for two reasons. Firstly, it provided us with a comprehensive list of possible factors that could influence intervention implementation. Secondly, the current synthesis is one of four syntheses of qualitative research that have informed the World Health Organization's OPTIMIZEMNH Guidelines (WHO 2012). The use of the SURE Framework across these syntheses made it possible to carry out an overarching analysis of factors influencing optimisation among different health worker groups.

- Indexing: Four review authors independently read and re-read the selected studies and applied the SURE framework, moving between the data and the themes covered by the framework, but also searching for additional themes until all the studies had been reviewed. The definitions and boundaries of each of the emerging themes were discussed among the authors. The SURE framework was then revised in line with the ideas and categories that emerged.

- Charting: We then developed the thematic synthesis further by rearranging data according to the appropriate part of the thematic framework to which they related, and formed charts. Our charts contained distilled summaries of evidence from different stakeholder perspectives and involved a high level of abstraction and synthesis. At the charting and mapping stage we used a cross-case analysis approach (Miles 1994) to explore whether there were differences between high, middle and low income countries in the barriers and facilitators we identified, and whether studies of trained traditional birth attendants differed from studies of other types of lay health workers. Any differences that were identified were indicated in the text of the results.

- Mapping and interpretation: Using the charts we then defined concepts, mapped the range and nature of phenomena, created typologies and found associations between themes as a way of developing explanations for the findings. The process of mapping and interpretation was influenced by the original review objectives as well as by the themes that have emerged from the data.

See Table 3 for an overview of the data synthesis process.

\section{Summary of qualitative findings tables}

After organising the data into themes and concepts, we summarised these findings in a summary of qualitative findings table. This table is similar to "Summary of Findings" tables used in Cochrane reviews of effectiveness and summarise the key findings and the certainty of evidence for each finding, and also provide an explanation of the assessment of the certainty of the qualitative evidence.

\section{Parallel synthesis of the qualitative evidence and the intervention review}

One of the objectives of the current synthesis was to integrate its findings with those of the effectiveness review. However, this type of integration is still a relatively novel approach without agreedupon standards or methods.

We decided to use a logic model approach to achieve this aim. The aim of a logic model is not to prove causal links between programme or policy elements and outcomes, but simply to present theories or assumptions about these links. There is no uniform template for developing logic models, although the most common approach involves identifying a logical flow that starts with specific planned inputs and activities and ends with specific outcomes or impacts, often with short-term or intermediate outcomes along the way.

Two authors (CG, SL) went through the findings from the summary of qualitative findings table and organized these findings into several chains of events that we propose might ultimately lead to the outcomes explored in the effectiveness review. Firstly, we categorised findings from the qualitative synthesis and outcome measures from the effectiveness review as one of the following:

- A component or planned element of the lay health worker programme (see Figure 2). All components were based on information from the synthesis of qualitative research. 


\section{Figure 2. Example of a logic model chain}
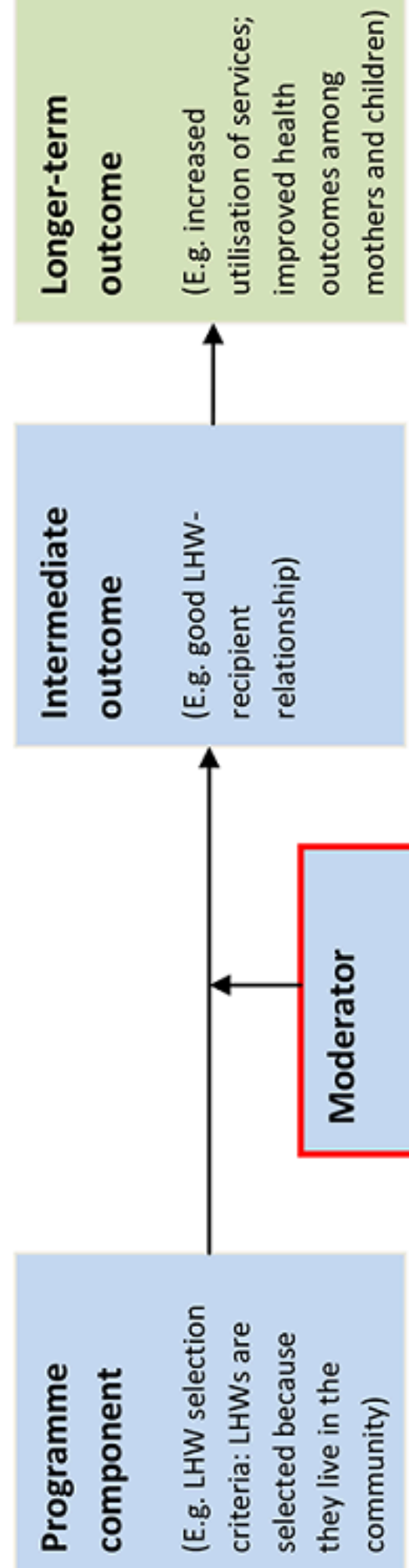

Barriers and facilitators to the implementation of lay health worker programmes to improve access to maternal and child health: a 
- Anintermediate outcome that the components might lead to (see Figure 2). Intermediate outcomes were based on information from the synthesis of qualitative research or were based on outcome measures that had been identified a priori as relevant in the review of effectiveness.

- Alonger-term outcome that the components might ultimately lead to (see Figure 2). All longer-term outcomes were based on outcome measures that had been identified a priori as relevant in the review of effectiveness.

- Amoderator, i.e. a factor that could affect, either positively or negatively, the relationship between a component and the intermediate or longer term outcome (see Figure 2). All moderators were based on information from the synthesis of qualitative research.

We then organised these elements into chains of events. This was an iterative process, and we developed several versions before agreeing on the model. All authors then commented on the draft model before it was finalised.

In the final model, components, moderators and intermediate outcomes that were based on evidence from the qualitative synthesis were shaded blue. Intermediate outcomes and longerterm outcomes that were taken from the effectiveness review were shaded green.
The process of categorising the findings in the qualitative synthesis as components, moderators or intermediate outcomes involved varying degrees of imputation. When describing programme components, we sometimes re-phrased "negative" findings as "positive" findings. For instance, one of the findings states that lay health workers expressed frustration where payment differed across regions or institutions. We re-phrased this in the logic model and presented "consistent lay health worker incentives" as a programme component. Moderators and intermediate outcomes also varied in the extent to which they were direct interpretations of the synthesis findings. For some, a degree of imputation was used. Where feasible, we have indicated which findings each element was base on by referring to the reference number of the relevant finding in the summary of qualitative findings table.

\section{RE S U L T S}

\section{Description of studies}

\section{Results of the search}

We identified a total of 7684 titles and abstracts and considered 179 full text papers for inclusion in this synthesis. Fifty-three studies of LHW programmes, described in 56 papers, were included in the synthesis (Figure 3), 51 of which were published after 2000 (See Characteristics of included studies). 
Figure 3. Study flow diagram.

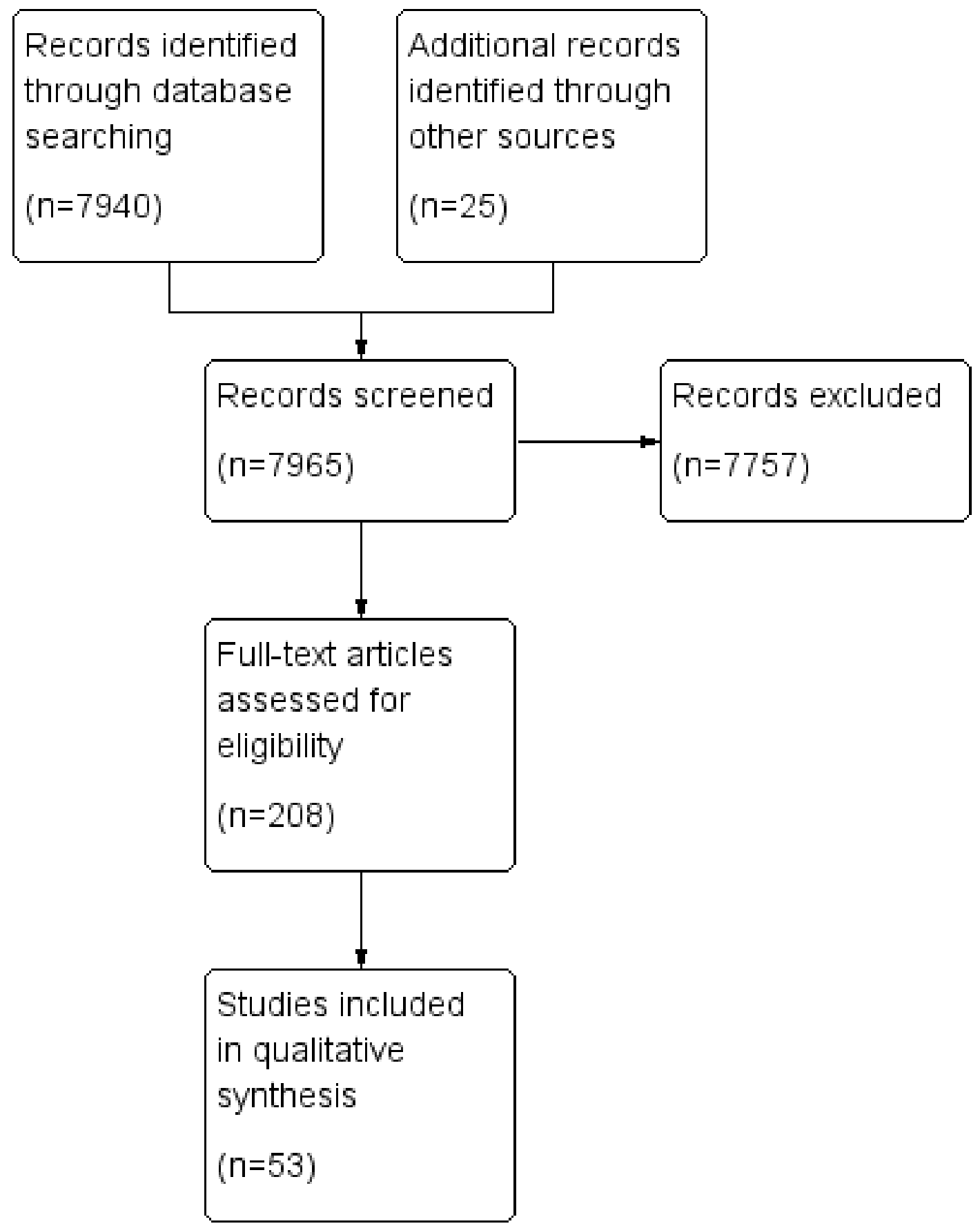

\section{Included studies}

\section{Study respondents}

In almost all of the studies, authors sought the perspectives of the LHWs themselves, although many studies also included programme recipients as respondents. Other respondents included health professionals working with the LHWs, programme staff, supervisors, community leaders and policy makers.

\section{Setting}

Seventeen of the LHW programmes were based in low income countries (Bangladesh, Ethiopia, Gambia, Kenya, Malawi, Nepal, Uganda, Viet Nam, Zambia, Zimbabwe); 19 programmes were based in middle income countries (Brazil, Ghana, Guatemala, Honduras, India, Iran, Mexico, Nicaragua, Pakistan, Papua New Guinea, South Africa, Thailand); and 17 programmes were based in high income countries (Australia, Canada, USA, UK). These assignments are based on the World Bank's 2011 classification (World Bank 2011). 
Most of the programmes from high income countries took place in urban settings and recipients often belonged to particular social groups, such as immigrants or refugees, families living in temporary accommodation, or teenage mothers. The programmes from low and middle income countries took place in both urban and rural settings, although most were in rural settings, and recipients were generally regarded as particularly in need of more accessible healthcare services.

The programmes were run by either non-government organisations (NGOs) or local and national governments, or a collaboration of these, and ranged from small pilot programmes to large-scale national programmes.

In 42 of the programmes the LHWs delivered services to people in their homes, in the community, or in both homes and the community. In the remaining 11 programmes, LHWs delivered services in health facilities although often in combination with home or community-based services.

\section{Healthcare services}

The healthcare services that LHWs delivered were generally poorly described and precise information was hard to obtain. LHWs provided services ranging from promotional and often relatively simple tasks to more complex sometimes curative tasks. LHW programmes from high income countries primarily provided promotional services. Where more complex, curative tasks were performed, or where medicines or contraceptives were distributed, this took place in low and middle income countries.

\section{Promotion, counselling and support}

In all of the studies from high income countries, as well as some studies from low and middle income countries, LHWs were used for promotion, counselling and support.

In six studies, the LHWs' main task was to offer breastfeeding advice and support. Four of these studies were from the UK (Beake 2005; Curtis 2007; Raine 2003) and the USA (Meier 2007), while two studies were from Uganda (Nankunda 2006) and South Africa (Daniels 2010). In the South African study, LHWs worked in the context of high HIV/AIDS prevalence and offered advice about both breastfeeding and bottle feeding in addition to promoting HIV testing and counselling.

In four USA-based studies (Behnke 2002; Hazard 2009; Korfmacher 2002; Low 2006b), LHWs gave teenage mothers and others in difficult socioeconomic circumstances emotional and practical support, and promoted healthy behaviours during pregnancy, childbirth and in the first few weeks after birth. In Australia, LHWs offered emotional and practical support to parents at risk of child abuse and neglect (Taggart 2000).

In approximately 13 studies, from Australia (Downie 2004), Canada (Heaman 2006; Woodgate 2007), UK (Murphy 2008; Perkins 2001; Smith 2007), USA (Sheppard 2004; Warrick 1992), Brazil (Wayland 2002), Mexico (Ramirez-Valles 2003), India (Alcock 2009), Papua New Guinea (Ashwell 2009) and Viet Nam (Hendrickson 2002), LHWs carried out a package of tasks that were primarily promotional, and mainly involved information and advice about topics such as family planning, pregnancy and childbirth, breastfeeding, vaccinations and other aspects of newborn and child health care.
In one Malawi-based study (Mkandawire 2005), LHWs cared for people with chronic illnesses, including those with HIV/AIDs, assisting them with household chores, accompanying them to hospital, and offering HIV counselling. In another study, in South Africa (Malema 2010), LHWs offered counselling and testing as a way of preventing of mother to child transmission of HIV/AIDs.

\section{Promotion and distribution}

In one Kenyan study, LHWs promoted and sold iron supplements and other micronutrients (Suchdev 2010). In three studies, based in Kenya (Kaler 2001), Ethiopia (Mekonnen 2008) and Uganda (Siu 2009), LHWs offered information about family planning and reproductive health. In the Kenyan and Ethiopian studies, the LHWs also distributed family planning methods.

\section{Diagnosis and treatment}

In Ghana, LHWs diagnosed and treated children with uncomplicated malaria, and referred children on if the condition worsened or if severe malaria was suspected (Chinbuah 2006).

\section{Packages of promotional, preventive and curative tasks}

In many studies LHWs delivered packages of assigned tasks. However, these tasks were often poorly specified and the following descriptions of task packages only give an approximation of their contents.

In approximately 11 studies, from Bangladesh (Khan 1998; Rashid 2001; Simmons 1990), Brazil (Lancman 2009), Honduras (McQuestion 2010), Iran (Javanparast 2009), Nepal (Glenton 2010), Nicaragua (George 2009), Pakistan (Haq 2009), South Africa (Mathews 1994) and Thailand (Kaufmann 1997), LHWs carried out a package of tasks that were primarily promotional but that also included the delivery of preventive and curative healthcare interventions. These tasks included the distribution of contraceptives, iron supplements, vitamin A supplements, deworming tablets, polio vaccines, and tetanus vaccines to children or pregnant women; tuberculosis (TB) management; diagnosis and management of malnutrition; provision of first aid treatment for accidental wounds and injuries; and the diagnosis and treatment of common childhood illnesses, including diarrhoea and pneumonia.

In approximately 11 studies, from Bangladesh (Dynes 2011), Ethiopia (Sibley 2006), Gambia (bij de Vaate 2002), Guatemala (Hinojosa 2004; Maupin 2008), Honduras (Low 2006), Malawi (Bisika 2008), Pakistan (Islam 2001), Papua New Guinea (Bettiol 2004), Zambia (Ngoma 2009) and Zimbabwe (Mathole 2005), LHWs delivered a number of promotional tasks tied to maternal and child health care, but some, often traditional birth attendants, were also trained to manage uncomplicated labour and to detect high risk pregnancies and labour complications so that timely referral could be made.

\section{Lay health worker (LHW) selection, training, supervision and incentives}

Information about how the LHWs were selected was often lacking. However, with very few exceptions, LHWs were local women. About a third of the studies specified that the LHWs were expected to have either a secondary level education or some level of literacy, while in at least seven studies this was not a requirement and LHWs were often illiterate or only semi-literate. Other common selection criteria were that the person should be respected and trusted in 
the community, should be married or have children, and should have particular personal traits such as communication skills, life experience, a willingness to learn, and an eagerness to work. In eight studies, the LHWs were traditional birth attendants from the community. The involvement of community members in the selection of the LHWs and in other aspects of the programmes was generally poorly described in the included studies. However, in at least 10 studies the community had been involved in the selection of LHWs.

Information about levels of training and supervision was also often lacking. Where this information was available, LHWs received between a few days and three months training, although two to three weeks, sometimes with refresher training, was most common. Information about levels of supervision and who provided this supervision was even less frequent, but in several cases supervision was provided by nurses or nurse-midwives, often from the health facility to which the LHWs were attached.

Some information about incentives was given in about two-thirds of the studies. In at least 11 studies, LHWs received some sort of direct financial compensation for the work they carried out, for instance through a fixed monthly salary or stipend, payment by the hour, or according to the number of women they had visited. This was most common in high income countries. In two studies, LHWs kept the profit from the supplements they had sold. In at least 17 studies, it appeared that LHWs were not salaried, although they often received other types of monetary and non-monetary incentives, including lunch money, travel money, access to microcredit, childcare and bicycles. In three or four of these studies, there was some expectation that the LHWs would be paid in cash or kind by recipients or by the community, for instance the village development committee.

\section{Risk of bias in included studies}

We did not perform a risk of bias assessment for the included studies as this is not an appropriate method for qualitative research. Instead, we appraised the quality of each study and the certainty of the review findings using approaches deemed relevant for qualitative research.

\section{The quality of the included qualitative studies}

Almost all of the included studies were published as papers in health research journals, leading to word limitations not particularly well suited for reporting of qualitative research. In general, studies gave some description of the strategies they had used to select participants and to collect and analyse data, although these descriptions tended to be brief. Most of the studies used interview or focus group methods, with very few instances of long-term ethnographic research. Few of the studies included any discussion of reflexivity. While we often assessed findings as being supported by the data, the descriptions of study context and the presentation of findings were relatively short. The general lack of 'thick description' may have been due to the choice of methods and the limitations set by the journals in which the studies were published (see also Table 2).

\section{Certainty of the review findings}

As described in the methods section, we used the CerQual approach to assess the certainty of each review finding, grading each finding as either of high, moderate or low certainty. None of the study findings were assessed to be of high certainty, because of weaknesses in study quality. We assessed a little less than half of the findings as of moderate certainty because the findings showed high levels of coherence, while we assessed a little more than half of the findings to be of low certainty because of concerns regarding both the coherence of the findings and the quality of the underlying studies.

\section{Effects of interventions}

Lay health worker (LHW) programme effectiveness has been assessed in another Cochrane review (Lewin 2013).

Here we present three analyses:

1. a framework synthesis, where we present the barriers and facilitators to the implementation of LHW programmes for maternal and child health;

2. a logic model, where we bring together the results of the qualitative and quantitative reviews;

3. an overview of hypotheses that are based on the logic model and that could serve as a basis for subgroup analyses in the review of LHW effectiveness.

\section{The framework synthesis}

Our first and main objective was to identify barriers and facilitators to LHW programme implementation. Our findings are presented here and are summarised in the summary of qualitative findings tables (Table 4, Table 5, Table 6, Table 7, Table 8, Table 9).

\section{Programme acceptability, appropriateness and credibility: the lay health worker (LHW)-recipient relationship}

\section{Close relationships and being based in the community often appreciated by recipients}

Programme recipients in both high, middle and low income countries were generally very positive to the LHW programmes (Chinbuah 2006; Dynes 2011; George 2009; Haq 2009; Hazard 2009; Heaman 2006; Islam 2001; Javanparast 2009; Kaler 2001; Korfmacher 2002; Mathews 1994; Meier 2007; Murphy 2008; Nankunda 2006; Perkins 2001; Rashid 2001; Sheppard 2004; Siu 2009; Smith 2007; Taggart 2000; Warrick 1992; Woodgate 2007). Central to programme acceptability were aspects tied to the closeness of the LHW-recipient relationship and the communitybased nature of the programmes.

\section{LHW-recipient relationship}

Recipients referred to a number of characteristics which they appreciated in the LHWs, including their respect, kindness and concern, and their non-dogmatic approach (Beake 2005; Bisika 2008; Chinbuah 2006; George 2009; Heaman 2006; Mathole 2005). In programmes from high income countries in particular, recipients emphasised the importance of LHWs as a source of emotional and social support (Beake 2005; Hazard 2009; Heaman 2006; Korfmacher 2002; Mathews 1994; Meier 2007; Murphy 2008; Perkins 2001; Sheppard 2004; Taggart 2000; Warrick 1992), and LHWs were often likened to family members or friends (Hazard 2009; Korfmacher 2002; Meier 2007; Perkins 2001; Sheppard 2004; Warrick 1992). In one study, utilisation of LHW services was reported as poor where no friendship bond had developed between the LHW and the recipient (Murphy 2008). 
LHWs often mirrored recipients' responses, emphasising the closeness of their relationship with programme recipients and seeing this as a strength of the programme (Alcock 2009;Behnke 2002; Hazard 2009; Hendrickson 2002; Korfmacher 2002; Warrick 1992). LHWs in some studies described how trust, empathy and respect were key in the establishment and maintenance of this relationship (Heaman 2006; Malema 2010; Meier 2007; Murphy 2008).

\section{LHWs as peers}

Recipients often appreciated the similarities they saw between themselves and the LHWs, either because they came from the same community or because they shared similar social backgrounds (George 2009; Hazard 2009; Kaler 2001; Nankunda 2006; Perkins 2001; Rashid 2001), although recipients in one study stated that this was not important (Heaman 2006). Utilisation of LHW services was sometimes reported as poor when LHWs had different cultures or languages than their target groups (Meier 2007; Murphy 2008).

\section{Community base}

The LHWs were usually from the communities they worked in and programme recipients appreciated the accessibility and availability of the LHWs. Recipients emphasised the amount of time that LHWs were able to spend with recipients, the continuity of care (Beake 2005; Murphy 2008), the fact that the LHWs could offer them services at any time and within easy reach (Bisika 2008; Chinbuah 2006; George 2009; Javanparast 2009; Mathews 1994; Mathole 2005; Rashid 2001), and the fact that services were either free or relatively cheap (George 2009; Javanparast 2009; Rashid 2001). For LHWs themselves, this community base often gave them the flexibility to fit their tasks around their regular activities, including work in the fields and household chores (Glenton 2010; Nankunda 2006).

\section{LHWs compared to health professionals}

Many recipients experienced interactions with LHWs as more favourable than their experiences with health professionals. In addition to the practical problems associated with visits to health professionals, such as greater distances, higher prices, longer queues and less time (Chinbuah 2006; Rashid 2001; Simmons 1990), health professionals were described as being too dogmatic or unrealistic (Beake 2005), "trying to tell them what to do" (Beake 2005), less trustworthy (Sheppard 2004), less friendly and concerned (Alcock 2009; Mathole 2005), more intimidating (Rashid 2001; Taggart 2000), and with disrespectful attitudes to their patients (Kaler 2001; Mathews 1994; Ngoma 2009; Simmons 1990). In one study the lack of privacy at clinics and the use of male health workers were also referred to as a problem (Simmons 1990). Recipients, LHWs and programme staff sometimes saw the LHW as an advocate for programme recipients (Meier 2007; Warrick 1992) and as a bridge between the community and the health services (Ashwell 2009; Hazard 2009; Mekonnen 2008; Simmons 1990; Taggart 2000).

\section{Access to other options}

In one study, however, recipients claimed that LHWs were not necessary because the village was so close to town and they therefore had easy access to health professionals (Kaufmann 1997). In another study villagers also had good access to doctors, and LHWs claimed that the villagers preferred to go to an educated rather than an uneducated health worker (Khan 1998). In one study villagers appreciated trained traditional birth attendants and stated that they needed their services but would have preferred to have access to health professionals (Ngoma 2009).

\section{Close relationships and being based in the community could lead to} problems for lay health workers (LHWs)

The closeness of the LHW-recipient relationship and the community-based nature of the programmes gave a number of benefits to programme recipients, and in part to the LHWs themselves, but these aspects of the programme were not unproblematic for the LHWs.

\section{Close relationships and the need for boundaries}

In several studies, LHWs and health professionals working alongside them described how the closeness of the LHW-recipient relationship and the magnitude of recipients' problems could be emotionally draining, create confidentiality problems, and prevent the LHWs from doing their jobs properly (Daniels 2010; Heaman 2006; Lancman 2009; Malema 2010; Meier 2007; Perkins 2001; Woodgate 2007). LHWs also struggled to deal with disagreements between them and their clients (Korfmacher 2002). LHWs and their supervisors saw the need to draw clear boundaries and to disassociate recipients' emotional needs from the LHWs' own personal lives (Daniels 2010; Heaman 2006; Lancman 2009; Low 2006b; Meier 2007; Woodgate 2007). However, as respondents in one study pointed out, drawing boundaries could be more challenging for a LHW than for a health professional as LHW tasks were often day-to-day activities and less likely to be perceived as professional tasks by recipients (Heaman 2006). These concerns were generally not voiced by recipients. However, in one USbased study recipients did worry that LHWs making home visits might observe and possibly report sensitive information, for instance about maternal depression or abuse (Sheppard 2004), while in another US-based study teen mothers feared a lack of confidentiality and complained that LHWs would share stories with each other about their clients (Korfmacher 2002). In one South African study women feared that being visited by a breastfeeding counsellor might lead other community members to think they were HIV-positive (Daniels 2010).

\section{Safety concerns}

In some communities, particularly in urban settings, povertyrelated and social problems such as violence and drug abuse were commonplace (Daniels 2010; Lancman 2009; Perkins 2001; Woodgate 2007). LHWs sometimes found themselves in dangerous situations, both in people's homes and in the neighbourhood, often with little or no means of assistance and no access to a telephone (Daniels 2010; Lancman 2009; Woodgate 2007). In Zambia, trained traditional birth attendants were reluctant to visit clients at night because of safety issues (Ngoma 2009). Safe transport was one of the measures called for to minimize risk (Daniels 2010; Ngoma 2009). In South Africa, LHWs sometimes asked people to accompany them for fear of attack (Daniels 2010); while in Brazil, LHWs developed a number of strategies to protect themselves, making use of community networks to exchange information about the area (Lancman 2009). In this study LHWs and other members of the health worker team "felt offended concerning their own integrity, because they had to remain silent in the face of situations of domestic violence or even disrespect for others" (Lancman 2009). 


\section{Restrictions on women's movements}

In two studies from Bangladesh, sociocultural norms restricting the movement of women led to some LHWs being reluctant to go on household visits. LHWs who did so were sometimes met with disapproval from family members, religious leaders, and other elders in the village (Khan 1998; Rashid 2001).

\section{Burden of responsibility}

One study from Kenya suggested that LHWs that lived in the same community as programme recipients may be more vulnerable to blame than other healthcare workers (Kaler 2001), "When things are good, a provider is very important [in the village], but when things go wrong, it is "an agent who brought [trouble] ..." (Kaler 2001).

\section{Lack of knowledge, user fees, or concerns about interventions could} lead to low utilization by recipients

Although recipients in most of the studies indicated a high level of acceptability with the LHW programmes, some studies also described less positive attitudes. In some studies the target groups had poor knowledge of the LHW programme itself or were not fully aware of the services that the programme could offer (Bisika 2008; Kaufmann 1997; Mathews 1994; Murphy 2008; Wayland 2002). In one study recipients were aware of the existence of trained traditional birth attendants but were mostly unable to utilize them because they could not afford their services (Ngoma 2009). In other studies, target groups apparently underutilized programme interventions because of a lack of understanding of intervention benefits (Low 2006) or because of concerns about intervention safety (Mathole 2005; Simmons 1990). For instance, recipients sometimes associated major suffering with the use of contraceptives (Kaler 2001; Simmons 1990), or an increased risk of having to undergo caesarean section if LHWs referred them to a health facility (Mathole 2005). These concerns were also sometimes shared by the LHW (Kaler 2001; Mathole 2005).

\section{Lack of programme appropriateness could lead to low acceptability}

\section{Relevance of LHW services}

Some studies pointed to a low use of LHW services when these services failed to meet the perceived needs of community members (Mathews 1994; Murphy 2008; Wayland 2002). LHWs were sometimes confronted with non-healthcare related problems such as housing, food insecurity, and social and domestic violence (Lancman 2009; Meier 2007); and, in some cases, the poverty-related and social problems recipients faced in their everyday lives were experienced as more pressing than the issues that the LHW programmes aimed to address (Meier 2007; Wayland 2002). In one study from Brazil, this led to an almost complete failure of the programme. Here, LHW tasks included assessing children's nutritional status, enrolling malnourished children into a milk programme, and spreading information about nutrition, immunisation, hygiene, respiratory infections, breastfeeding and prenatal care. According to study authors, programme administrators "[assumed that] once people learn how to correctly manage their environment and care for their children, health will improve" (Wayland 2002). Community members disagreed with this assumption, arguing that they knew how to care for their children but that their income and living conditions prevented them from doing so. While they accepted those services they perceived to be of use, such as enrolment in the milk programme, they regarded most of the services on offer as ineffectual, patronising and intrusive. As a result, many LHWs, who received a 'less than warm welcome during home visits' became frustrated and eventually stopped performing their duties (Wayland 2002).

\section{Adequacy of LHW services}

In other programmes, services may have been relevant but were not always sufficient. Recipients' poor access to other health services, particularly in the studies from low and middle income countries, meant that LHWs were often approached about issues outside the scope of their training. Recipients asked about issues such as mental health, malaria, HIV/AIDS and emerging diseases (Alcock 2009; Haq 2009); and requested treatment for minor childhood diseases such as scabies, worms or eye infections, women's health complaints, and other complaints (Kaufmann 1997; Mkandawire 2005; Simmons 1990). LHWs were also asked to help recipients to access other services (Meier 2007) and accompany them to health facilities (Simmons 1990), which was a task that may have been particularly important in situations where clients had strained relationships with health professionals or where cultural constraints discouraged women from travelling unaccompanied.

LHWs in a programme in India were given more training to cover some of these additional health topics (Siu 2009), while in a Nicaraguan programme the role of the LHW was extended to include curative health care, leading to an increase in LHW motivation and community respect and satisfaction (George 2009). However, many LHWs, particularly those providing only promotional and preventive healthcare, were unable to meet these additional requests (Kaufmann 1997; Mkandawire 2005; Simmons 1990). In addition, programme priorities meant that LHWs did not always have the time or the transport to accompany women to healthcare facilities (Simmons 1990).

\section{Irrelevant or insufficient services and feelings of impotence}

An inability to respond to the expressed needs of the community led to feelings of frustration and impotence (Daniels 2010; Lancman 2009; Mkandawire 2005; Wayland 2002). While some LHWs wanted to be able to offer more information (Haq 2009), others wanted to provide what was referred to as 'real health care' such as medicines and immunisations (Mkandawire 2005; Wayland 2002) and to be trained as paramedical personnel (Kaler 2001). In studies in Iran and South Africa (Javanparast 2009; Mathews 1994), LHWs and others also called for more LHW involvement or more community involvement in programme planning: "In this way, the help can be organised and spent in the best way to meet people's needs" (Javanparast 2009). However, the opportunity to offer 'real health care' could also represent a 'double-edged sword' as it could also leave the LHW vulnerable to blame if things went wrong (Kaler 2001).

\section{Lay health worker (LHW) credibility, appropriateness and acceptance} influenced by collaboration with other stakeholders

\section{Visible ties to the health system}

Recipients expressed confidence in the knowledge and skills of the LHWs and saw them as a useful source of information (Bisika 2008; Chinbuah 2006; Daniels 2010; George 2009; Hazard 2009; Hendrickson 2002; Islam 2001; Javanparast 2009; Mathews 1994; Sheppard 2004; Warrick 1992). Several studies, particularly those from low and middle income countries, described how LHW 
credibility in the community was strengthened by their connection with the formal health system. Here, knowledge that the LHWs were trained and supervised through the formal health system, and had good access to the health system, helped to strengthen community trust in the programme (Alcock 2009; Ashwell 2009; Daniels 2010; Hinojosa 2004; Kaler 2001). Conversely, a lack of visible support from the health system could weaken LHW credibility (Ashwell 2009; Low 2006; Rashid 2001).

Both LHWs and community members described how LHW credibility was enhanced through visible symbols of their connection to the health system, for instance through their use of safe delivery kits, signboards, uniforms, and educational picture cards (Alcock 2009; Glenton 2010; Islam 2001; Kaler 2001). Visits from supervisors, visible contact with health professionals, making referrals to clinics, and accompanying programme recipients to these clinics also served to emphasise the LHWs' ties to and recognition by the health services (Ashwell 2009; Kaler 2001; Nankunda 2006). LHWs also believed that their credibility had been enhanced through messages in the media, arguing that people believed in the information they provided when it was repeated on television (Haq 2009).

While strong ties to the health system appeared to enhance LHW credibility, many community members also had negative attitudes towards and experiences of health professionals. In at least one study LHWs feared that too strong an association with health professionals could damage their credibility, and wished to disassociate themselves from some of the more negative aspects, for instance by emphasising that they were unpaid (Glenton 2010). In another study the credibility of peer counsellors was questioned by mothers who asked if they were being paid to visit them and they "did not want to be used in what they suspected was the peer supporters' process of enriching themselves" (Daniels 2010).

\section{Community leader support}

Some studies, all based in low and middle income countries, suggested that LHW programme credibility and acceptability, as well as necessary community mobilization, could be enhanced through the active support by and participation of community leaders (Ashwell 2009; Dynes 2011; Mekonnen 2008). This support could be encouraged through community leaders' involvement in programme training (Ashwell 2009); community leaders' participation in programme activities (Dynes 2011), their exposure to successful examples of similar programmes (Ashwell 2009), and LHWs' participation in community leadership meetings, including local village health committees (Bisika 2008). However, the success of this type of involvement was said to be primarily useful where local leaders had authority and respect and were dynamic and responsive to community needs (Ashwell 2009; McQuestion 2010), and less successful in communities where leadership was weak and where communities lacked strong social and political organisation (Ashwell 2009; Dynes 2011). In addition, LHWs sometimes found it challenging to establish or participate in these types of meetings (Haq 2009).

\section{Choice of target group}

Respondents in some studies pointed to the importance of support and participation from other family members, including motherin-laws, but particularly husbands and partners, for programme success (Ashwell 2009; Daniels 2010; Dynes 2011; Haq 2009; Mekonnen 2008; Nankunda 2006; Raine 2003; Rashid 2001;
Warrick 1992). Some concern was expressed over the lack of male involvement (Dynes 2011), and LHWs and programme staff suggested that education programmes and campaigns should more actively target men (Bisika 2008), for instance through maleonly meetings (Dynes 2011) and through adding male characters to mass media campaigns (Haq 2009). The inclusion of men was not without its challenges, however. In one study, MexicanAmerican LHWs ran prenatal care classes that were attended by both women and their spouses or boyfriends. "Initially, women had difficulty adjusting to the presence of men in the classes, especially spouses or boyfriends of other women, and they were hesitant to speak out. Their embarrassment was shared by some of the promotoras who had difficulty, with males present, broaching intimate topics such as birth control or showing the birthing film" (Warrick 1992). In Pakistan, LHWs found it difficult to talk to men about family planning, and felt that their communication skills could be improved (Haq 2009). In South Africa, LHWs called for training in counselling of couples for HIV/AIDs (Malema 2010).

\section{Programme acceptability, appropriateness and credibility: the lay health worker (LHW)-health professional relationship}

Different experiences with the lay health worker (LHW)-health professional relationship

\section{Health professionals' appreciation ofLHW contribution}

Relationships between LHWs and health professionals were experienced differently across groups, within programmes, and across programmes. In one study, LHWs defined a good LHW-health professional relationship as one that was characterised by support, mutual respect, trust and partnership (Heaman 2006). In some programmes, LHWs generally felt respected and supported by the health professionals with whom they collaborated (George 2009; Heaman 2006; Malema 2010). However, professional acceptance of LHWs was described as being a gradual process (George 2009; Raine 2003). In at least two programmes (George 2009; Smith 2007) health professionals were initially negative to the LHWs but had changed their attitudes with a growing acknowledgement of the positive impact the LHWs could have on the health services and on people's health. Health professionals in several studies emphasised the LHWs' valuable contribution to their busy workload (Curtis 2007; George 2009; Hazard 2009; Raine 2003; Smith 2007). Some described the LHWs as key to the success of the programme (Heaman 2006), admiring their skills in communicating with the target population and their knowledge and experience of the issues at hand (George 2009; Hazard 2009; Heaman 2006; Raine 2003; Siu 2009). Some health professionals believed that these skills could lead to better access to the target population (Siu 2009), more culturally appropriate care (Hazard 2009), and greater community mobilisation (George 2009). LHWs were also respected for their commitment and dedication to their patients and the community (Dynes 2011; Hazard 2009). In one study, health professionals suggested that the collaboration with LHWs had changed the way they themselves perceived and worked with their clients (Curtis 2007), while a health professional in another study described LHWs as lending her 'street credibility' by association (Raine 2003).

\section{LHWs, health professionals, and equality}

But while health professionals in one study described the LHWs as "like friends, co-workers, very much part of the team" (Hazard 2009), authors of another study suggested that "there was little evidence to suggest that health professionals regarded 
the volunteers as colleagues with whom they might establish relationships of trust and equality" (Curtis 2007). In other studies the relationship was "recognised by all as unequal and that the lay health worker was subservient" (Mathews 1994), LHWs felt "way at the bottom of the totem pole" (Heaman 2006), and some LHWs believed that health professionals looked down upon them (Malema 2010). In one study LHW responses indicated that programme staff had made few efforts to make the LHWls feel as if they were part of the organisation (Siu 2009). In at least three studies trained traditional birth attendants complained of arrogance and lack of respect from health professionals (Hinojosa 2004; Low 2006; Mathole 2005).

\section{Factors influencing the health professional-LHW relationship}

The studies suggested a number of factors that may have threatened the development of good working relationships between LHWs and health professionals. Nurses in one programme pointed out that they were expected to function simultaneously as partners, supervisors and evaluators, and some found these roles conflicting. In another programme, health professionals complained that the programme had added to their workload (Woodgate 2007). In other programmes (Beake 2005; Curtis 2007; Heaman 2006), health professionals emphasised the importance of maintaining boundaries between their roles and the roles of the LHWs. Overstepping these boundaries could be viewed negatively and health professional narratives in one study suggested a fear that they would lose some of their own authority if LHWs were given more authority (Curtis 2007).

Some studies suggested that the closer the collaboration was between the health professional and the LHW, the better the relationship was likely to be. In three programmes, health professionals who worked closely with LHWs appeared to have a more respectful or equal relationship with them than those working at a greater distance (Ashwell 2009; Curtis 2007; Mathews 1994). In one of these programmes, good relationships were observed to be stronger where local health professionals had been actively involved in training LHWs than where they had not been involved (Ashwell 2009)

\section{Lay health worker (LHW) motivation and incentives}

\section{Lay health workers (LHWs) often driven by several, intertwined motives}

Respondents had a number of often intertwined motives for working as LHWs, both intrinsic and extrinsic.

\section{Altruism}

Altruistic motives were expressed by LHWs in many of the studies. LHWs described how they felt good about helping others (Curtis 2007; Hazard 2009; Low 2006b; Meier 2007) and wanted to contribute to and serve the community (Behnke 2002; Bettiol 2004; Downie 2004; Hendrickson 2002; Javanparast 2009; Khan 1998; Malema 2010). Some referred to religious or moral callings or convictions (Glenton 2010; Low 2006; Maupin 2008; Mkandawire 2005).

\section{Gain of knowledge and skills}

LHWs also sought out and took pride in the knowledge and skills they gained (Bettiol 2004; Downie 2004; Glenton 2010; Warrick 1992), stating that this knowledge could be advantageous not only to recipients but also to themselves and their families (Hendrickson 2002; Khan 1998; Nankunda 2006).

\section{Social recognition}

LHWs were also motivated by the respect they received from programme recipients (Curtis 2007; George 2009; Malema 2010) and an increased social status in their own homes and in the community (Alcock 2009; Glenton 2010; Nankunda 2006; Rashid 2001), particularly in low and middle income countries. LHWs believed that social recognition was a result of their being trained (George 2009), their ability to treat illnesses (Khan 1998; Rashid 2001), their moral standing as unpaid volunteers and good hearted people (Glenton 2010; Kaler 2001), and their social importance (Kaler 2001). In one Uganda-based study, some of the LHWs stated that their role had helped them gain an identity and an image which were important for their political engagement (Siu 2009).

\section{Empowerment}

LHWs' acquisition of knowledge and skills, their increased social status, participation in a process that was valued by others, and experiences of success in achieving programme goals often led to feelings of empowerment, increased confidence and self-esteem (Alcock 2009; Ashwell 2009; Behnke 2002; Curtis 2007; Downie 2004; Hendrickson 2002; Nankunda 2006; Raine 2003; Sibley 2006; Warrick 1992). Authors of one UK-based study commented that "For women living in disadvantaged areas, whose opportunities for self-advancement are few, [the value of] this type of outcome should not be underestimated" (Raine 2003). Some LHWs described how this new self-perception had led to changes in their behaviour both within the programme and in other areas of their lives. LHWs experienced greater assertiveness, for instance with authority figures (Curtis 2007), greater autonomy in decision making (Alcock 2009), greater confidence in their ability to deliver existing tasks (Daniels 2010), confidence enough to request additional training in new areas (Warrick 1992), and greater confidence in taking care of their own families and participating in community activities (Hendrickson 2002).

\section{Possibility of future employment}

Some LHWs hoped their jobs would lead to further education or future employment (Curtis 2007; Low 2006b; Meier 2007; Nankunda 2006; Siu 2009).

\section{Social life}

Some LHWs also referred to the social benefits of the work, such as the opportunity to get out of the house and meet new people (Curtis 2007; Downie 2004; Glenton 2010).

\section{Shared goals}

One Mexican study described how LHWs' decision to join a programme was influenced by the extent to which they were able to align their own world view with that of the programme (RamirezValles 2003).

\section{Monetary and non-monetary incentives often important but not unproblematic}

In addition to the sources of motivation mentioned above, LHWs also received different types of formal incentives through the programmes. 


\section{Regular salaries}

Most of the LHWs in high income countries received regular payment, but the situation was far more mixed among LHWs in low and middle income countries. Unsalaried LHWs in some programmes expressed a strong desire for regular payment (Kaler 2001; Nankunda 2006) and were distressed by the fact they were not permanently employed (Malema 2010). In other programmes, salaried LHWs were dissatisfied with their wages (Daniels 2010; Meier 2007; Smith 2007; Woodgate 2007), believing that the wage did not reflect their abilities (Woodgate 2007), their level of responsibility (Smith 2007), or their increase in skills as they acquired further training and education (Meier 2007). In some programmes, LHWs and other stakeholder groups argued that LHWs were likely to drop out if other, better paid jobs were available to them (Daniels 2010; Glenton 2010; Khan 1998).

Policy makers in one study from Nepal regarded LHW salaries as financially unsustainable (Glenton 2010). One person pointed out that as the entire health system employed 23,000 staff, the financial impact of hiring the 48,000 LHWs working for the programme would be enormous. They emphasised the need for consistency over time, urging donors and others to avoid starting anything that could not be sustained, but suspecting international organisations used payment to achieve the short-term results they needed regardless of whether this was sustainable in the long term (Glenton 2010). In the same study, programme managers, policy makers and the LHWs themselves were sceptical with respect to the introduction of regular payment as they feared that this might threaten the LHWs' social status (Glenton 2010). This scepticism was expressed in a context where the LHW's social status was closely tied to her moral standing as an unpaid volunteer, and where widespread negative attitudes existed towards the moral status of paid health workers and other government employees. LHWs and policy makers in this study agreed on a number of conditions that made this lack of payment acceptable, including the LHWs' freedom to deliver services when and if they wanted. The introduction of tasks not in line with these conditions were considered differently, and LHWs expected some form of compensation for such tasks.

The issue of being paid to work in one's own community also caused some problems in a South African study. Here, mothers were concerned that peer counsellors were using home visits as a means to gaining a personal income and they "did not want to be used in what they suspected was the peer supporters' process of enriching themselves" (Daniels 2010). In Australia, volunteer LHWs felt that payment would change the dynamics of the friendship between them and the mothers they visited, while the mothers themselves appreciated the volunteers because they visited them out of free will (Taggart 2000).

\section{Monetary incentives}

In many of the studies where LHWs were not paid, other types of monetary incentives were often given and were appreciated. These included lunch money (Kaler 2001), facilitation allowances (Siu 2009), health insurance and educational stipends (Meier 2007). These types of incentives often aimed to ensure that LHWs did not have out-of-pocket expenses. In one programme in Thailand, however, unsalaried LHWs were required to attend continuing education classes without remuneration for transportation costs, causing dissatisfaction (Kaufmann 1997).

\section{Non-monetary incentives}

Formal non-monetary incentives included bicycles (Nankunda 2006), uniforms (Glenton 2010; Kaler 2001; Nankunda 2006), 'tool boxes', bags, signboards (Alcock 2009; Glenton 2010;Kaler 2001) and promotional material such as T-shirts (Siu 2009). While these incentives were primarily meant to help the LHWs perform their tasks more efficiently, they also appeared to motivate LHWs, for instance by increasing their visibility and social recognition (Glenton 2010; Kaler 2001; Nankunda 2006). However, lack of the tools necessary to perform their work could also lead to frustration and demotivation (Rashid 2001).

\section{User fees}

In some programmes LHWs were paid, at least in part, through the profit they earned from selling drugs and supplements. In one programme, in Bangladesh, high dropout rates among LHWs were partly blamed on programme staff giving the LHWs an inflated idea of the profit they would be making (Khan 1998). Other problems included people buying medicine on credit. While community members saw this as an advantage (Rashid 2001), LHWs in at least one study found it difficult to collect the money afterwards (Khan 1998). In this same study people were also reluctant to buy medicine because of their perception that the programme got the medicine free (Khan 1998). In Kenya, LHWs sold iron supplements to members of the community but encountered a number of problems, including competition from untrained vendors of the same supplements, negatively affecting their motivation (Suchdev 2010).

\section{Community-based payment}

The possibility of financing LHW incentives or other parts of the programme through community-based systems was discussed in two studies, in Gambia and Malawi. In both studies communities preferred that incentives were provided by others, for instance governments or NGOs (Chinbuah 2006; Mkandawire 2005). In Malawi, this reluctance to support the programme financially was attributed to experiences with forced financial support to political parties and a desire to move away from this kind of community support (Mkandawire 2005).

\section{Performance-based incentives}

In one study, policy makers and programme managers were sceptical of the performance-based incentives sometimes adopted by international donor organisations, referring to experiences of over-reporting of tasks among other cadres (Glenton 2010).

\section{Differences in payment}

In two programmes LHWs referred to frustration when payment differed from region to region or across different types of institutions (Glenton 2010; Mekonnen 2008).

\section{How could lay health workers (LHWs) influence which incentives they receive?}

Few of the studies discussed how LHWs could voice their demands regarding payment and other incentives. In Iran, LHWs complained that there was nobody to hear their voice and no place to complain (Javanparast 2009). In Nepal, policy makers pointed out that LHWs could voice their opinions through the Village Health Committee, where they had a seat, at least in those areas where these committees were functioning (Glenton 2010). However, collective 
rather than individual demands were more difficult to make. While such demands had been made by LHW associations in Nepal, the representativity of these associations was questioned, and policy makers, programme managers and LHW representatives pointed to social, financial and topographical constraints that made it difficult for LHWs to establish representative bodies (Glenton 2010).

\section{Lay health worker (LHW) training, supervision and working conditions}

\section{Wide variations in the perceived quality of training}

Adequate training was regarded as key to the effective and safe delivery of healthcare interventions, but satisfaction with training varied within and across studies. LHWs in several studies were happy with the knowledge gained and found the training very useful (bij de Vaate 2002; Meier 2007; Nankunda 2006). Aspects of training that were highlighted as positive included the use of practical demonstrations, picture cards, frequent refresher training, and training in recent knowledge (bij de Vaate 2002; Malema 2010; Sibley 2006).

Several studies pointed to LHW training as an area that needed to be addressed, and highlighted a number of weaknesses with current practice (Low 2006b; Malema 2010; Meier 2007; Rashid 2001; Simmons 1990; Smith 2007; Woodgate 2007). Some studies pointed out that training schedules were not always flexible enough to respond to turnover and the recruitment of new LHWs, leaving them untrained or inactive for shorter or longer periods (Rashid 2001; Woodgate 2007). Some study authors and some LHWs questioned the quality of the actual training, including the competence of the trainers and the degree to which it gave LHWs the necessary skills to perform their tasks (Daniels 2010; Malema 2010; Meier 2007; Simmons 1990; Smith 2007; Woodgate 2007).

\section{Lay health workers (LHWs) called for training in counselling and} communication skills

LHWs particularly emphasised the importance of training in health promotion and counselling. While LHWs in at least one study felt that training had been adequate for this task (Siu 2009), communicating with community members about different healthcare issues was seen as a complex task (Alcock 2009), and LHWs in several other studies felt unprepared (Haq 2009;Malema 2010; Meier 2007; Mekonnen 2008). In one study LHWs struggled to find a balance between giving information and giving advice, particularly as the giving of advice also brought with it the burden of responsibility in the case of problems (Nankunda 2006). In another study the authors pointed out that the trainers themselves had no specific qualifications in health education (Siu 2009).

\section{Learning communication skills}

When learning communication skills, LHWs in one study found that following an experienced LHW as she interacted with participants was particularly helpful (Meier 2007). In another study the LHWs identified and discussed cultural beliefs that community members might have and that might represent obstacles to the intervention, and were therefore better prepared when communicating about the intervention (Nankunda 2006).

\section{Tools and techniques for communication}

When communicating with community members, other studies noted that a number of tools and techniques had been particularly helpful. These included the use of visual tools, such as picture cards and flipcharts, videos, and dolls (Alcock 2009; Ashwell 2009; Dynes 2011; George 2009; Meier 2007). Mass media campaigns repeating the messages that LHWs gave were also seen as useful (Haq 2009). Explanations, personal follow-up and materials designed for people of low literacy were referred to as particularly helpful in improving recipient understanding (George 2009). In Ethiopia, LHWs used a variety of venues and opportunities to spread information to community members, including "community meetings, coffee ceremony, woman's association weekly meetings, antenatal and immunization outreach sessions, when fetching water or firewood, and even during labor" (Sibley 2006).

\section{Lay health workers (LHWs) called for more training in tasks outside their current scope}

In addition to more training in counselling skills, LHWs in some studies wanted training in topics outside the scope of their role (Kaufmann 1997; Low 2006; Low 2006b; Warrick 1992). In one study (Kaufmann 1997) LHWs wanted more information about common health problems that their work brought them into contact with, while in another study (Low 2006b) they called for training in how to deal with sexual abuse, substance abuse, domestic violence, and housing difficulties. In another study trained trained birth attendants felt confident in their ability to deal with a normal birth but were concerned about their lack of knowledge in dealing with complications and wanted additional training (Low 2006). In a fourth study the increased confidence that training and repetition gave led to requests for additional training in new areas (Warrick 1992).

\section{Training did not always reflect the local context}

In one Zimbabwean study, the authors suggested that problems with compliance among trained traditional birth attendants could be tied to the way training was conducted (Mathole 2005). The authors argue that "the training made little effort to integrate into the health care system the elements for which TBA care continues to appeal to women", including a common understanding between traditional birth attendants and recipients regarding the spiritual and supernatural aspects of pregnancy (Mathole 2005). In Guatemala, the authors suggested that the emphasis on theoretical knowledge at the expense of experiential knowledge reflected in the contents of the training, the manner in which training was carried out, and the background of the trainers may limit midwives' acceptance of the training material (Maupin 2008).

\section{Supervision was seen as important but was often neglected}

For programme staff, supervision was an opportunity to assess and strengthen the knowledge and skills of the LHW and the quality of intervention delivery (Daniels 2010). Some supervisors highlighted the importance of 'non-technical' aspects of supervision, including emotional support to LHWs and help in setting boundaries, as well as motivating LHWs and building up the esteem of women who may never previously have worked outside of their own homes (Daniels 2010). For the LHWs themselves, supervision was seen as a way of achieving support and guidance and addressing ongoing challenges and as a mechanism for continued training (Dynes 2011; George 2009; Heaman 2006; Nankunda 2006). Visible supervision could also increase LHW credibility in the community (Nankunda 2006). Despite widespread acknowledgement of the importance of supervision, satisfaction with current practice varied (Meier 2007) and the studies showed definite room for improvement (Bisika 
2008; Chinbuah 2006; Dynes 2011; Mathole 2005; Rashid 2001; Smith 2007).

\section{Field supervision}

Supervisory field visits were highlighted as important as a lack of such visits meant that supervisors could not properly assess the work of the LHWs (Daniels 2010; George 2009) and they were sometimes unfamiliar with the conditions under which the LHWs worked and the problems of the community (Wayland 2002). A number of reasons were offered for lack of supervision, including supervisors' lack of time (George 2009), too much time spent on routine paperwork and reporting (Simmons 1990), responsibility for large districts (Bisika 2008), lack of transportation (George 2009; Simmons 1990), and gender roles making it difficult for female supervisors to move around in a large field area (Simmons 1990).

\section{Supervision and skills}

Health professionals did not always feel prepared for their role as supervisors (Woodgate 2007). In one study, LHWs appreciated the manner in which supervisors talked to them, without reprimanding them, while the supervisors themselves emphasised the importance of working alongside the LHWs as a team (George 2009). In another study, however, nurses expressed varying levels of comfort with the dual role of partners and supervisors or evaluators. In a third study the supervisors pointed out that while they were in charge, they also needed to balance this position of authority with the respect they were expected to display to LHWs who were their elders (Daniels 2010). In the same study the supervisors also emphasised the importance of understanding the LHWs' circumstances, particularly their HIV status, in order to be able to support them sufficiently. In a fourth study some supervisors needed to be taught how to first observe the LHWs and then correct them at the end of the observation rather than take over their tasks (Nankunda 2006).

\section{Peer support}

LHWs in some studies wanted the opportunity to meet regularly with other LHWs in order to share experiences and give each other support (Low 2006b; Taggart 2000).

\section{Working conditions were often associated with challenges}

\section{Workload}

LHWs and supervisors in several studies expressed concern about the LHWs' workload and the distances they had to cover (Dynes 2011; Javanparast 2009; Kaufmann 1997; Mekonnen 2008; Murphy 2008; Nankunda 2006; Simmons 1990; Wayland 2002). In one study from Bangladesh, many women received no visits from the LHWs, while those who did often received no services: "These are instances where the worker's sole interest is to sign the household visitation card kept in the client's house, in order to convey to her supervisor the impression of regular visits" (Simmons 1990). The study authors saw the LHWs' unrealistic workloads as a main cause of these problems (Simmons 1990).

\section{Poor facilities}

In two studies trained traditional birth attendants complained of poor working conditions, including inadequate lighting and small and dirty rooms (Bisika 2008; Hinojosa 2004), while LHWs in one study asked for more space and additional benches or mats in their clinics so that they could organise meetings (Dynes 2011).

\section{High turnover}

In two studies high turnover of LHWs was described as a problem for the running of the programme (Khan 1998; Woodgate 2007).

\section{Lack of supplies}

In some studies a lack of supplies, including medicines, and a lack of equipment such as timers to count breathing and flipcharts were a source of frustration among LHWs and some recipients (Low 2006; McQuestion 2010; Rashid 2001; Simmons 1990; Suchdev 2010).

In Bangladesh, LHWs were unable to distribute iron for anaemia because there was no provision for field distribution of iron tablets or any other medical supplies in the government programme (Simmons 1990). These LHWs were also supposed to distribute oral rehydration solution. However, "pervasive service rivalries" had led to a lack of co-ordination between the department responsible for oral rehydration solution distribution and the department responsible for the LHW programme, leaving these LHWs without supplies (Low 2006).

\section{Bureaucracy}

In one study (Javanparast 2009) LHWs complained about the amount of paperwork required of them, while supervisors in another study were also hampered by the amount of routine paperwork and report writing (Simmons 1990). At the same time, the absence of a client-oriented record-seeking system was seen to hamper these tasks (Simmons 1990).

\section{Patient flow processes}

Several obstacles prevented lay health workers (LHWs) from referring clients on

In eight studies traditional birth attendants (TBAs) were trained to recognise danger signs in pregnant women or women giving birth and to refer these women on to health professionals (bij de Vaate 2002; Bisika 2008; Hinojosa 2004; Islam 2001; Low 2006; Mathole 2005; Maupin 2008; Ngoma 2009; Sibley 2006). Compliance was not always high, however, and health centre staff in one study were concerned that trained TBAs were overconfident about their ability to manage certain danger signs on their own or lacked the knowledge to recognise such signs. However, the studies suggested that lack of TBA knowledge about danger signs was not the main barrier to referrals (Bisika 2008; Hinojosa 2004; Low 2006; Mathole 2005). Instead, a number of other obstacles were pointed to including a lack of health professionals to refer patients to, lack of transport, compliance factors among the women themselves, and poor relationships between trained TBAs and health professionals.

\section{Lack of health professionals}

While TBAs were trained to refer problematic pregnancies or births on, short-staffing at the clinic was reported as a problem by trained TBAs and community members (Islam 2001; Low 2006).

\section{Poor compliance, and attitudes and fears in the community}

In a Gambian study, trained TBAs reported that women did not complain about being referred to the hospital (bij de Vaate 2002). According to the TBAs, mothers accepted their decisions as they trusted the trained TBAs, because women who were referred came back safely with their babies, and because relatives agreed that it was necessary to refer on (bij de Vaate 2002). In a Zambian study, on the other hand, many families did not use the services 
of the trained TBAs at all because they could not afford to pay them, and they were also concerned that the TBAs would refer them on, which would lead to more costs, for instance for transport and additional healthcare services Ngoma 2009). Trained TBAs in Malawi and Honduras complained that pregnant women and their relatives were often ignorant of the need for referral (Bisika 2008), or reluctant to be referred to hospitals or health centres (Low 2006). This reluctance was apparently tied to perceptions of clinic staff as arrogant and rude as well as a fear of caesarean section, a fear that was also shared by TBAs (Mathole 2005). Trained TBAs reported that women avoided going to the clinic by contacting the TBA too late for referral to be an option (Bisika 2008; Low 2006; Mathole 2005). In these situations TBAs felt obliged to deal with cases they would normally refer on but described the tension between ignoring their training and risking blame from the health centre staff if anything went wrong and ignoring the needs of the woman and risking blame from the woman's family (Bisika 2008; Low 2006; Mathole 2005): "So what do you do? You cannot run away from a woman and leave her groaning, you just have to assist" (Mathole 2005).

\section{Poor relationship between trained TBAs and health professionals}

In addition to the women's misgivings, trained TBAs themselves were sometimes reluctant to refer women on because of the treatment they received by health professionals. They described varied experiences when arriving at the health centre, including having to wait for long periods of time (Low 2006) and being treated with arrogance and lack of respect, which discouraged them from accompanying women to the clinic (Mathole 2005). Trained TBAs in another study reported that when they escorted a woman in labour to hospital, the midwives sent them out of the hospital, leaving them with no place to sleep (bij de Vaate 2002). A climate of mistrust and competition between the trained TBAs and the clinic staff was also referred to by the TBAs as a reason for not referring (Mathole 2005).

One study described particularly serious problems tied to health professionals' attitudes towards TBA referral (Hinojosa 2004). In this Guatemala-based study, trained TBAs often spent much energy trying to identify a physician who would assist women with complicated pregnancy or labour. Some physicians refused to carry out what they referred to as the repair work of the TBAs, and would only attend women who had been under their control for the entire pregnancy. The physicians were not only concerned about the outcomes of the cases but were concerned about their prestigio, or public prestige and reputation, and did not want to be blamed for an infant or maternal death (Hinojosa 2004). The study pointed out that this selectiveness of clients was also seen among the trained TBAs, although to a lesser extent. Here and in another Guatemalan study (Maupin 2008), trained TBAs were reluctant to take on pregnant women who may have been at higher risk and were quick to refer on. The authors suggested that this was a result of the authorities' tacit and overt encouragement of the TBAs to question their own diagnostic and management abilities (Hinojosa 2004), and of a change in the social status and authority of the traditional midwife (Maupin 2008).

\section{Logistical factors}

Other obstacles to referral included logistical factors, particularly the lack of transport necessary to move the woman to the clinic, and also lack of money to pay for transport, or a telephone with which to call an ambulance (Bettiol 2004; bij de Vaate 2002; Bisika 2008; Low 2006: Mathole 2005; Maupin 2008).

\section{Other obstacles to trained TBA referral}

In one study trained TBAs reported that some women delivered on their own, and TBAs therefore had no opportunity to refer them on (bij de Vaate 2002). In another study women sometimes travelled outside of their district to visit particular TBAs that had been recommended to them, making referral systems difficult (Mathole 2005).

\section{Referral by LHWs other than trained TBAs}

Studies of LHWs other than trained TBAs showed varying experiences with referral. In Nicaragua (George 2009) and Kenya (Kaler 2001), patients accompanied by LHWs were given preferential treatment by clinic staff. In South Africa, LHWs reported that NGO health services were usually far more responsive to referral than any of the government health services (Mathews 1994).

The issue of referral and possible overconfidence was also discussed in some of the studies of other types of LHWs. Low compliance was a matter of concern in at least one study where Gambian LHWs were trained to diagnose, treat and refer children with malaria (Chinbuah 2006). Although not instructed to do so, LHWs performed follow-up visits to many of the children they had treated to review the condition of the child. These visits were partially explained by the study authors as a sign of overconfidence. However, the LHWs themselves mentioned that "often they were uncertain and thus preferred to follow up to determine the child's condition rather than refer immediately. They insisted that even when referred, most caregivers would not go to the health facility citing lack of funds as a reason" (Chinbuah 2006).

In one UK-based study, authors also described how established and confident LHWs made decisions without consulting their supervisors but using their own judgement and past experience (Perkins 2001). While this worked well in some instances, there was also a call for clearer guidelines on accountability, "both for the sake of the (lay health workers) and the health visitors who were ultimately responsible" (Perkins 2001).

\section{Referral from health professionals to lay health workers (LHWs) influenced by close ties}

In one US-based programme, clinic staff were expected to refer women on to LHWs for breastfeeding support. According to the LHWs, referrals were more frequent when the clinic was close to the LHW's office, where the relationship was communicative, and where clinic staff were breastfeeding friendly (Meier 2007).

\section{Service integration}

In several studies, respondents pointed out that the LHW programme could be strengthened if it was more strongly integrated into other services, and if other services were more aware of the programme. In the UK, recipients were happy with the programme because it provided a 'seamless service' with individual projects working together (Smith 2007). In another UK-based programme, however, LHWs were concerned that if they were working with a client, social work support would be withdrawn because of a lack of understanding regarding the role of LHWs and their limitations (Perkins 2001). In Uganda, LHWs provided HIV/ 
AIDs and reproductive health education in isolation from related services such as condoms, pills or HIV testing (Siu 2009). In USA, LHWs offering breastfeeding support wanted to develop ties to clinic staff and hospital staff, to encourage breastfeeding and to refer eligible patients to them (Meier 2007).

\section{Social and cultural conditions}

The studies sometimes referred to the manner in which social conditions as well as societal beliefs and values sometimes influenced LHW programme initiation, implementation or acceptance in the community. For example, one study in Papua New Guinea suggested that service changes that required community involvement appeared to occur more readily among recipients living in matrilineal regions because women had more influence on initiating changes (Ashwell 2009). In Honduras, community involvement was more successful where local leaders were dynamic and responsive to community needs, while factors such as economic hardship and rivalries among neighbours made community involvement and collective action difficult (McQuestion 2010). In Malawi, the behaviour of a former government, where people were forced to contribute to the support of party political expenses, made it difficult for programmes to demand resources from the community to support current programmes (Mkandawire 2005). In two studies, recipients living close to town appeared to prefer health professionals over lay health workers (Kaufmann 1997; Khan 1998). In Canada, a home visiting programme was made difficult to implement by the fact that recipients moved a lot (Woodgate 2007). In Bangladesh, the norms of purdah posed challenges to the movement of female LHWs from house to house (Rashid 2001). In Kenya, the sale of supplements by LHWs was negatively influenced by factors including post-election violence closing roads and limiting people's ability to work and access cash (Suchdev 2010).

\section{Donor policies and short-term thinking}

In Nicaragua, one LHW programme was implemented in collaboration between the Ministry of Health and national and international NGOs; Ministry of Health $(\mathrm{MOH})$ representatives viewed this collaboration in a positive light. The authors pointed to the fact that NGO representatives included former $\mathrm{MOH}$ personnel, which implied a shared understanding of their respective roles, functions and organisation culture and encouraged close collaboration (George 2009). In Nepal, however, policy makers and local programme staff were concerned about what they regarded to be the short-term focus of outside donor organisations (Glenton 2010). Respondents were critical of donor organisations' introduction of incentives, particularly performance-based incentives, which they had poor experiences of and which they regarded as unsustainable in the long term: "There are many organizations (that) have implemented a programme and need a report, so in order to (get) a report they do all sorts of things. (But) this kind of small thing destroys the system, and as donors or outsiders, they should really be strengthening the system and making it work. But people don't care about the motivation of the FCHVs, just getting the work done. The Millennium Development Goals are fine, but I think our children should live beyond the Millennium Development Goals!" (Glenton 2010). In the same study, respondents were also concerned that foreign donors and organisations lacked sufficient understanding in the culture and context of the country (Glenton 2010).

\section{Bringing together the results of the quantitative and qualitative reviews in a logic model}

Our second objective was to integrate the findings of this qualitative synthesis with the findings of the Cochrane review that assessed LHW programme effectiveness (Lewin 2013). Ideally, the two reviews would have included trials and qualitative studies that assessed the same LHW programmes. However, before embarking on this synthesis we did attempt to identify qualitative studies that had been carried out alongside the randomised trials from the effectiveness review, but had found very few that would have been appropriate (Glenton 2011). Nevertheless, the two reviews do include data from comparable types of programmes with regard to the populations targeted, although more of the trials than the qualitative studies were from high income countries. The studies from both reviews were also similar with regard to the manner in which LHWs were selected, trained and supervised, and the types of tasks they delivered.

The logic model provided us with one approach to bringing together the results of the two reviews. Here, the findings of the qualitative review were organised into chains of events that we proposed could lead to the outcomes measured in the review of effectiveness. The logic model is presented in Figure 4 and Figure 5, and is also summarised in narrative form below. 
Figure 4. Logic model, part 1

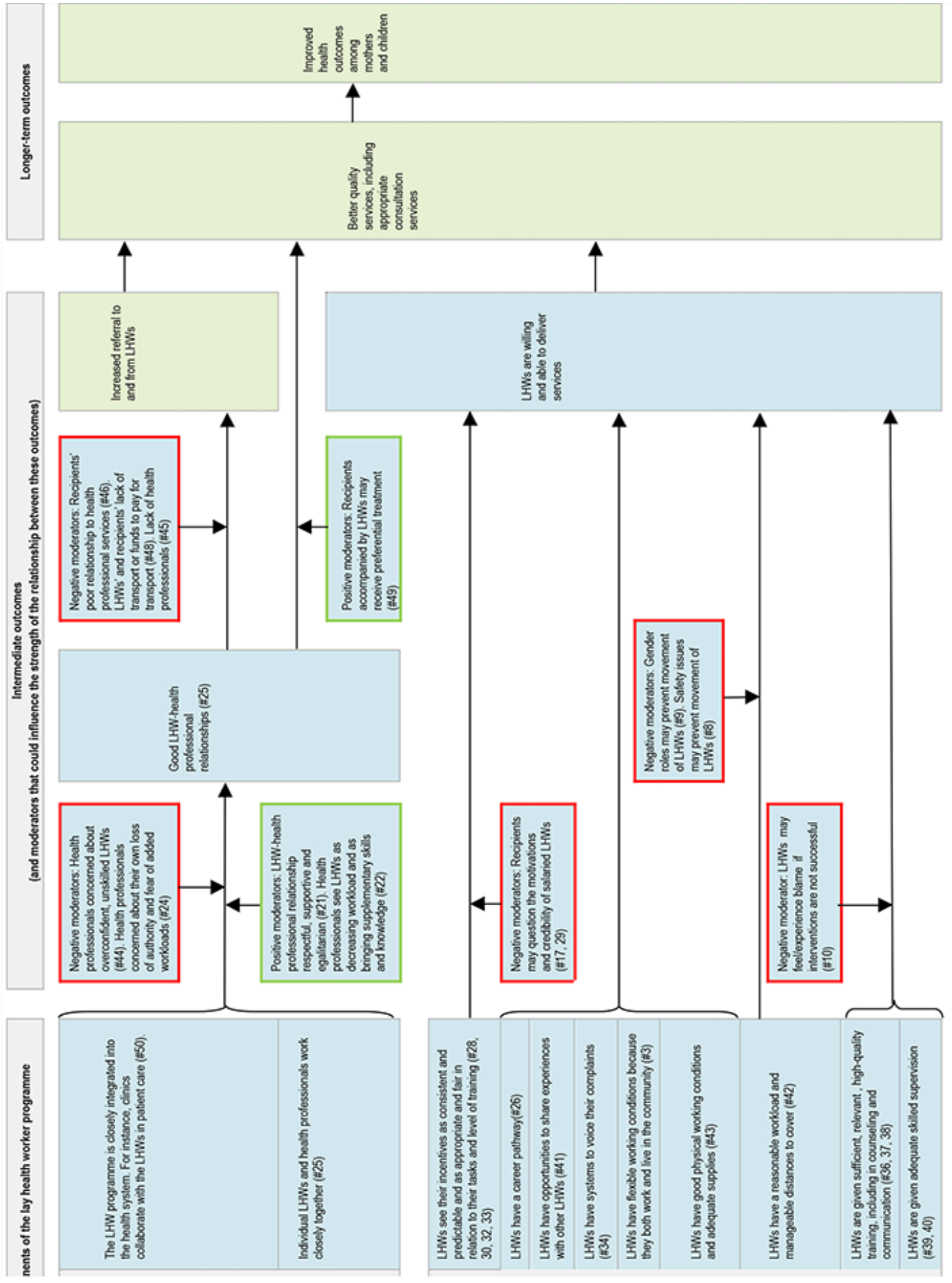

Barriers and facilitators to the implementation of lay health worker programmes to improve access to maternal and child health: a 
Figure 4. (Continued)

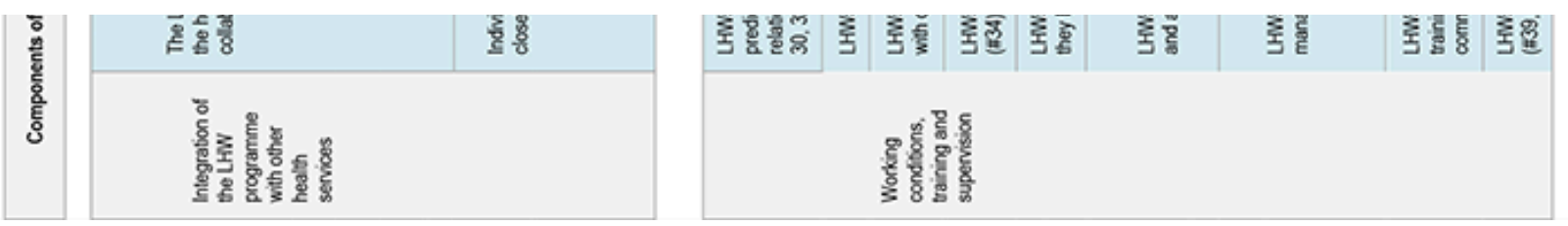


Figure 5. Logic model, part 2

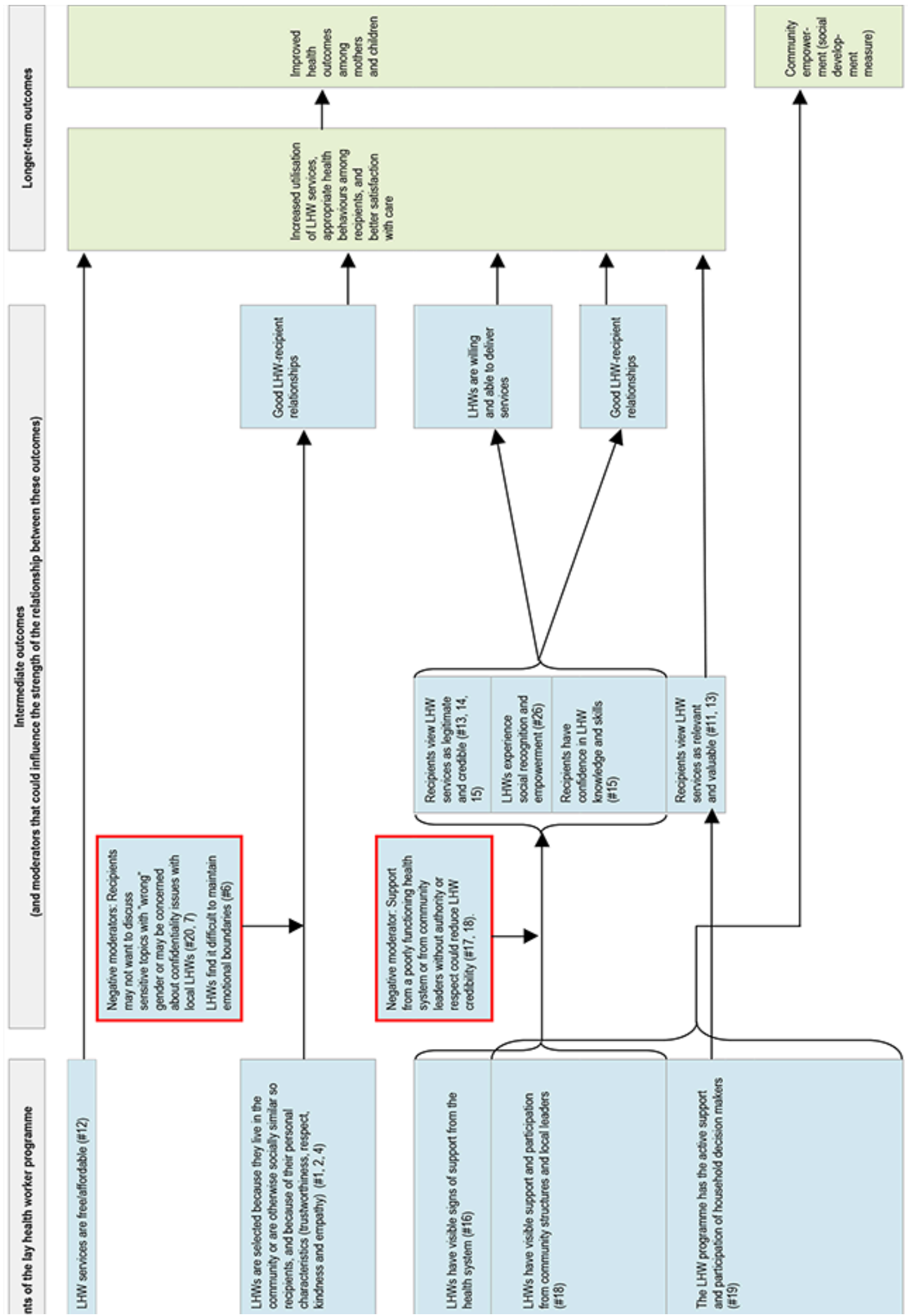

Barriers and facilitators to the implementation of lay health worker programmes to improve access to maternal and child health: a 
Figure 5. (Continued)

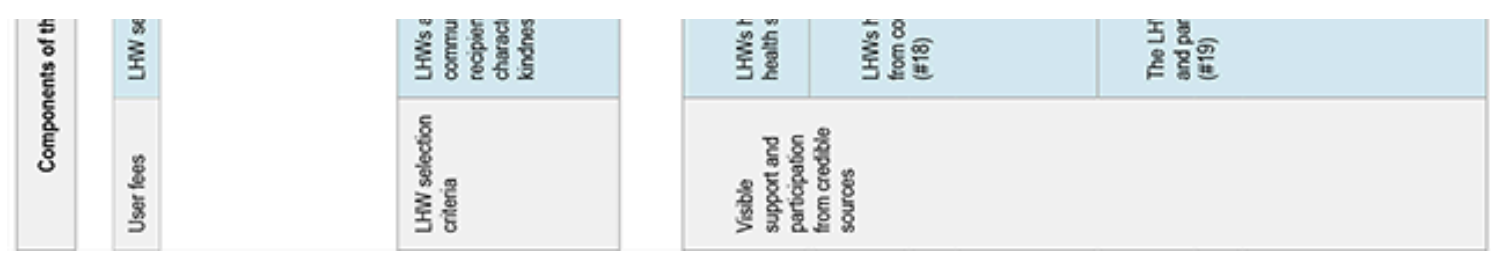

\section{Integration of the lay health worker (LHW) programme with other health services}

In the first chain of events, the LHW programme is closely integrated into the health system. Clinics are aware of and make use of LHW services, and health professionals and LHWs work closely together. This can lead to better relationships between the LHW and the health professional, which in turn can lead to increased referral to and from LHWs and increases their willingness and ability to deliver services. This can lead to better quality services and to improved health outcomes for mothers and children.

This chain of events may be threatened or enhanced in a number of ways. Good relationships may be threatened if health professionals are concerned that LHWs are overconfident or unskilled, or if they are concerned about their own loss of authority or added workload. On the other hand, relationships may be strengthened if health professionals see LHWs as decreasing their workload and bringing supplementary skills and knowledge, and if the relationship is characterised by respect, support and egalitarianism.

Although a good relationship between LHWs and health professionals may lead to increased referral, this process may be threatened if the healthcare recipients themselves have poor relationships to health professionals, if there is a lack of transport or funds to get to the health facilities, or if the facilities are so poorly staffed that recipients are deterred from attending. Increased referral may be more likely, on the other hand, if recipients who are accompanied by LHWs receive preferential treatment.

\section{Lay health worker (LHW) working conditions, training and supervision}

In the second chain of events, the LHWs see their incentives as consistent and predictable, appropriate and fair in relation to their tasks and level of training, and they have a career pathway. They have opportunities to share experiences with other LHWs and they have systems whereby they can voice their complaints. They have good physical working conditions and adequate supplies, a reasonable workload, and manageable distances to cover. Because the LHWs both live and work in the community their working conditions are flexible. They are given sufficient, relevant and high quality training, including training in counselling and communication, and have adequate and skilled supervision. These components can increase their willingness and ability to deliver services, which in turn can lead to better quality services and to improved health outcomes for mothers and children.

This chain of events may be threatened in a number of ways. While LHWs may have a reasonable workload and manageable distances to cover, gender roles or safety issues may prevent their movement in the community. While the LHWs may feel that their incentives are appropriate, recipients may question the motivation and credibility of LHWs who are salaried rather than volunteers. While they may receive sufficient training, they may experience fear, or blame from the community, if the services they deliver are not successful. All of these issues may thereby threaten their willingness and ability to deliver care.

\section{User fees}

In the third chain of events, LHW services are either free or very affordable. This can lead to increased utilization of LHW services, and finally to improved health outcomes for mothers and children.

\section{Lay health worker (LHW) selection criteria}

In the fourth chain of events, LHWs are selected because they live in the community already, or are in other ways socially similar to recipients, and because they possess certain personal characteristics such as trustworthiness, respect, kindness and empathy. This can lead to good relationships between LHWs and recipients thereby to increase recipient uptake of services and improve health outcomes for mothers and children.

This chain of events may be threatened if recipients prefer not to discuss sensitive topics with local LHWs or LHWs of the 'wrong' gender. In addition, LHWs may find it difficult to maintain emotional boundaries with recipients who live close by or who they develop a close relationship to.

\section{Support and participation from credible sources}

In the fifth chain of events, the formal health system, community structures and local leaders visibly support and participate in the LHW programme. Decision makers at the household level also actively support and participate in the programme. This can lead recipients to view the LHWs as legitimate and credible, to have confidence in their knowledge and skills and to view their services as relevant and valuable, and gives the LHWs social recognition and empowerment. This in turn can lead to good relationships between LHWs and recipients and can also increase the willingness and ability of LHWs to deliver services. This pathway may be undermined if the health system or the community structures or leaders that offer support to the LHWs are regarded as poorly functioning or they are without authority or respect.

In addition, the participation of community members can lead to community empowerment, defined here as "the means by which individuals within community contexts have opportunities to gain experience and skills to transform their own lives and their living situation" (Rifkin 2001).

\section{Using the logic model to identify hypotheses for subgroup analyses in the review of effectiveness}

The final objective of this synthesis was to identify hypotheses for subgroup analyses in the Cochrane review of the effectiveness of LHW programmes. As part of the development of the logic model, we identified programme components, that is planned elements 
of the LHW programme that we propose could ultimately lead to the outcomes described in the review of effectiveness. These components include the following.

- The close integration of the LHW programme into the health system.

- Visible support from the health system.

- Close collaboration between individual LHWs and health professionals.

- The active support and participation of community structures, local leaders, and household decision makers.

- Free or affordable LHW services.

- The selection of LHWs that live in the community, or are otherwise socially similar so recipients, and that possess certain personal characteristics such as trustworthiness, respect, kindness and empathy.

- Consistent and predictable incentives that LHWs regard as appropriate and fair in relation to their tasks and level of training.

- A LHW career pathway.

- Opportunities to share experiences with other LHWs.

- Systems where LHWs can voice their complaints.

- Flexible and appropriate working conditions and adequate supplies.

- A reasonable workload and manageable distances to cover.

- Sufficient, relevant, high quality training, including in counseling and communication.

- Adequate skilled supervision.

In future updates of the review of LHW effectiveness, authors could explore the extent to which the presence of these components influences the success of the programmes. This would require that trials report on these components. The importance of these components may vary for different types of programmes. For instance, programmes primarily offering breastfeeding support may be less dependent on visible support from the health system and close collaboration with health professionals than programmes offering treatment for sick children. More work is needed to explore how trials of LHW programmes should be grouped when testing these hypotheses.

\section{DISCUSSION}

\section{Summary of main results}

This synthesis included 53 qualitative studies from diverse countries and settings. The synthesis identified a number of potential barriers and facilitators to the successful implementation of lay health worker (LHW) programmes, including factors tied to the relationship between LHWs and community members, and between these two groups and health professionals. Other identified barriers and facilitators included factors tied to LHW training, supervision, working conditions, incentives and selection criteria, and the integration of the programmes into the health system.

While we explored whether there were differences between high, middle and low income countries in the barriers and facilitators we identified, the differences we did find were perhaps surprisingly few. Many of the findings were based on studies from high, middle and low income countries, suggesting that distinctions other than the low and middle income country with high income country divisions often used by both study and review authors may be more relevant for future reviews.

Some differences between settings did emerge, however. Situations where LHWs were approached about issues outside the scope of their training were more often reported in low and middle income countries, probably reflecting the general lack of services available in these countries. Visible support from community leaders and from the health system also appeared to play a larger role for the credibility of LHWs in these countries, which may reflect differences in social structures between high and low or middle income countries. While the relationship between LHWs and recipients was described in very similar ways in all settings, with an emphasis on the importance of trust, respect, kindness and empathy, recipients from high income countries were more likely to emphasise the importance of LHWs as a source of emotional and social support, and to compare lay health workers to friends or family members. It is possible that recipients in these studies, usually members of vulnerable populations in urban settings, were less likely to have access to supportive social networks. Finally, the importance of social recognition and respect was mainly reported among LHWs in low and middle income countries. This may have been influenced by the fact that most LHWs in high income countries received regular payment, while the situation was far more mixed among LHWs in low and middle income countries. The LHWs' reasons for becoming LHWs and the factors likely to motivate them may therefore have varied.

We also set out to explore whether there were differences in the barriers and facilitators we identified between trained TBAs and other types of LHWs. However, the fact that the trained TBAs usually carried out different tasks than the other LHWs made meaningful comparison difficult.

\section{Overall completeness and applicability of evidence}

A majority of the included studies focused on the perspectives of the LHWs themselves, their recipients, and the health professionals that worked alongside or supervised them. Almost none of the studies explored the perspectives of policy makers, programme planners and managers or community leaders. We were therefore unable to explore these stakeholders' views and experiences. This type of data could have added important information about higher level circumstances and decisions, for instance with regard to the establishment and running of the programmes. In addition, an understanding of these stakeholders' values and priorities could have allowed us to compare their values and priorities with those of stakeholders at ground level, as differences between the groups could represent important barriers to programme success.

We aimed to include a sample of studies from a range of geographical settings. However, the pragmatic decision to only include English language studies affected our ability to include evidence coming from certain regions, including Latin America. While we did try to address this issue by showing particular lenience towards Latin American studies when applying our inclusion criteria, we were still only able to include a few studies from this region.

Barriers and facilitators to the implementation of lay health worker programmes to improve access to maternal and child health: a 


\section{Quality of the evidence and certainty of the findings}

Almost all of the included studies used individual or group interviews. Very few studies made use of long-term ethnographic approaches, where observation of processes as they unfold in their natural environment is a primary component. While the use of individual or group interviews allow researchers to collect data on what people say, observational methods also allow researchers to explore what people actually do, and would therefore have been particularly appropriate "for studying how organisations work, the roles played by different staff and the interaction between staff and clients" (Pope 2008). Qualitative interviews appear to be the most commonly used approach among qualitative researchers in the field of health services research, perhaps because this method is usually less time-consuming than observational studies. It is possible that additional searches in non-health related databases would have allowed us to identify studies where the researcher had studied a LHW programme in one setting over a longer period of time using ethnographic methods of data collection. The identification of such studies is something that should be considered in an update of this review.

This lack of in-depth, long-term studies was also one of the reasons why we assessed that none of our findings were of high certainty. We did assess a number of our findings to be of moderate certainty, however, as the findings were based on relatively well-conducted studies that showed high levels of coherence.

\section{Agreements and disagreements with other studies or reviews}

This synthesis was one of a series of reviews that aimed to inform the World Health Organization's 'Recommendations for Optimizing Health Worker Roles to Improve Access to key Maternal and Newborn Health Interventions through Task Shifting' (OPTIMIZEMNH) (WHO 2012). Other syntheses of qualitative research that were carried out in connection with this work included a review of LHWs and their use of compact prefilled autodisabled devices (Glenton 2013) and a multi-country case study synthesis of LHW and other task shifting programmes to optimise the health workforce (Gopinathan 2013). In addition, syntheses of qualitative research on barriers and facilitators to doctor-nurse substitution (Rashidian 2013) and to task shifting in midwifery services (Colvin 2013) were carried out. In addition to cadre-specific considerations, these four syntheses highlighted a set of considerations and concerns similar to those identified in the current synthesis, including challenges with existing training and supervision; the importance of the relationship between different types of health workers for health worker motivation and service delivery; and the issue of accountability when health workers are asked to deliver specific services that may place them in a position of social or legal liability. These syntheses also supported the idea that recipients of health care may be willing to accept services from 'lower level' health workers and may in some cases prefer these health workers, although there may be important exceptions. In addition, the country case synthesis was able to expand our understanding of these phenomena by describing how 'upstream' factors such as regulatory decisions, financing decisions, management and administration could influence the success of these types of initiatives (Gopinathan 2013).

Several other efforts have been made to understand factors that can influence the success of LHW programmes across settings and for both maternal and child health and other healthcare areas. These include Kane 2010, where evidence from 10 randomised trials of child health interventions in low and middle income settings was extracted and a realist approach was adopted to explore the working of the interventions. The findings from this synthesis are similar to our own and emphasised the importance of training, supervision and good referral systems. The synthesis also describes the importance of close ties between the LHW and the community and their impact on recipient relationships and the LHW's motivation and sense of responsibility. In addition, the synthesis describes how the nature of the relationship between the LHW and the local health services can influence the LHW's legitimacy and credibility. Our own synthesis reflects these findings but also elaborates on them, for instance by describing how close relationships between LHWs and recipients can be problematic for both parts, and by describing how any legitimacy offered by the health system depends on the legitimacy of the health system itself. The relative depth of our own synthesis compared to Kane's realist synthesis probably reflects the fact that the randomised trials were not designed to offer this type of information, an issue also noted by the authors (Kane 2010).

Another effort to explore LHW programmes was made by the Global Health Workforce Alliance in 2010 (Bhutta 2010). This group carried out country case studies of programmes in eight low and middle income countries using published and unpublished reports and through direct contact with key personnel. Their report points to a number of factors that appear to limit programme success, including shortage of supplies and equipment, inadequate education and supervision, low status and remuneration, and inadequate linkages to the health system. However, the main output of these studies was to document how each country programme is organised and the extent to which it functions effectively, rather than to explore specific barriers and across programmes, and these topics are therefore only superficially covered.

Lehmann and Sanders' literature review from 2007 (Lehmann 2007) also has a developing country focus but is otherwise broad in scope and includes both programmatic and academic studies. The review examines the history of LHW programmes, who the LHWs are in terms of gender, age, status etc, and the roles and activities they perform. In addition, the review describes existing literature that has assessed LHW performance, programme use, retention and attrition, programme effectiveness and costeffectiveness, and presents findings regarding LHW programme management, governance, ownership and accountability. While the aim of the review is to describe what we currently know about these programmes, rather than to analyse barriers or facilitators to programme success, the review does point to a number of lessons learnt from the literature, including the importance of training, management, supervision, logistics, appropriate incentives and community embeddedness. In addition, their inclusion of programmatic evidence may have given the authors a better insight into issues tied to management and governance than we were able to achieve with our focus on academic studies.

Jaskiewicz and Tulenko's review (Jaskiewicz 2012) includes published and unpublished articles and reports of LHW programmes in developing countries. This review focuses specifically on the working conditions of LHWs and the impact these may have on work productivity. While their findings are 
similar to the findings from our own synthesis, their focus on this one aspect of the LHW programme allows them to explore this topic in greater detail.

These reviews of LHW programmes have all focused on low and middle income countries, while our own inclusion of studies from all regions has allowed us to explore similarities and differences across regions. Other differences between these reviews and the current synthesis are the aim of the review and the choice of literature. Our own synthesis aimed specifically to identify barriers and facilitators to LHW programmes and only included studies where the primary focus was the experiences and attitudes of stakeholders towards these programmes, while the other reviews had more varied aims. In addition, our own synthesis only included qualitative studies, while the other reviews either included data from randomised trials, studies using several research designs, or both programmatic reports and academic studies. There are advantages and disadvantages to our own approach. While the inclusion of studies that are similar in aim and in methods may have allowed us to compare topics in more depth, this may also have narrowed the type of data we had access to and may, for instance, explain why we have identified few barriers and facilitators concerning higher level issues such as management and governance.

\section{The use of novel methodological approaches in the synthesis}

While methods for synthesising qualitative studies are becoming more common, this is still a relatively new approach and agreement on how best to carry out such syntheses is still emerging. Methods to assess the certainty of findings are even more novel. Our development of the Cerqual approach, and its use in this and other OPTIMIZEMNH-related syntheses (Colvin 2013; Rashidian 2013), is therefore relatively innovative, although the similarities and differences to the GRADE approach are discussed in the methods section. While the logic model approach is well-established as a means of describing how programmes might work, its use in the integration of findings from reviews of qualitative and effectiveness studies is novel.

Another approach to integrating the findings from these two types of reviews is to develop a matrix that juxtaposes recommendations for interventions derived from the synthesis of qualitative evidence against the actual interventions assessed in the review of effectiveness (Candy 2011). We chose to explore the logic model approach for pragmatic reasons, as our summary of qualitative findings tables appeared to lend themselves well to this approach. However, we would like to explore the matrix approach in future updates of this review.

The aim of our logic model approach was to suggest how the barriers and facilitators we had identified in the synthesis could impact on outcomes assessed in the review of programme effectiveness. Two intermediate outcomes that were included in the logic model but that were not included in the effectiveness review involved LHWs' willingness and ability to deliver services and good relationships between LHWs and recipients. Many of the barriers and facilitators identified in the synthesis refer directly or indirectly to the impact of certain situations on these outcomes, and they were therefore added to the model. Some measurement of LHW motivation or work satisfaction as well as some measurement of the LHW-recipient relationship would be useful to include in future trials and reviews of LHW programme effectiveness.

When carrying out the synthesis, we used a theory-informed conceptual framework, the SURE Framework, to guide our identification of themes and categories (The SURE Collaboration 2011). The SURE Framework offered us a useful starting point for our analysis as it provided us with a comprehensive list of possible factors that could influence intervention success. It also allowed us to link the findings from this synthesis to the findings from the other syntheses developed as part of the OPTIMIZEMNH work, and to the broader debate around task shifting among all cadres of health workers. But while the framework encouraged us to compartmentalise findings into specific categories, such as stakeholder attitudes or health system constraints, the logic model approach encouraged us to think through relationships and processes across and between these categories.

One criticism of the logic model approach is that it is too reductionistic. Several of the components and moderators we identified represent complex phenomena in themselves, such as the issue of LHW incentives and motivation, and could have had a model of their own. Furthermore, LHW programmes are embedded in particular sociopolitical contexts and specific health systems with specific governance, financial and delivery arrangements. We were not able to explore the interaction between these contexts and the proposed chains of events because the studies rarely reported this type of data. Another limitation of our logic model is that we chose to present it as a linear process and did not indicate possible feedback loops or interactive cycles even though this could have been done. While any synthesis of research studies requires that studies are to a greater or lesser degree simplified and decontextualised, the logic model takes this process even further.

"A logic model is, by necessity, an abstraction that omits detail for the sake of clarity of representation" (Williams 2009), and a balance needs to be struck between reflecting the complexity of the findings while creating a model that might be useful and understandable. While simplicity is one of the weaknesses of the logic model, it is possibly also one of its strengths, as it can be used to develop practical information for programme planners regarding the optimal design of LHW programmes. At the same time, this use depends on the programme planner's ability to place this information in his or her own context, as is the case for findings from reviews of effectiveness (Lavis 2009). The logic model may be a useful tool for trial and review authors as it can be used to suggest relevant outcomes and subgroup analyses. In addition, qualitative researchers can further explore the connections between components and outcomes that are assumed in the model.

The integration of the two reviews in the logic model was made easier by the fact that there was overlap in review authorship. The logic model was carried out by researchers who were co-authors of, and therefore very familiar with, both reviews.

\section{AUTHORS' CONCLUSIONS}

\section{Implications for practice}

Rather than being seen as a lesser trained health worker, lay health workers may represent a different and sometimes preferred type of health worker. The often close relationship between lay health 
workers and their recipients is a strength of such programmes. However, programme planners must consider how best to achieve the benefits of closeness while minimizing the drawbacks. Other factors that may be important include the development of services that recipients perceive as relevant; regular and visible support from other health workers and from community leaders; and sufficient training, supervision and incentives.

\section{Implications for research}

Future qualitative studies of lay health worker programmes should consider exploring the perceptions of a broader group of stakeholders, including programme planners and managers, policy makers and community leaders. This could give us a better understanding of barriers and facilitators to the establishment and management of lay health worker programmes, and could allow us to compare these stakeholders' values and priorities with those of stakeholders on the ground.

Future qualitative studies should consider making use of observational methods in order to explore stakeholders' actions within and in response to the programmes.

Future trials of lay health worker programme effectiveness should offer more information about how the lay health workers are selected, trained, supervised, and incentivised; how the programme is incorporated into the rest of the health system; and what role, if any, community structures play in the establishment and management of the programmes.
Future trials of lay health worker programme effectiveness should also consider including some measure of lay health worker motivation or work satisfaction as well as some measure of the lay health worker-recipient relationship.

Future reviews of qualitative research that are carried out alongside reviews of intervention effectiveness should aim to include some overlap of authors as the presence of authors that are familiar with the studies and results of both reviews is a great advantage to review integration.

\section{ACKN OWLEDGEMENTS}

We would like to thank Marit Johansen, Norwegian Knowledge Centre for the Health Services, and Andrew Booth, University of Sheffield, for their support in developing the search strategies for this review; Heather Munthe-Kaas, Norwegian Knowledge Centre for the Health Services, for her contribution to the development the CerQual approach; and Metin Gülmezoglu and the UNDP/ UNFPA/UNICEF/WHO/World Bank Special programme of Research, Development and Research Training in Human Reproduction, Department of Reproductive Health and Research, World Health Organization for their overall support in the development of the review. We would also like to acknowledge The Norwegian Agency for Development Cooperation (NORAD) and the Alliance for Health Policy and Systems Research for their financial support. The section of the review entitled 'Description of the intervention' is drawn largely from Lewin 2010, with small adaptations. 


\section{RE F E R E N C E S}

\section{References to studies included in this review}

Alcock 2009 \{published data only\}

Alcock GA, More NS, Patil S, Porel M, Vaidya L, Osrin D. Community-based health programmes: role perceptions and experiences of female peer facilitators in Mumbai's urban slums. Health Education Research 2009;24:957-66.

\section{Ashwell 2009 \{published data only\}}

Ashwell HE, Barclay L. Outcome evaluation of community health promotion intervention within a donor funded project climate in Papua New Guinea. Rural and Remote Health 2009;9(4):1219.

\section{Beake 2005 \{published data only\}}

Beake S, McCourt C, Rowan C, Taylor J. Evaluation of the use of health care assistants to support disadvantaged women breastfeeding in the community. Maternal \& Child Nutrition 2005;1:32-43.

\section{Behnke 2002 \{published data only\}}

Behnke EF, Hans SL. Becoming a Doula. Zero to Three 2002; November:9-13.

\section{Bettiol 2004 \{published data only\}}

Bettiol L, Griffin E, Hogan C, Heard S. Village birth attendants in Papua New Guinea. Australian Family Physician 2004;33:764-5.

\section{bij de Vaate 2002 \{published data only\}}

bij de Vaate A, Coleman R, Manneh H, Walraven G. Knowledge, attitudes and practices of trained traditional birth attendants in the Gambia in the prevention, recognition and management of postpartum haemorrhage. Midwifery 2002;18:3-11.

\section{Bisika 2008 \{published data only\}}

Bisika T. The effectiveness of the TBA programme in reducing maternal mortality and morbidity in Malawi. East African Journal of Public Health 2008;5:103-10.

\section{Chinbuah 2006 \{published data only\}}

Chinbuah AM, Gyapong JO, Pagnoni F, Wellington EK, Gyapong M. Feasibility and acceptability of the use of artemether-lumefantrine in the home management of uncomplicated malaria in children 6-59 months old in Ghana. Tropical Medicine \& International Health 2006;11:1003-16.

\section{Curtis 2007 \{published data only\}}

Curtis P, Woodhill R, Stapleton $\mathrm{H}$. The peer-professional interface in a community-based, breast feeding peer-support project. Midwifery 2007;23:146-56.

\section{Daniels 2010 \{published data only\}}

* Daniels K, Nor B, Jackson D, Ekstrom EC, Doherty T. Supervision of community peer counsellors for infant feeding in South Africa: an exploratory qualitative study. Human Resources for Health 2010;8:6.

Nkonki LL, Daniels KL. Selling a service: experiences of peer supporters while promoting exclusive infant feeding in three sites in South Africa. International Breastfeeding Journal 2010;5:17.

Downie 2004 \{published data only\}

Downie J, Clark K, Clemenston K. Volunteerism: 'community mothers' in action. Contemporary Nurse 2004;18:188-98.

Dynes 2011 \{published data only\}

Dynes M, Rahman A, Beck D, Moran A, Rahman A, Pervin J, et al. Home-based life saving skills in Matlab, Bangladesh: a process evaluation of a community-based maternal child health programme. Midwifery 2011;27:15-22.

George 2009 \{published data only\}

* George A, Menotti EP, Rivera D, Montes I, Reyes CM, Marsh DR. Community case management of childhood illness in Nicaragua: transforming health systems in underserved rural areas. Journal of Health Care for the Poor \& Underserved 2009;20:99-115.

George A, Menotti EP, Rivera S, Marsh DR. Community case management in Nicaragua: lessons in fostering adoption and expanding implementation. Health Policy and Planning 2011;26:327-37.

\section{Glenton 2010 \{published data only\}}

Glenton C, Scheel IB, Pradhan S, Lewin S, Hodgins S, Shrestha V. The female community health volunteer programme in Nepal: Decision makers'perceptions of volunteerism, payment and other incentives. Social Science and Medicine 2010;70(12):1920-7.

\section{Haq 2009 \{published data only\}}

Haq Z, Hafeez A. Knowledge and communication needs assessment of community health workers in a developing country: a qualitative study. Human Resources for Health 2009;7:59.

\section{Hazard 2009 \{published data only\}}

Hazard CJ, Callister LC, Birkhead A, Nichols L. Hispanic Labor Friends Initiative: supporting vulnerable women. American Journal of Maternal Child Nursing 2009;34:115-21.

Heaman 2006 \{published data only\}

* Heaman M, Chalmers K, Woodgate R. Early childhood home visiting programme: factors contributing to success. Journal of Advanced Nursing 2006;55(3):291-300.

Heaman M, Chalmers K, Woodgate R, Brown J. Relationship work in an early childhood home visiting program. Journal of Pediatric Nursing 2007;22:319-30.

\section{Hendrickson 2002 \{published data only\}}

Hendrickson JL, Dearden K, Pachon H, An NH, Schroeder DG, Marsh DR. Empowerment in rural Viet Nam: exploring changes in mothers and health volunteers in the context of an integrated nutrition project. Food \& Nutrition Bulletin 2002;23:86-94. 
Hinojosa 2004 \{published data only\}

Hinojosa S. Authorizing tradition: vectors of contention in Highland Maya midwifery. Social Science \& Medicine 2004;59:637-51.

\section{Islam 2001 \{published data only\}}

Islam A, Malik FA. Role of traditional birth attendants in improving reproductive health: lessons from the family health project, Sindh. Journal of the Pakistan Medical Association 2001;51:218-22.

\section{Javanparast 2009 \{published data only\}}

Javanparast S, Coveney J, Saikia U. Exploring health stakeholders' perceptions on moving towards comprehensive primary health care to address childhood malnutrition in Iran: a qualitative study. BMC Health Services Research 2009;9:36.

Kaler 2001 \{published data only\}

Kaler A, Watkins SC. Disobedient distributors: Street-level bureaucrats and would-be patrons in community-based family planning programs in rural Kenya. Studies in Family Planning 2001;32(3):254-69.

\section{Kaufmann 1997 \{published data only\}}

Kaufmann KS, Meyers $\mathrm{H}$. The changing role of village health volunteers in Northeast Thailand: an ethnographic field study. International Journal of Nursing Studies 1997;34(4):249-55.

\section{Khan 1998 \{published data only\}}

Khan SH, Chowdhury AMR, Karim F, Barua MK. Training and retraining Shastyo Shebika. Reasons for turnover. The Health Care Supervisor 1998;17(1):37-47.

\section{Korfmacher 2002 \{published data only\}}

Korfmacher J, Marchi I. The helping Relationship in a Teen Parenting Program. Zero to Three 2002;November:21-26.

\section{Lancman 2009 \{published data only\}}

Lancman S, Ghirardi MI, Castro ED, Tuacek TA. Repercussions of violence on the mental health of workers of the Family Health Program. Revista de Saude Publica 2009;43:682-8.

Low 2006 \{published data only\}

Low LK, Scheib H, Bailey JM, Sacks E. Challenges for traditional birth attendants in northern rural Honduras. Midwifery 2006;22:78-87.

\section{Low 2006b \{published data only\}}

Low LK, Moffat A, Brennan P. Doulas as Community Health Workers: Lessons Learned from a Volunteer Program. Journal of Perinatal Education 2006;15(3):25-33.

\section{Malema 2010 \{published data only\}}

Malema RN, Malaka DW, Mothiba TM. Experiences of lay counsellors who provide VCT for PMTCT of HIV and AIDS in the Capricorn District, Limpopo Province. Curationis 2010;33(15-33):15-23.
Qualitative evaluation of a community health worker project in Khayelitsha. South African Medical Journal 1994;84:659-63.

Mathole 2005 \{published data only\}

Mathole T, Lindmark G, Ahlberg BM. Competing knowledge claims in the provision of antenatal care: a qualitative study of traditional birth attendants in rural Zimbabwe. Health Care for Women International 2005;26:937-56.

Maupin 2008 \{published data only\}

Maupin JN. Remaking the Guatemalan midwife: Health care reform and midwifery training programs in highland Guatemala. Medical Anthropology 2008;27(4):353-82.

McQuestion 2010 \{published data only\}

McQuestion MJ, Quijano CA, Drasbek C, Harkins T, Sagastume LJ. Social integration and health behavioral change in San Luis, Honduras. Health Education \& Behavior 2010;37:694-708.

\section{Meier 2007 \{published data only\}}

Meier ER, Olson BH, Benton P, Eghtedary K, Song WO. A qualitative evaluation of a breastfeeding peer counselor program. Journal of Human Lactation 2007;23:262-8.

Mekonnen 2008 \{published data only\}

Mekonnen A, Sophie A, Dramaix-Willmet M, Bantayehu A. Factors affecting continuity and success of community-based reproductive health service programme in rural community of Northeast Ethiopia. East African Medical Journal 2008;85:487-99.

Mkandawire 2005 \{published data only\}

Mkandawire WC, Muula AS. Motivation of community care givers in a peri-urban area of Blantyre, Malawi. African Journal of Health Sciences 2005;12:21-5.

Murphy 2008 \{published data only\} Murphy CA, Cupples ME, Percy A, Halliday HL, Stewart MC. Peermentoring for first-time mothers from areas of socio-economic disadvantage: a qualitative study within a randomised controlled trial. BMC Health Services Research 2008;8:46.

\section{Nankunda 2006 \{published data only\}}

Nankunda J, Tumwine JK, Soltvedt Å, Semiyaga N, Ndeezi G, Tylleskär T. Community based peer counsellors for support of exclusive breastfeeding experiences from rural Uganda. International Breastfeeding Journal 2006;1:19.

Ngoma 2009 \{published data only\}

Ngoma CM, Himwiila L. Community perceptions of trained traditional birth attendants. African Journal of Midwifery and Women's Health 2009;3(3):142-5.

Perkins 2001 \{published data only\}

Perkins ER, MacFarlane J. Family support by lay workers: a health visiting initiative. British Journal of Community Nursing 2001;6:26-32.

\section{Mathews 1994 \{published data only\}}

Mathews C, Van der WH, Barron P. A shotgun marriage-community health workers and government health services.

Barriers and facilitators to the implementation of lay health worker programmes to improve access to maternal and child health: a 
Raine 2003 \{published data only\}

Raine P. Promoting breast-feeding in a deprived area: the influence of a peer support initiative. Health \& Social Care in the Community 2003;11:463-9.

\section{Ramirez-Valles 2003 \{published data only\}}

Ramirez-Valles J. Translocal and gender dimensions of frame alignment: community mobilization and recruitment processes among women community health workers in Mexico. Critical Public Health 2003;13(3):207-30.

\section{Rashid 2001 \{published data only\}}

Rashid SF, Hadi A, Afsana K, Begum SA. Acute respiratory infections in rural Bangladesh: cultural understandings, practices and the role of mothers and community health volunteers. Tropical Medicine \& International Health 2001;6:249-55.

\section{Sheppard 2004 \{published data only\}}

Sheppard VB, Williams KP, Richardson JT. Women's priorities for lay health home visitors: implications for eliminating health disparities among underserved women. Journal of Health \& Social Policy 2004;18:19-35.

\section{Sibley 2006 \{published data only\}}

Sibley L, Buffington S, Tedessa L. Home-Based Life Saving Skills in Ethiopia: an update on the second phase of field testing. Journal of Midwifery \& Women's Health 2006;51(4):284-91.

\section{Simmons 1990 \{published data only\}}

Simmons R, Koenig MA, Huque AA. Maternal-child health and family planning: user perspectives and service constraints in rural Bangladesh. Studies in Family Planning 1990;21:187-96.

\section{Siu 2009 \{published data only\}}

Siu G, Whyte S. Increasing access to health education in eastern Uganda: rethinking the role and preparation of volunteers. Health Education Journal 2009;68(2):83-93.

\section{Smith 2007 \{published data only\}}

Smith C, Prosser M, Joomun L. A research evaluation of health support workers in a Sure Start project. Community Practitioner 2007;80:32-5.

\section{Suchdev 2010 \{published data only\}}

Suchdev PS, Ruth L, Obure A, Were V, Ochieng C, Ogange L, et al. Monitoring the marketing, distribution, and use of Sprinkles micronutrient powders in rural western Kenya. Food \& Nutrition Bulletin 2010;31:168-78.

\section{Taggart 2000 \{published data only\}}

Taggart AV, Short SD, Barclay L. She has made me feel human again': an evaluation of a volunteer home-based visiting project for mothers. Health \& Social Care in the Community 2000 2000;8(1):1-8.

\section{Warrick 1992 \{published data only\}}

Warrick LH, Wood AH, Meister JS, de Zapian JG. Evaluation of a peer health worker prenatal outreach and education program for Hispanic farmworker families. Journal of Community Health 1992;17(1):13-26.

\section{Wayland 2002 \{published data only\}}

Wayland C. Acceptable and appropriate: program priorities vs. felt needs in a CHW program. Critical Public Health 2002;12(4):335-50.

\section{Woodgate 2007 \{published data only\}}

Woodgate R, Heaman M, Chalmers K, Brown J. Issues related to delivering an early childhood home-visiting program. American Journal of Maternal Child Nursing 2007;March:95-101.

\section{References to studies excluded from this review}

\section{Ahmed 2006 \{published data only\}}

Ahmed S, Macfariane A, Naylor J, Hastings J. Evaluating bilingual peer support for breastfeeding in a local Sure Start. British Journal of Midwifery 2006;14(8):467-70.

Ainbinder 1998 \{published data only\}

Ainbinder JG, Blanchard LW, Singer GH, Sullivan ME, Powers LK, Marquis JG, et al. A qualitative study of Parent to Parent support for parents of children with special needs. Consortium to evaluate Parent to Parent. Journal of Pediatric Psychology 1998;23:99-109.

\section{Attree 2004 \{published data only\}}

Attree P. 'It was like my little acorn, and it's going to grow into a big tree': a qualitative study of a community support project. Health \& Social Care in the Community 2004;12:155-61.

\section{Carr 2005 \{published data only\}}

Carr S. Peer educators--contributing to child accident prevention. Community Practitioner 2005;78:174-7.

\section{Cupples 2011 \{published data only\}}

Cupples ME, Stewart MC, Percy A, Hepper P, Murphy C, Halliday HL. A RCT of peer-mentoring for first-time mothers in socially disadvantaged areas (the MOMENTS Study). Archives of Disease in Childhood 2011;96:252-8.

\section{Farquhar 2006 \{published data only\}}

Farquhar SA, Parker EA, Schulz AJ, Israel BA. Application of qualitative methods in program planning for health promotion interventions. Health Promotion Practice 2006;7:234-42.

\section{Hoddinott 2006 \{published data only\}} Hoddinott P, Chalmers M, Pill R. One-to-one or group-based peer support for breastfeeding? Women's perceptions of a breastfeeding peer coaching intervention. Birth 2006;33:139-46.

Ingram 2005 \{published data only\}

Ingram J, Rosser J, Jackson D. Breastfeeding peer supporters and a community support group. Maternal \& Child Nutrition 2005;1(2):5-12.

\section{Lagendyk 2005 \{published data only\}}

Lagendyk LE, Thurston WE. A case study of volunteers providing labour and childbirth support in hospitals in Canada. Midwifery 2005 2005;21:14-22.

Barriers and facilitators to the implementation of lay health worker programmes to improve access to maternal and child health: a 
Lavender 2005 \{published data only\}

Lavender T, Thompson S, Wood L. Supporting teenage mothers with breastfeeding guardians. British Journal of Midwifery 2005;13(6):354-9.

\section{Locklin 1995 \{published data only\}}

Locklin MP. Telling the world: low income women and their breastfeeding experiences. Journal of Human Lactation 1995;11:285-91.

\section{Martens 2002 \{published data only\}}

Martens PJ. Increasing breastfeeding initiation and duration at a community level: an evaluation of Sagkeeng First Nation's community health nurse and peer counselor programs. Journal of Human Lactation 2002;18:236-46.

\section{Moran 2006 \{published data only\}}

Moran VH, Dykes F, Burt S, Shuck C. Breastfeeding support for adolescent mothers: similarities and differences in the approach of midwives and qualified breastfeeding supporters. International Breastfeeding Journal 2006;1:23.

\section{Paris 2008 \{published data only\}}

Paris R. "For the dream of being here, one sacrifices...": voices of immigrant mothers in a home visiting program. American Journal of Orthopsychiatry 2008;78:141-51.

Raine 2003b \{published data only\}

Raine P, Woodward P. Promoting breastfeeding: A peer support initiative. Community Practitioner 2003;76(6):211-3.

\section{Schroeder 2005 \{published data only\}}

Schroeder C, Bell J. Doula birth support for incarcerated pregnant women. Public Health Nursing 2005;22:53-8.

\section{Scott 2003 \{published data only\}}

Scott JA, Mostyn T. Women's experiences of breastfeeding in a bottle-feeding culture. Journal of Human Lactation 2003;19(3):270-7.

\section{Smith 2004 \{published data only\}}

Smith S, Randhawa G. Extending the role of the linkworker in weaning support. Community Practitioner 2004;77(4):146-9.

\section{Suppiah 1994 \{published data only\}}

Suppiah C. Working in partnership with community mothers. Health Visitor 1994;67(2):51-3.

Wade 2009 \{published data only\}

Wade D, Haining S, Day A. Breastfeeding peer support: are there additional benefits?. Community Practitioner 2009;82:30-3.

\section{Zadoroznyj 2006 \{published data only\}}

Zadoroznyj M. Postnatal care in the community: report of an evaluation of birthing women's assessments of a postnatal home-care programme. Health \& Social Care in the Community 2006;15(1):35-44.

\section{Additional references}

\section{Atkins 2008}

Atkins S, Lewin S, Smith H, Engel M, Fretheim A, Volmink J. Conducting a meta-ethnography of qualitative literature: lessons learnt. BMC Medical Research Methodology 2008 Apr;16(8):21.

\section{Bhutta 2010}

Bhutta ZA, Lassi ZS, Pariyo G, Huicho L. Global Experience of Community Health Workers for Delivery of Health Related Millennium Development Goals: A Systematic Review, Country Case Studies, and Recommendations for Integration into National Health Systems. Global Health Workforce Alliance/ World Health Organization 2010.

\section{Booth 2012}

Booth A, Papaioannou D, Sutton A. Systematic Approaches to a Successful Literature Review. Sage Publications, 2012.

\section{Candy 2011}

Candy B, King M, Jones L, Oliver S. Using qualitative synthesis to explore heterogeneity of complex interventions. BMC Medical Research Methodology 2011;11:124.

\section{Carlsen 2007}

Carlsen B, Glenton C, Pope C. Thou shalt versus thou shalt not. A qualitative meta-analysis of GPs' attitudes to clinical practice guidelines. British Journal of General Practice 2007;57(545):971-8.

\section{CASP 2006}

Critical Appraisal Skills Programme (CASP). Qualitative Appraisal Checklist for Qualitative Research. Available from http://www.casp-uk.net/wp-content/uploads/2011/11/CASP_ Qualitative_Appraisal_Checklist_140ct10.pdf 2006.

\section{Chen 2004}

Chen L, Evans T, Anand S, Boufford JI, Brown H, Chowdhury M, et al. Human resources for health:overcoming the crisis. Lancet 2004;364(9449):1984-90.

\section{Chopra 2008}

Chopra M, Munro S, Lavis JN, Vist G, Bennett S. Effects of policy options for human resources for health: an analysis of systematic reviews. Lancet 2008;371(9613):668-74.

\section{Colvin 2013}

Colvin CJ, de Heer J, Winterton L, Mellencamp M, Glenton C, Noyes $\mathrm{J}$, et al. A systematic review of qualitative evidence on barriers and facilitators to the implementation of task-shifting in midwifery services. Midwifery In press.

\section{Darmstadt 2005}

Darmstadt GL, Bhutta ZA, Cousens S, Adam T, Walker N, de Bernis L, et al. Evidence-based, cost-effective interventions: how many newborn babies can we save?. Lancet 2005;365(9463):977-88. 


\section{De Brouwere 2009}

De Brouwere V, Dieng T, Diadhiou M, Witter S, Denerville E. Task shifting for emergency obstetric surgery in district hospitals in Senegal. Reproductive Health Matters 2009 May;17(33):32-44.

\section{Doyle 2003}

Doyle LH. Synthesis through meta-ethnography: paradoxes, enhancements, and possibilities. Qualitative Research 2003;3:321-44.

\section{Filippi 2006}

Filippi V, Ronsmans C, Campbell OM, Graham WJ, Mills A, Borghi J, et al. Maternal health in poor countries: the broader context and a call for action. Lancet 2006;368(9546):1535-41.

\section{Frankel 1992}

Frankel S. The Community Health Worker: Effective Programmes for Developing Countries. Oxford: Oxford University Press, 1992.

\section{Garner 2007}

Garner P, Smith H, Munro S, Volmink J. Promoting adherence to tuberculosis treatment. Bulletin of the World Health Organization 2007;85(5):404-6.

\section{Glenton 2011}

Glenton C, Lewin S, Scheel IB. Still too little qualitative research to shed light on results from reviews of effectiveness trials: A case study of a Cochrane review on the use of lay health workers. Implementation Science 2011 May;27(6):53.

\section{Glenton 2013}

Glenton C, Khanna R, Morgan C, Nilsen ES. The effects, safety and acceptability of compact, prefilled, autodisable injection devices when delivered by lay health workers. Tropical Medicine \& International Health 2013;18(8):1002-16.

\section{Goldsmith 2007}

Goldsmith MR, Bankhead CR, Austoker J. Synthesising quantitative and qualitative research in evidence-based patient information. Journal of Epidemiology and Community Health 2007 March;61(3):262-70.

\section{Gopinathan 2013}

Gopinathan U, Lewin SA, Glenton C. Implementing large scale programmes to optimise the health workforce: a multi-country case study synthesis. Submitted for publication 2013.

\section{Guyatt 2011}

Guyatt G, Oxman AD, Akl EA, Kunz R, Vist G, Brozek J, et al. GRADE guidelines: 1. Introduction-GRADE evidence profiles and summary of findings tables. Journal of Clinical Epidemiology 2011;64:383-94.

\section{Hadley 2000}

Hadley M, Maher D. Community involvement in tuberculosis control: lessons from other health care programmes. International Journal of Tuberculosis and Lung Disease 2000;4(5):401-8

\section{Haines 2007}

Haines A, Sanders D, Lehmann U, Rowe AK, Lawn JE, Jan S, et al. Achieving child survival goals: potential contribution of community health workers. Lancet 2007;369(9579):2121-31.

\section{Hermann 2009}

Hermann K, Van Damme W, Pariyo GW, Schouten E, Assefa Y, Cirera A, et al. Community health workers for ART in subSaharan Africa: learning from experience - capitalizing on new opportunities. Human Resources for Health 2009;7:31. [DOI: 10.1186/1478-4491-7-31]

\section{Hesselink 2009}

Hesselink AE, Verhoeff AP, Stronks K. Ethnic health care advisors: a good strategy to improve the access to health care and social welfare services for ethnic minorities?. Journal of Community Health 2009;34(5):419-29.

\section{Jaskiewicz 2012}

Jaskiewicz W, Tulenko K. Increasing community health worker productivity and effectiveness: a review of the influence of the work environment. Human Resources for Health 2012;10(1):38.

\section{Kane 2010}

Kane SS, Gerretsen B, Scherpbier R, Dal Poz M, Dieleman M. A realist synthesis of randomised control trials involving use of community health workers for delivering child health interventions in low and middle income countries. BMC Health Services Research 2010;10(286):1-7.

\section{Lavis 2009}

Lavis JN, Oxman AD, Souza NM, Lewin S, Gruen RL, Fretheim A. SUPPORT Tools for evidence-informed health policymaking (STP) 9: Assessing the applicability of the findings of a systematic review.. Health Research Policy and Systems 2009;7 Suppl 1:S9.

\section{Lehmann 2007}

Lehmann U, Sanders D. Community health workers: What do we know about them? The state of the evidence on programmes, activities, costs and impact on health outcomes of using community health workers. Geneva: Evidence and Information for Policy, Department of Human Resources for Health, World Health Organization, 2007.

\section{Lehmann 2009}

Lehmann U, Van Damme W, Barten F, Sanders D. Task shifting: the answer to the human resources crisis in Africa?. Human Resources for Health 2009;7:49. [DOI: 10.1186/1478-4491-7-49]

\section{Lewin 2005}

Lewin SA, Dick J, Pond P, Zwarenstein M, Aja G, van Wyk B, et al. Lay health workers in primary and community health care. Cochrane Database of Systematic Reviews 2005, Issue 1. [DOI: 10.1002/14651858.CD004015]

\section{Lewin 2008}

Lewin S, Lavis JN, Oxman AD, Bastías G, Chopra M, Ciapponi A, et al. Supporting the delivery of cost-effective interventions in primary health-care systems in low-income and middle- 
income countries: an overview of systematic reviews. Lancet 2008;372(9642):928-39.

\section{Lewin 2010}

Lewin S, Munabi-Babigumira S, Glenton C, Daniels K, Bosch-Capblanch X, van Wyk BE, et al. Lay health workers in primary and community health care for maternal and child health and the management of infectious diseases. Cochrane Database of Systematic Reviews 2010, Issue 3. [DOI: 10.1002/14651858.CD004015.pub3]

\section{Lewin 2013}

Lewin S, et al. Lay health workers in primary and community health care for maternal and child health and the management of infectious diseases. Cochrane Database of Systematic Reviews 2010, Issue 3. [DOI: 10.1002/14651858.CD004015.pub3]

\section{Lincoln 1985}

Lincoln YS, Guba EG. Naturalistic enquiry. London: Sage, 1985.

\section{Maher 1999}

Maher D, van Gondrie PCFM, Raviglione M. Community contribution to tuberculosis care in countries with high tuberculosis prevalence: past, present and future. The International Journal of Tuberculosis and Lung Disease 1999;3(9):762-8.

\section{Miles 1994}

Miles MB, Huberman AM. Qualitative data analysis: an expanded sourcebook. Qualitative data analysis: an expanded sourcebook. 2nd Edition. London: Sage Publications, 1994.

\section{Munro 2007}

Munro S, Lewin S, Smith H, Engel M, Fretheim A, Volmink J. Adherence to tuberculosis treatment: a qualitative systematic review of stakeholder perceptions. PLOS Medicine 2007;4(7):e238.

\section{Noyes 2007}

Noyes J, Popay J. Directly observed therapy and tuberculosis: how can asystematic review of qualitative research contribute to improving services? A qualitative meta-synthesis. Journal of Advanced Nursing 2007;57(3):227-43.

\section{Noyes 2009}

Noyes J, Popay J, Pearson A, Hannes K, Booth A for the Cochrane Qualitative Methods Group. Chapter 20: Qualitative research and Cochrane reviews. In: Higgins JPT, Green S editor(s). Cochrane Handbook for Systematic Reviews of Interventions Version 5.0.2 [updated September 2009]. Chichester: John Wiley \& Sons, 2009.

\section{Noyes 2011}

Noyes J, Lewin S. Chapter 6: Supplemental Guidance on Selecting a Method of Qualitative Evidence Synthesis, and Integrating Qualitative Evidence with Cochrane Intervention Reviews. In: Noyes J, Booth A, Hannes K, Harden A, Harris J, Lewin S, Lockwood C editor(s). Supplementary Guidance for Inclusion of Qualitative Research in Cochrane Systematic Reviews of Interventions. Vol. Version 1 (updated August
2011), Cochrane Collaboration Qualitative Methods Group, 2011.

\section{Pope 2008}

Pope C, Mays N. Qualitative research in health care. 3rd Edition. Blackwell Publishing, 2008.

\section{Rashidian 2013}

Rashidian A, Karimi-Shahanjarini A, Shakibazadeh E, Glenton C, Noyes J, Lewin S, Colvin C, Laurant M. Barriers and facilitators to the effectiveness and implementation of doctor-nurse substitution programmes:qualitative evidence synthesis. Cochrane Database of Systematic Reviews 2013, Issue 2. [DOI: 10.1002/14651858.CD010412]

\section{Rifkin 2001}

Rifkin S. Ten best readings on community participation and health. African Health Sciences August 2001;1(1):42-5.

\section{Schneider 2008}

Schneider H, Hlophe H, van Rensburg D. Community health workers and the response to HIV/AIDS in South Africa: tensions and prospects. Health Policy and Planning 2008;23:179-87.

\section{The SURE Collaboration 2011}

The SURE Collaboration. SURE Guides for Preparing and Using Evidence-Based Policy Briefs: 5. Identifying and addressing barriers to implementing policy options. Version 2.1 [updated November 2011]. Available from www.who.int/evidence/sure/ guides.

\section{Thomas 2008}

Thomas J, Harden A. Methods for the thematic synthesis of qualitative research in systematic reviews. BMC Medical Research Methodology 2008;8:45.

\section{Volmink 2007}

Volmink J, Garner P. Directly observed therapy for treating tuberculosis. Cochrane Database of Systematic Reviews 2007, Issue 4. [DOI: 10.1002/14651858.CD003343.pub3]

\section{Walt 1990}

Walt G. Community health workers in national programmes: just another pair of hands?. Open University Press, 1990.

\section{WHO 2005}

The Millenium Development Goals will not be attained without new research addressing health system constraints to delivering effective interventions: Report of the WHO Task Force on Health Systems Research. Available at http://www.who.int/rpc/ summit/en/Task Force on Health Systems Research.pdf 2005.

\section{WHO 2006}

World Health Organization. The World Health Report 2006: working together for health. Geneva: World Health Organization, 2006.

\section{WHO 2007}

World Health Organization. Task shifting: rational redistribution of tasks among health workforce teams. Geneva: World Health Organization, 2007. 


\section{WHO 2010}

World Health Organization. Increasing access to health workers in remote and rural areas through improved retention. Global policy recommendations. Geneva: World Health Organization, 2010.

\section{WHO 2012}

World Health Organization. Optimizing health worker roles to improve access to key maternal and newborn health interventions through task shifting. Geneva: World Health Organization. Available at http://www.optimizemnh.org (Accessed on 24th January 2013) 2012.

\section{WHO/PEPFAR/UNAIDS 2007}

WHO/PEPFAR/UNAIDS. Task Shifting: Rational redistribution of tasks among health workforce teams. Global recommendations and guidelines. Geneva: World Health Organization, 2007.

\section{Williams 2009}

Williams VL, Eiseman E, Landree E, Adamson DM. Demonstrating and communicating research impact. Preparing NIOSH programs for external review. Rand Corporation (http:// www.rand.org/pubs/monographs/MG809.html) 2009.

\section{CHARACTERISTICS OF STUDIES}

Characteristics of included studies [ordered by study ID]

\section{Witmer 1995}

Witmer A, Seifer SD, Finocchio L, Leslie J, O’Neil EH. Community health workers: integral members of the healthcare work force. American Journal of Public Health 1995;85(8 Pt 1):1055-8.

\section{World Bank 2011}

World Bank. Country and lending groups. http:// data.worldbank.org/about/country-classifications/countryand-lending-groups.

\section{Yakan 2009}

Yakan JC, Gruénais ME. Involving new actors to achieve ART scaling-up: difficulties in an HIV/AIDS counselling and testing centre in Cameroon. International Nursing Review 2009;56(1):50-7.

\section{Zachariah 2009}

Zachariah R, Ford N, Philips M, Lynch S, Massaquoi M, Janssens $\mathrm{V}$, et al. Task shifting in HIV/AIDS:

opportunities, challenges and proposed actions for sub-Saharan Africa. Transactions of the Royal Society of Tropical Medicine and Hygiene 2009;103:549-58.

* Indicates the major publication for the study

Alcock 2009

\begin{tabular}{ll} 
Methods & $\begin{array}{l}\text { Qualitative data collection (focus group interviews, semi-structured interviews, observation) and quali- } \\
\text { tative data analysis }\end{array}$ \\
\hline Participants & Programme staff; LHWs \\
\hline Interventions & $\begin{array}{l}\text { LHWs (Female Peer Facilitators) established and strengthened community groups and facilitated par- } \\
\text { ticipatory discussions and experience sharing on pregnancy, childbirth, postpartum care and newborn } \\
\text { health }\end{array}$
\end{tabular}

Notes

$-$

\section{Ashwell 2009}

\begin{tabular}{ll}
\hline Methods & $\begin{array}{l}\text { Qualitative data collection (focus group interviews, semi-structured interviews, observation) and quali- } \\
\text { tative data analysis }\end{array}$ \\
\hline Participants & Policy makers; programme managers; NGO representatives; health professionals; LHWs; recipients \\
\hline Interventions & $\begin{array}{l}\text { LHWs (Village Home Volunteers) served as health educators in their community, linked the village and } \\
\text { health service; encouraged a healthier lifestyle; helped coordinate community health activities; sup- } \\
\text { ported prevention of health problems; and encouraged the use of maternal and child health services. }\end{array}$
\end{tabular}

Notes 
Beake 2005

\begin{tabular}{ll}
\hline Methods & $\begin{array}{l}\text { Qualitative data collection (focus group interviews, semi-structured interviews) and qualitative data } \\
\text { analysis }\end{array}$ \\
\hline Participants & Health professionals, LHWs and recipients \\
\hline Interventions & $\begin{array}{l}\text { LHWs (Infant Feeding Support Workers) made home visits, hospital visits, and worked with other pro- } \\
\text { gramme workers to support mothers breastfeeding }\end{array}$ \\
\hline Notes & - \\
\hline
\end{tabular}

\section{Behnke 2002}

\begin{tabular}{ll}
\hline Methods & Qualitative data collection (semi-structured interviews) and qualitative data analysis \\
\hline Participants & LHWs \\
\hline Interventions & $\begin{array}{l}\text { Doulas made contact with adolescent mothers during pregnancy to help them prepare for childbirth } \\
\text { and parenthood and support them during labour, and supported them for several months after child- } \\
\text { birth with breastfeeding and parenthood }\end{array}$ \\
\hline Notes & - \\
\hline
\end{tabular}

\section{Bettiol 2004}

\begin{tabular}{ll}
\hline Methods & Qualitative data collection (semi-structured interviews) and qualitative data analysis \\
\hline Participants & LHWs \\
\hline $\begin{array}{l}\text { Interventions } \\
\text { LHWs (Village birth attendants) assisted at deliveries, assisted with maternal and child health patrols, } \\
\text { antenatal checks, referrals, health promotion, referring women requesting family planning }\end{array}$ \\
\hline Notes & - \\
\hline
\end{tabular}

\section{bij de Vaate 2002}

Methods Qualitative data collection (focus group interviews and semi-structured interviews) and qualitative da-
ta analysis

\begin{tabular}{ll}
\hline Participants & Health professionals and LHWs \\
\hline Interventions & LHWs (trained Traditional Birth Attendants) offered care during pregnancy and childbirth and were \\
& trained to prevent recognize and control postpartum haemorrhage \\
\hline Notes & - \\
\hline
\end{tabular}


Bisika 2008 $\begin{array}{ll}\text { Methods } & \begin{array}{l}\text { Qualitative data collection (focus group interviews and in-depth interviews) and qualitative data analy- } \\ \text { sis }\end{array}\end{array}$

\begin{tabular}{ll}
\hline Participants & Programme managers, health professionals, LHWs, community leaders and recipients \\
\hline Interventions & LHWs (trained TBAs) offered delivery service for pregnant women, including distribution of iron tablets, \\
referral for ANC, health education, screening for danger signs, advise on pregnancy and neonatal care, \\
ANC, etc
\end{tabular}

Notes

Chinbuah 2006

\begin{tabular}{ll}
\hline Methods & Qualitative data collection (focus group interviews) and qualitative data analysis \\
\hline Participants & LHWs, community leaders and recipients \\
\hline Interventions & $\begin{array}{l}\text { LHWs (community-based agents) diagnosed and treated children with uncomplicated malaria, referred } \\
\text { children on if the condition worsened or if severe malaria was suspected }\end{array}$ \\
\hline Notes & - \\
\hline
\end{tabular}

\section{Curtis 2007}

\begin{tabular}{ll}
\hline Methods & Qualitative data collection (focus group interviews) and qualitative data analysis \\
\hline Participants & Health professionals and LHWs \\
\hline Interventions & $\begin{array}{l}\text { LHWs (volunteer peer supporters) worked with women to encourage them to breastfeed their babies } \\
\text { and to support them with their breastfeeding }\end{array}$ \\
\hline
\end{tabular}

\section{Notes}

\section{Daniels 2010}

\begin{tabular}{ll}
\hline Methods & Qualitative data collection (interviews and focus groups) and qualitative data analysis \\
\hline Participants & Supervisors and LHWs \\
\hline $\begin{array}{l}\text { Interventions } \\
\text { LHWs (community peer counsellors) established what feeding choice the mother had made after birth } \\
\text { (exclusive breastfeeding or formula), discouraged mixed feeding, and supported the mother in her } \\
\text { choice. They encouraged women to know their HIV status and to disclose this status to their family }\end{array}$ \\
\hline Notes & Data describing this study/programme was also collected from Nkonki 2010 \\
\hline
\end{tabular}

Methods Qualitative data collection (telephone interviews) and qualitative data analysis

Barriers and facilitators to the implementation of lay health worker programmes to improve access to maternal and child health: a qualitative evidence synthesis (Review)

Copyright ( 2019 The Cochrane Collaboration. Published by John Wiley \& Sons, Ltd. 
Downie 2004 (Continued)

Participants LHWs

\begin{tabular}{ll}
\hline Interventions & LHWs (Community Mothers) visited mothers at home and aimed to help them feel more confident and \\
empowered in their child rearing
\end{tabular}

\section{Notes}

Dynes 2011

\begin{tabular}{ll}
\hline Methods & Qualitative data collection (focus group interviews and interviews) and qualitative data analysis \\
\hline Participants & Programme staff, health professionals, LHWs and recipients \\
\hline Interventions & $\begin{array}{l}\text { LHWs (Community Health Research Workers) participated in a home-based life saving skills pro- } \\
\text { disseminated through a training cascade. The aim of the programme was to decrease delays in recogni- } \\
\text { tion and response to major complications; increase access to emergency maternal and neonatal care; } \\
\text { and encourage timely, appropriate emergency referral }\end{array}$ \\
\hline Notes & - \\
\hline
\end{tabular}

\section{George 2009}

\begin{tabular}{ll}
\hline Methods & $\begin{array}{l}\text { Qualitative data collection (focus group interviews and semi-structured interviews) and qualitative da- } \\
\text { ta analysis }\end{array}$ \\
\hline Participants & Ministry of Health staff, NGO staff, LHWs and recipients \\
\hline Interventions & LHWs (Brigadistas) diagnosed, treated and referred common childhood illnesses \\
\hline Notes & Data describing this study/programme was also collected from George 2011 \\
\hline
\end{tabular}

\section{Glenton 2010}

\begin{tabular}{ll}
\hline Methods & Qualitative data collection (semi-structured interviews) and qualitative data analysis \\
\hline Participants & Policy makers, NGO representatives and LHWs \\
\hline Interventions & $\begin{array}{l}\text { LHWs (Female Community Health Volunteers) delivered promotional, preventive and some curative } \\
\text { services tied to maternal and child health, including distribution of vitamin A, iron and de-worming } \\
\text { tablets, immunisation, family planning, and care of children with common childhood diseases }\end{array}$ \\
\hline Notes & - \\
\hline
\end{tabular}


Haq 2009 (Continued)

Participants Supervisors and LHWs

\begin{tabular}{ll}
\hline Interventions & LHWs (Lady Health Workers) provided health information, including family planning and maternal and \\
child health information
\end{tabular}

\section{Notes}

\section{Hazard 2009}

\begin{tabular}{ll}
\hline Methods & Qualitative data collection (interviews) and qualitative data analysis \\
\hline Participants & Health professionals, LHWs and recipients \\
\hline $\begin{array}{l}\text { Interventions } \\
\text { LHWs (Hispanic Labor Friends) attended one prenatal visit with the patient, supported the woman dur- } \\
\text { ing labour and birth, participated in the discharge teaching on the mother/baby unit, and made at least } \\
\text { one follow-up postpartum visit }\end{array}$ \\
\hline Notes & - \\
\hline
\end{tabular}

Heaman 2006

\begin{tabular}{ll}
\hline Methods & Qualitative data collection (in-depth semi-structured interviews) and qualitative data analysis \\
\hline Participants & Health professionals, LHWs and recipients \\
\hline Interventions & $\begin{array}{l}\text { LHWs (paraprofessional home visitors) promoted healthy and safe growth of infants and children in } \\
\text { high-risk families through a home visiting programme }\end{array}$ \\
\hline Notes & Data describing this study/programme was also collected from Heaman 2007 \\
\hline
\end{tabular}

\begin{tabular}{ll}
\hline Hendrickson 2002 & Qualitative data collection (semi-structured interviews) and qualitative data analysis \\
\hline Participants & LHWs and recipients \\
\hline Interventions & $\begin{array}{l}\text { LHWs (Health Volunteers) organised a 12-day nutrition education and rehabilitation programmes with } \\
\text { caregivers of malnourished children. They also monitored the growth of commune children, visited } \\
\text { homes to encourage good food behaviours, and reported progress to rest of community }\end{array}$ \\
\hline Notes & - \\
\hline
\end{tabular}

\section{Hinojosa 2004}

\begin{tabular}{ll}
\hline Methods & $\begin{array}{l}\text { Qualitative data collection (individual interviews and ethnographic fieldwork) and qualitative data } \\
\text { analysis }\end{array}$
\end{tabular}

Participants Health professionals and LHWs

Barriers and facilitators to the implementation of lay health worker programmes to improve access to maternal and child health: a qualitative evidence synthesis (Review)

Copyright (c) 2019 The Cochrane Collaboration. Published by John Wiley \& Sons, Ltd. 
Hinojosa 2004 (Continued)

Interventions LHWs (traditional midwives or "comadronas") received additional training in midwifery

\section{Notes}

\section{Islam 2001}

Methods Qualitative data collection (focus group interviews, semi-structured interviews, observations) and
qualitative data analysis

\begin{tabular}{ll}
\hline Participants & LHWs and recipients \\
\hline Interventions & $\begin{array}{l}\text { LHWs (trained Traditional Birth Attendants) provided an array of services including delivery. Their } \\
\text { training included safe and clean delivery and recognising high risk pregnancies so that timely referral } \\
\text { could be made to a health facility and avoid further complications }\end{array}$ \\
\hline
\end{tabular}

\section{Notes}

\begin{tabular}{ll}
\hline Javanparast 2009 & Qualitative data collection (individual and focus group interviews) and qualitative data analysis \\
\hline Participants & Policy makers, LHWs and recipients \\
\hline Interventions & $\begin{array}{l}\text { LHWs ("Behvarz") provided promotional, preventive and some curative services, primarily tied to ma- } \\
\text { ternal and child health }\end{array}$ \\
\hline Notes & -
\end{tabular}

\section{Kaler 2001}

\begin{tabular}{ll}
\hline Methods & Qualitative data collection (interviews and focus group discussions) and qualitative data analysis \\
\hline Participants & Health professionals, LHWs, community leaders and recipients \\
\hline Interventions & $\begin{array}{l}\text { LHWs (community-based distributors) were responsible for supplying the contraceptive needs of } \\
\text { households }\end{array}$ \\
\hline Notes & - \\
\hline
\end{tabular}

\section{Kaufmann 1997}

\begin{tabular}{ll}
\hline Methods & $\begin{array}{l}\text { Qualitative data collection (focus group interviews, semi-structured interviews, observations) and } \\
\text { qualitative data analysis }\end{array}$ \\
\hline Participants & LHWs, community leaders and recipients \\
\hline Interventions & $\begin{array}{l}\text { LHWs (Village Health Volunteers) informed villagers about issues related to health; collected vital sta- } \\
\text { tistics including pregnancies, deaths and migration; conducted a needs assessment of their village; } \\
\text { taught and advised the villagers in all aspects of PHC; carried out and coordinated village-specific de- }\end{array}$ \\
\hline
\end{tabular}

Barriers and facilitators to the implementation of lay health worker programmes to improve access to maternal and child health: a 
Kaufmann 1997 (Continued)

velopment activities in conjunction with other intersectoral development activities; weighed preschool children and distributed supplementary foods for malnourished children; provided simple symptomatic medical by using home remedies or medicines approved by the Ministry of Public Health; provided first aid; distributed birth control pills and condoms to villagers who had already been examined by government health staff

Notes

Khan 1998

\begin{tabular}{ll}
\hline Methods & Qualitative data collection and qualitative data analysis \\
\hline Participants & LHWs \\
\hline Interventions & $\begin{array}{l}\text { LHWs ("Shasthyo Shebika”) gave health education, motivation and mobilization regarding Essential } \\
\text { Health Care (EHC); sold medicine, contraceptives, sanitary latrines, tubewells and vegetable seeds; di- } \\
\text { agnosed, treated and provided education on diarrhea, dysentery, fever, common cold, anaemia, worm } \\
\text { infection, gastric ulcer, allergic reaction, scabies and ringworm infection; went on follow-up visits and } \\
\text { encouraged pregnant women to utilize government facilities }\end{array}$ \\
\hline
\end{tabular}

Notes

Korfmacher 2002

Methods Qualitative data collection (semi-structured interviews) and qualitative data analysis

\begin{tabular}{ll}
\hline Participants & LHWs and recipients \\
\hline Interventions & LHWs (family advocates) offered weekly visits either at school, at home, at LHW's office or in group \\
meetings. Promote infant learning and development
\end{tabular}

$$
\text { Notes }
$$

\begin{tabular}{ll}
\hline Lancman 2009 & Qualitative data collection ("reflection groups") and qualitative data analysis \\
\hline Participants & Health professionals and LHWs \\
\hline Interventions & $\begin{array}{l}\text { LHWs (community health agents) provided promotional, preventive and some curative services as part } \\
\text { of the Programa Saúde da Família (Family Health Program) }\end{array}$ \\
\hline Notes & - \\
\hline
\end{tabular}

Low 2006

\begin{tabular}{ll}
\hline Methods & Qualitative data collection (focus group interviews) and qualitative data analysis \\
\hline Participants & LHWs \\
\hline \hline
\end{tabular}

Barriers and facilitators to the implementation of lay health worker programmes to improve access to maternal and child health: a 
Low 2006 (Continued)

Interventions LHWs (traditional Birth Attendants - "parteras") received additional training in midwifery and in recognizing and referring complications

Notes

$-$

Low 2006b

\begin{tabular}{ll}
\hline Methods & Qualitative data collection (focus group discussions) and qualitative data analysis \\
\hline Participants & LHWs \\
\hline Interventions & $\begin{array}{l}\text { LHWs (doulas) provided support during pregnancy and the birth process and into the immediate post- } \\
\text { partum period (included transportation to prenatal visits; accompaniment to prenatal classes; prena- } \\
\text { tal home visits; answers to questions about pregnancy, childbirth, and parenting; education to pro- } \\
\text { mote healthy behaviors throughout pregnancy; support during labour; assistance with breastfeeding, if } \\
\text { needed; home visits during the postpartum period; and availability by phone for any questions) }\end{array}$ \\
\hline Notes & - \\
\hline
\end{tabular}

Malema 2010

\begin{tabular}{ll}
\hline Methods & Qualitative data collection (semi-structured interviews) and qualitative data analysis \\
\hline Participants & LHWs \\
\hline Interventions & $\begin{array}{l}\text { LHWs (lay counsellors) worked with nurses at hospitals and clinics, providing HIV counselling to preg- } \\
\text { nant women and encouraged them to get tested for HIV }\end{array}$ \\
\hline
\end{tabular}

Notes

(1)

Mathews 1994

\begin{tabular}{ll}
\hline Methods & $\begin{array}{l}\text { Qualitative data collection (free-attitude interviews and focus group discussions) and qualitative data } \\
\text { analysis }\end{array}$ \\
\hline Participants & Project staff, health professionals, LHWs and recipients \\
\hline Interventions & $\begin{array}{l}\text { LHWs (community health workers) ensured that all families were aware of the available health facili- } \\
\text { ties; that all children under } 5 \text { had a Road-To-Health card and were up to date with immunisations, that } \\
\text { health education on breastfeeding, oral rehydration, family spacing, nutrition and TB was given to } \\
\text { mothers, and that malnourished children were brought to clinics. Also, followed up TB defaulters and } \\
\text { new births, home visits to contacts of patients with TB and STD, domiciliary treatment of TB patients, } \\
\text { undertook projects that will contribute to community }\end{array}$
\end{tabular}

\section{Notes}


Mathole 2005

\begin{tabular}{ll}
\hline Methods & Qualitative data collection (interviews and focus group discussions) and qualitative data analysis \\
\hline Participants & LHWs \\
\hline Interventions & $\begin{array}{l}\text { LHWs (Traditional Birth Attendants) received additional training in midwifery and in recognizing and } \\
\text { referring complications }\end{array}$ \\
\hline Notes & -
\end{tabular}

\section{Maupin 2008}

\begin{tabular}{ll}
\hline Methods & Qualitative data collection (interviews and observation) and qualitative data analysis \\
\hline Participants & LHWs \\
\hline Interventions & LHWs (trained traditional midwives) offered antenatal and intrapartum care \\
\hline Notes & - \\
\hline
\end{tabular}

\section{McQuestion 2010 \\ Methods}

Qualitative data collection (key informant interviews and focus group interviews) and qualitative data analysis

\begin{tabular}{ll}
\hline Participants & Local government representatives, teachers, health workers and recipients \\
\hline Interventions & LHWs (Red Cross volunteers) organised community-level health education workshops, performed \\
home visits, and attended village health committee meetings to promote IMCI key practices
\end{tabular}

Meier 2007

\begin{tabular}{ll}
\hline Methods & Qualitative data collection (focus group discussions) and qualitative data analysis \\
\hline Participants & LHWs and recipients \\
\hline Interventions & $\begin{array}{l}\text { LHWs (breastfeeding peer counselors) promoted breastfeeding and offered encouragement and sup- } \\
\text { port through home visits, hospital visits and phone calls. }\end{array}$ \\
\hline
\end{tabular}

Notes

\section{Mekonnen 2008}

Methods

Qualitative data collection (in-depth interviews and focus group discussions) and qualitative data analysis

Participants

Programme staff, supervisors, health professionals, LHWs and recipients

Barriers and facilitators to the implementation of lay health worker programmes to improve access to maternal and child health: a qualitative evidence synthesis (Review)

Copyright ( 2019 The Cochrane Collaboration. Published by John Wiley \& Sons, Ltd. 
Mekonnen 2008 (Continued)

Interventions LHWs (community-based reproductive health workers) promoted contraceptives

\section{Notes}

Mkandawire 2005

\begin{tabular}{ll}
\hline Methods & Qualitative data collection (in-depth interviews) and qualitative data analysis \\
\hline Participants & Community leaders and LHWs \\
\hline Interventions & $\begin{array}{l}\text { LHWs (community health volunteers) visited the sick in hospital and at home, assisted with household } \\
\text { chores, bathed the patient and helped with cooking; provided food; accompanied orphaned children } \\
\text { and chronically sick persons to hospital; offered HIV counselling; escorted people to HIV test centres; } \\
\text { offered psychospiritual support through prayer and companionship; and sometimes paid school fees }\end{array}$ \\
\hline Notes & -
\end{tabular}

Murphy 2008

\begin{tabular}{ll}
\hline Methods & Qualitative data collection (semi-structured interviews) and qualitative data analysis \\
\hline Participants & Supervisors, LHWs and recipients \\
\hline $\begin{array}{l}\text { Interventions } \\
\text { LHWs (peer mentors) offered home visiting throughout pregnancy and one year after birth, offered ad- } \\
\text { vice about mothers' and baby's healthcare, and help in accessing professional health and social care } \\
\text { services as required }\end{array}$ \\
\hline Notes & - \\
\hline
\end{tabular}

Nankunda 2006

\begin{tabular}{ll}
\hline Methods & $\begin{array}{l}\text { Qualitative data collection (focus group interviews, semi-structured interviews, observations) and } \\
\text { qualitative data analysis }\end{array}$
\end{tabular}

\begin{tabular}{ll}
\hline Participants & LHWs and recipients \\
\hline Interventions & $\begin{array}{l}\text { LHWs (peer counsellors) recruited pregnant mothers, visited them in their homes, and offered informa- } \\
\text { tion about breastfeeding. For women planning to breastfeed, they offered to help the mother with this } \\
\text { after the birth }\end{array}$
\end{tabular}

Notes

$-$

\section{Ngoma 2009}

\begin{tabular}{ll}
\hline Methods & Qualitative data collection (focus group interviews) and qualitative data analysis \\
\hline Participants & Programme recipients and potential recipients \\
\hline
\end{tabular}


Ngoma 2009 (Continued)

Interventions

LHWs (trained Traditional Birth Attendants) trained in safe delivery, recognition of danger signs, and referral practices. Also offer health promotion and family planning

Notes

Perkins 2001

\begin{tabular}{ll}
\hline Methods & Qualitative data collection (semi-structured interviews and focus groups) and qualitative data analysis \\
\hline Participants & Programme staff, health professionals, LHWs and recipients \\
\hline $\begin{array}{l}\text { Interventions } \\
\text { LHWs (Family Support Workers) offered practical and social support, participated in health promotion } \\
\text { Notes }\end{array}$ & - \\
\hline
\end{tabular}

Raine 2003

\begin{tabular}{ll}
\hline Methods & Qualitative data collection (semi-structured interviews) and qualitative data analysis \\
\hline Participants & Health professionals, LHWs and recipients \\
\hline Interventions & LHWs (lay supporters) offered breastfeeding support \\
\hline
\end{tabular}

Notes

$-$

\section{Ramirez-Valles 2003}

\begin{tabular}{ll}
\hline Methods & $\begin{array}{l}\text { Qualitative data collection (semi-structured interviews, participant observation and text analysis) and } \\
\text { qualitative data analysis }\end{array}$ \\
\hline Participants & Programme staff and LHWs \\
\hline Interventions & $\begin{array}{l}\text { LHWs (Community workers) offered education and services tied to issues including maternal and child } \\
\text { health, family planning, sex education and nutrition }\end{array}$ \\
\hline Notes & - \\
\hline
\end{tabular}

\section{Rashid 2001}

\begin{tabular}{ll}
\hline Methods & Qualitative data collection (interviews) and qualitative data analysis \\
\hline Participants & Programme staff, LHWs and recipients \\
\hline Interventions & $\begin{array}{l}\text { LHWs (Community Health Volunteers) provided information and services on family planning including } \\
\text { the supply of contraceptives, sanitation and hygiene, immunisation, tuberculosis, ARI, nutrition, repro- } \\
\text { ductive health and treatment of common disease }\end{array}$ \\
\hline
\end{tabular}


Rashid 2001 (Continued)

Notes

Sheppard 2004

\begin{tabular}{ll}
\hline Methods & Qualitative data collection (focus group discussions) and qualitative data analysis \\
\hline Participants & Programme recipients \\
\hline Interventions & $\begin{array}{l}\text { LHWs (Resource Mothers) gave home visits with the aim of improving access to prenatal care, encour- } \\
\text { aging proper nutrition and self-care during pregnancy, supporting utilization of prenatal care, and pro- } \\
\text { viding linkages to necessary social groups }\end{array}$ \\
\hline Notes & - \\
\hline
\end{tabular}

\section{Sibley 2006}

\begin{tabular}{ll}
\hline Methods & Qualitative data collection (focus group discussions) and qualitative data analysis \\
\hline Participants & LHWs and recipients \\
\hline $\begin{array}{l}\text { Interventions } \\
\text { LHWs (Traditional Birth Attendants trained as Home Based Life Saving Skills (HBLSS) guides) received } \\
\text { additional training in midwifery and in recognizing, dealing with and referring complications in moth- } \\
\text { ers and babies }\end{array}$ \\
\hline Notes & - \\
\hline
\end{tabular}

Simmons 1990

\begin{tabular}{ll}
\hline Methods & Qualitative data collection (participant observation) and qualitative data analysis \\
\hline Participants & LHWs and recipients \\
\hline Interventions & $\begin{array}{l}\text { LHWs (Family Welfare Assistants) gave information and referred on with regard to family planning and } \\
\text { gave information about maternal and child health }\end{array}$ \\
\hline
\end{tabular}

\section{Notes}

Siu 2009

\begin{tabular}{ll}
\hline $\begin{array}{l}\text { Methods } \\
\text { Qualitative data collection (in-depth interviews and focus group discussions) and qualitative data } \\
\text { analysis }\end{array}$ \\
\hline Participants & Programme staff, LHWs and recipients \\
\hline Interventions & LHWs (Health Education Volunteers) gave family planning information and HIV information \\
\hline Notes & - \\
\hline
\end{tabular}

Barriers and facilitators to the implementation of lay health worker programmes to improve access to maternal and child health: a 
Smith 2007

\begin{tabular}{ll}
\hline Methods & Qualitative data collection (interviews) and qualitative data analysis \\
\hline Participants & Health professionals, LHWs and recipients \\
\hline Interventions & LHWs (Health Support Workers) offered a wide range of support for parenting/child health \\
\hline Notes & -
\end{tabular}

Suchdev 2010

\begin{tabular}{ll} 
Methods & Qualitative data collection (key informant interviews and focus groups) and qualitative data analysis \\
\hline Participants & LHWs
\end{tabular}

Interventions LHWs (SWAP vendors) promoted and sold iron supplements, participating in promotional launches in each village, purchasing "Sprinkles" and reselling them in their villages for a slight profit, which they kept or that contributed to the activities of their community groups

Notes

\section{Taggart 2000}

\begin{tabular}{ll}
\hline Methods & Qualitative data collection (semi-structured interviews, observations) and qualitative data analysis \\
\hline Participants & LHWs, recipients, and a LHW co-ordinator \\
\hline Interventions & $\begin{array}{l}\text { LHWs (Volunteers) visited new mothers in their homes with an aim to befriend, listen and help with the } \\
\text { day-to-day practical skills of mothering in order to prevent child abuse and neglect }\end{array}$ \\
\hline
\end{tabular}

Notes

\section{Warrick 1992}

\begin{tabular}{ll}
\hline Methods & $\begin{array}{l}\text { Qualitative data collection (field observation, semi-structured interviews, gathering of life histories) } \\
\text { and qualitative data analysis }\end{array}$ \\
\hline Participants & Programme staff, LHWs and recipients \\
\hline Interventions & $\begin{array}{l}\text { LHWs ("promotoras") delivered 12-week courses to people in the community about prenatal care but } \\
\text { also did home visits }\end{array}$ \\
\hline Notes & - \\
\hline
\end{tabular}

\section{Wayland 2002}

Methods Qualitative data collection (interviews, observations) and qualitative data analysis

Barriers and facilitators to the implementation of lay health worker programmes to improve access to maternal and child health: a 
Wayland 2002 (Continued)

Participants Programme staff, supervisors, LHWs and recipients

Interventions LHWs (community health workers) expected to visit each house in their territory each month, measure the nutritional status of pregnant women and children under 2, register malnourished women and children for milk/supplement program, and deliver the supplemental food to family each month until nutritional status improves. Also distributes hypochlorite (for water quality), educates about various health topics, gives advice about health problems and monitors children with health problems

\section{Notes}

\section{Woodgate 2007}

Methods Qualitative data collection (in-depth, semi-structured interviews) and qualitative data analysis

\begin{tabular}{ll}
\hline Participants & Health professionals and LHWs \\
\hline Interventions & LHWs (Lay Home Visitors) promoted healthy and safe growth of infants and children in high-risk fami- \\
& lies. They worked mainly alone but nurse might also pay home visits to the same family
\end{tabular}

Notes

Characteristics of excluded studies [ordered by study ID]

\begin{tabular}{|c|c|}
\hline Study & Reason for exclusion \\
\hline Ahmed 2006 & $\begin{array}{l}\text { UK-based study. Excluded because of lack of focus on review question and small amount of data. } \\
\text { Also, this is an evaluation of a Sure Start programme, of which we already have two included }\end{array}$ \\
\hline Ainbinder 1998 & $\begin{array}{l}\text { USA-based study. Excluded because of low relevance for review question. The focus of the paper } \\
\text { was on social support for children with special needs, which we defined as slightly outside the } \\
\text { scope of maternal and child health }\end{array}$ \\
\hline Attree 2004 & $\begin{array}{l}\text { UK-based study. Excluded because of overlap with other included studies (Evaluation of a Sure } \\
\text { Start programme, of which we already have two included) }\end{array}$ \\
\hline Carr 2005 & $\begin{array}{l}\text { UK-based study. Excluded because of low relevance for review question. The focus of the paper was } \\
\text { on child accident prevention, which we defined as slightly outside the scope of maternal and child } \\
\text { health }\end{array}$ \\
\hline Cupples 2011 & $\begin{array}{l}\text { UK-based study. Excluded because it is the same study as Murphy, and Murphy presents more or } \\
\text { less the same data }\end{array}$ \\
\hline Farquhar 2006 & $\begin{array}{l}\text { USA-based study. Excluded because of lack of focus on review question. The focus of the paper is to } \\
\text { describe how the LHWs used qualitative methods to plan programmes }\end{array}$ \\
\hline Hoddinott 2006 & $\begin{array}{l}\text { UK-based study. Excluded because of low focus on review question. Most of the focus is on the } \\
\text { breastfeeding groups run by health professionals. Very little data on the LHW personal coaches }\end{array}$ \\
\hline Ingram 2005 & $\begin{array}{l}\text { UK-based study. Excluded because of low focus on review question. Also covers a questionnaire } \\
\text { study and the data are relatively thin }\end{array}$ \\
\hline
\end{tabular}




\begin{tabular}{|c|c|}
\hline Study & Reason for exclusion \\
\hline Lagendyk 2005 & $\begin{array}{l}\text { Canada-based study. Excluded because of low focus on review question. The main focus of the } \\
\text { study is not stakeholders' perceptions of the LHW programme, but how two LHW programmes } \\
\text { were merged }\end{array}$ \\
\hline Lavender 2005 & $\begin{array}{l}\text { UK-based study. Excluded because of lack of focus on review question (main focus is mothers' } \\
\text { views of breastfeeding) }\end{array}$ \\
\hline Locklin 1995 & $\begin{array}{l}\text { USA-based study. Excluded because of low focus on review question. The primary focus is on } \\
\text { women's experiences of breastfeeding, and only parts of it are about their views of the LHW pro- } \\
\text { gramme }\end{array}$ \\
\hline Martens 2002 & $\begin{array}{l}\text { Canada-based study. Excluded because of low focus on review question. Also covers a quantitative } \\
\text { study and the qualitative data are relatively thin }\end{array}$ \\
\hline Moran 2006 & $\begin{array}{l}\text { UK-based study. Excluded because of low focus on review question. Focuses on midwives' and LH- } \\
\text { Ws' views and attitudes of breastfeeding support rather than on the LHW programme }\end{array}$ \\
\hline Paris 2008 & $\begin{array}{l}\text { USA-based study. Excluded because of low focus on review question. A lot of the results section fo- } \\
\text { cused on the experiences of immigrant mothers that were not directly relevant to the programme }\end{array}$ \\
\hline Raine 2003b & $\begin{array}{l}\text { UK-based study. Excluded because this is the same study as Raine } 2003 \text { and presents more or less } \\
\text { the same data }\end{array}$ \\
\hline Schroeder 2005 & $\begin{array}{l}\text { USA-based study. Excluded because of low relevance to the review question. The study took place } \\
\text { in jail, and much of the date focuses on the experience of birth and the role of the doula in this par- } \\
\text { ticular setting }\end{array}$ \\
\hline Scott 2003 & $\begin{array}{l}\text { UK-based study. Excluded because of low focus on review question. The primary focus is on } \\
\text { women's experiences of breastfeeding, and only a small part deals with their views of the LHW pro- } \\
\text { gramme }\end{array}$ \\
\hline Smith 2004 & $\begin{array}{l}\text { UK-based study. Excluded because of overlap with other included studies (evaluation of a UK- } \\
\text { based programme with breastfeeding support focus). Also relatively thin description }\end{array}$ \\
\hline Suppiah 1994 & $\begin{array}{l}\text { UK-based study. Excluded because of overlap with other included studies (evaluation of a pro- } \\
\text { gramme based in the UK and with a focus on breastfeeding support, nutrition and parenting skills) }\end{array}$ \\
\hline Wade 2009 & $\begin{array}{l}\text { UK-based study. Excluded because of low focus on review question. Also, study very similar to oth- } \\
\text { er UK-based studies of breastfeeding and thin description }\end{array}$ \\
\hline Zadoroznyj 2006 & $\begin{array}{l}\text { Australia-based study. Excluded because of low relevance for review question. The focus of the pa- } \\
\text { per was on home support, including domestic and social support, which we defined as slightly out- } \\
\text { side the main scope of maternal and child health }\end{array}$ \\
\hline
\end{tabular}

\section{ADDITIONAL TABLES}

Table 1. Key domains of the SURE framework

\begin{tabular}{ll}
\hline Level & Factors affecting implementation \\
\hline Recipients of care & Knowledge and skills \\
\cline { 2 - 2 } & Attitudes regarding programme acceptability, appropriateness and credibility \\
\hline
\end{tabular}

Barriers and facilitators to the implementation of lay health worker programmes to improve access to maternal and child health: a 
Table 1. Key domains of the SURE framework (Continued)

Motivation to change or adopt new behavior

\begin{tabular}{|c|}
\hline Providers of care \\
\hline $\begin{array}{l}\text { Other stakeholders (including } \\
\text { other healthcare providers, } \\
\text { community health committees, }\end{array}$ \\
\hline $\begin{array}{l}\text { community leaders, pro- } \\
\text { gramme managers, donors, } \\
\text { policymakers and opinion lead- } \\
\text { ers) }\end{array}$ \\
\hline
\end{tabular}

Knowledge and skills

Attitudes regarding programme acceptability, appropriateness and credibility

Motivation to change or adopt new behavior

Knowledge and skills

Attitudes regarding programme acceptability, appropriateness and credibility

Motivation to change or adopt new behavior

Health system constraints

Accessiblity of care

Financial resources

Human resources

Educational and training system, including recruitment and selection

Clinical supervision, support structures and guidelines

Internal communication

External communication

Allocation of authority

Accountability

Community participation

Management and/or leadership

Information systems

Scale of private sector care

Facilities

Patient flow processes

Procurement and distribution systems

Incentives

Bureaucracy

Relationship with norms and standards 
Table 1. Key domains of the SURE framework (Continued)

\begin{tabular}{l} 
Governance \\
\hline Short-term thinking \\
\hline Contracts \\
\hline Legislation or regulation \\
\hline Donor policies \\
\hline Influential people \\
\hline Corruption \\
\hline Political stability and commitment
\end{tabular}

Table 2. Quality criteria assessment

\begin{tabular}{|c|c|c|c|}
\hline Question & & $\begin{array}{l}\text { Yes/ } \\
\text { somewhat }\end{array}$ & No \\
\hline 1. & Is this study qualitative research? & 53 & 0 \\
\hline 2. & Is the study context clearly described? & 42 & 11 \\
\hline 2. & Is there evidence of researcher reflexivity? & 15 & 38 \\
\hline 4. & $\begin{array}{l}\text { Is the sampling method clearly described and appropriate for } \\
\text { the research question? }\end{array}$ & 45 & 8 \\
\hline 5. & $\begin{array}{l}\text { Is the method of data collection clearly described and appropri- } \\
\text { ate to the research question? }\end{array}$ & 53 & 0 \\
\hline 6. & $\begin{array}{l}\text { Is the method of analysis clearly described and appropriate to } \\
\text { the research question? }\end{array}$ & 41 & 12 \\
\hline 7. & $\begin{array}{l}\text { Are the claims made supported by sufficient evidence? I.e. did } \\
\text { the data provide sufficient depth, detail and richness? }\end{array}$ & 46 & 7 \\
\hline
\end{tabular}

Table 3. Data synthesis approach

\begin{tabular}{lll}
\hline $\begin{array}{l}\text { Main elements of the data } \\
\text { synthesis }\end{array}$ & Purpose & $\begin{array}{l}\text { Tools and frameworks } \\
\text { used }\end{array}$ \\
\hline $\begin{array}{l}\text { Identifying a theoretical } \\
\text { model of barriers and facilita- } \\
\begin{array}{l}\text { tors to health systems inter- } \\
\text { vention implementation }\end{array}\end{array}$ & $\begin{array}{l}\text { - To inform the synthesis of the included studies } \\
\text { tive data within a broader, but relevant theme }\end{array}$ & The SURE framework \\
\hline $\begin{array}{l}\text { Developing a synthesis of the } \\
\text { included studies }\end{array}$ & $\begin{array}{l}\text { - To identify and list the barriers and facilitators to implementation re- } \\
\text { ported }\end{array}$ & $\begin{array}{l}\text { Framework thematic } \\
\text { synthesis }\end{array}$
\end{tabular}


Table 3. Data synthesis approach (Continued)

- To explore the relationships between reported barriers and facilitators

$\begin{array}{ll}\begin{array}{l}\text { Exploring differences across } \\ \text { contexts }\end{array} & \begin{array}{l}\text { - To explore possible differences in barriers and facilitators between high, } \\ \text { middle and low income countries and between studies of trained tradi- } \\ \text { tional birth attendants and other type of lay health workers }\end{array}\end{array}$

Assessing the certainty of the - To assess the quality of the individual studies findings

- To assess the certainty of the evidence for drawing conclusions about

Elements of the CASP tool barriers and facilitators to lay health worker programme implementation CerQual tool

\section{Integrating the findings} of the synthesis with the Cochrane review of LHW programme effectiveness
- To suggest how specific chains of activities and events identified in the synthesis of qualitative studies could lead to the outcomes described in

Logic model approach

Table 4. Summary of qualitative findings, part 1

$\begin{array}{lll}\text { Summary statement } & \begin{array}{l}\text { Certainty in the evi- } \\ \text { dence }\end{array} & \begin{array}{l}\text { Explanation of certainty in the } \\ \text { evidence assessment }\end{array}\end{array}$

\section{Programme acceptability, appropriateness and feasibility:} The lay health worker-recipient relationship I

\begin{tabular}{|c|c|c|}
\hline $\begin{array}{l}\text { 1. Both programme recipients and LHWs emphasised } \\
\text { the importance of trust, respect, kindness and empathy } \\
\text { in the LHW-recipient relationship. }\end{array}$ & Moderate certainty & $\begin{array}{l}\text { In general, the studies were of moderate qual- } \\
\text { ity, and the finding was seen across several } \\
\text { studies and settings. }\end{array}$ \\
\hline
\end{tabular}

\section{Recipients appreciated the similarities they saw be- Moderate certainty} tween themselves and the LHWs.

In general, the studies were of moderate quality, and the finding was seen across several studies and settings.

\section{Some LHWs expressed an appreciation of the com munity-based nature of the programmes, which al- lowed them a certain amount of flexibility in their working hours.}

\section{Low certainty}

The studies were of moderate quality. However, the finding is only from two studies in Uganda and Nepal.

\section{LHWs were compared favourably with health profes-} sionals, whom recipients often regarded as less accessible, less friendly, more intimidating, and less respectful.

\section{Moderate certainty}

In general, the studies were of moderate quality, and the finding was seen across several studies and settings.

\section{Some recipients who had easy access to doctors indi- cated a preference for these health professionals.}

Low certainty
The studies were of moderate quality. However, the finding is only from two studies in Thailand and Bangladesh.
6. LHWs reported difficulties in managing emotional relationships and boundaries with recipients.

\section{Moderate certainty} In general, the studies were of moderate quality, and the finding was seen across several studies and settings.

Low certainty
7. Some recipients were concerned that home visits from LHWs might lead the LHWs to observe and share personal information or might lead neighbours to think recipients were HIV-positive.
The studies were of moderate quality. However, the finding is only from three studies in USA and South Africa. 


\section{Table 4. Summary of qualitative findings, part 1 (Continued)}

\begin{abstract}
8. LHWs, particularly those working in urban settings, reported difficulties maintaining personal safety when working in dangerous settings or at night.
\end{abstract}

Moderate certainty

In general, the studies were of moderate quality, and the finding was seen across several studies and settings, although predominantly in urban areas.
9. In some settings, gender norms meant that female LHWs could not easily move within their community to fulfil their responsibilities.
Low certainty
The studies were of moderate quality. However, the finding is only from two studies in Bangladesh.

10. Some LHWs feared the burden of responsibility and blame if interventions delivered to other community

Low certainty members were unsuccessful.

The studies were of moderate quality. However, the finding is only from two studies in Nepal and Kenya.

Table 5. Summary of qualitative findings, part 2

\begin{tabular}{lll}
\hline Summary statement & $\begin{array}{l}\text { Certainty in the cer- } \\
\text { tainty }\end{array}$ & $\begin{array}{l}\text { Explanation of certainty in the } \\
\text { evidence assessment }\end{array}$ \\
\hline
\end{tabular}

\section{Programme acceptability, appropriateness and feasibility: \\ The lay health worker-recipient relationship II}

\begin{abstract}
1. Some recipients failed to utilize LHW services because of concerns about intervention safety or a lack of understanding about the programme or the benefits of the intervention.
\end{abstract}

\section{Moderate certainty}

In general, the studies were of moderate quality, and the finding was seen across several studies and settings.

\section{Some recipients failed to utilize LHW services because they could not afford these services.}

\section{Low certainty}

The studies were of moderate quality. However, the finding is only from one study in Zambia.

\begin{abstract}
3. Recipients sometimes perceived LHW services as not relevant to their needs or not sufficient, particularly when services focused on promotional activities.
\end{abstract}

\section{Moderate certainty} In general, the studies were of moderate quality, and the finding was seen across several studies and settings.

\begin{abstract}
4. Recipients' and LHWs' perceptions of the LHW services as not relevant or not sufficient could lead to feelings of impotence and demotivation among the LHWs. LHWs who primarily offered promotional and counselling services sometimes expressed a need to offer "real healthcare" in order to better respond to the expressed needs of the community.
\end{abstract}

\section{Moderate certainty} In general, the studies were of moderate quality, and the finding was seen across several studies and settings.

\section{Recipients expressed confidence in the knowledge and skills of the LHWs and saw them as a useful source of information.}

\section{Moderate certainty}

In general, the studies were of moderate quality, and the finding was seen across several studies and settings.

\section{Moderate certainty}

In general, the studies were of moderate quality, and the finding was seen across several studies and settings.

Low certainty
The studies were of moderate quality. However, the finding is only from two studies in Nepal and South Africa. ty, but not always. In one study where community members had little respect for health professionals, LHWs attempted to disassociate themselves by emphasizing their status as unpaid volun- 
Table 5. Summary of qualitative findings, part 2 (Continued) teers. In another study, LHW credibility was questioned because they received payment.

8. LHW credibility and acceptance was believed to be strengthened through the active support and participation of community leaders and community structures. However, the success of this type of involvement was seen as useful primarily where community leaders had authority and respect.

\section{Moderate certainty}

In general, the studies were of moderate quality, and the finding was seen across several studies and settings, although primarily in LMIC countries.
9. LHW credibility and acceptance was believed to be strengthened through the active support and participation of family members involved in health decision-making.

\section{Moderate certainty}

In general, the studies were of moderate quality, and the finding was seen across several studies and settings.
10. Female LHWs and male family members sometimes found it embarrassing to communicate about family planning or HIV counselling
Low certainty
The studies were of moderate quality. However, the finding is only from three studies in USA, Pakistan and South Africa.

Table 6. Summary of qualitative findings, part 3

$\begin{array}{lll}\text { Summary statement } & \begin{array}{l}\text { Certainty in the } \\ \text { evidence }\end{array} & \begin{array}{l}\text { Explanation of cer- } \\ \text { tainty in the } \\ \text { evidence assess- } \\ \text { ment }\end{array}\end{array}$

Programme acceptability, appropriateness and feasibility: The lay health worker-health professional relationship

21. Where LHWs described good relationships with health professionals, they referred to these relationships as being respectful, supportive and egalitarian, and where LHWs were regarded as possessing complementary and valuable skills.

\section{Low certainty}

22. In studies where health professionals expressed appreciation of LHWs, they emphasised the LHWs' contribution to the health professionals' busy workload; their skills in communicating with the target population and their knowledge and experience of the issues at hand; and their commitment and dedication to their patients and the community.
23. In studies describing poor relationships between LHWs and health professionals, LHWs were regarded as unequal, subservient, not part of the organisation, and LHWs complained of arrogance and lack of respect from health professionals.

\section{Moderate certain-} ty quality, and the finding was seen across
The studies were of moderate quality. However, the finding is only from three studies in Nicaragua, Canada and South Africa.

\footnotetext{
24. In a few studies, health professionals described problems with working with LHWs. These health professionals pointed to the tension between being expected to function as partners, supervisors and evaluators, added workloads, and fear that they would lose authority.
}

\section{Moderate certain- In general, the studies were of moderate ty quality, and the finding was seen across several studies and settings.} several studies and settings.

\begin{tabular}{|c|c|c|}
\hline $\begin{array}{l}\text { 25. Some studies suggested that the closer the collaboration } \\
\text { was between the health professional and the LHW, the better } \\
\text { the relationship was likely to be. }\end{array}$ & $\begin{array}{l}\text { Low } \\
\text { certainty }\end{array}$ & $\begin{array}{l}\text { The studies were of moderate quality. } \\
\text { However, the finding is only from three } \\
\text { studies in Papua New Guinea, UK, and } \\
\text { South Africa. }\end{array}$ \\
\hline
\end{tabular}


Table 7. Summary of qualitative findings, part 4

\begin{tabular}{lll}
\hline Summary statement & $\begin{array}{l}\text { Certainty in the } \\
\text { evidence }\end{array}$ & $\begin{array}{l}\text { Explanation of cer- } \\
\text { tainty in the } \\
\text { evidence assess- } \\
\text { ment }\end{array}$ \\
\hline
\end{tabular}

\title{
Lay health worker motivation and incentives
}

26. LHWs were driven by a wide range of inter-connected motives, both intrinsic and extrinsic, including altruism and social engagement, social status and recognition, knowledge and skills gain, career development, and a general sense of empowerment. These motives were seen across a range of settings although the issue of social recognition appeared to be less common in HIC settings, where LHWs were often not from the same neighbourhood as their clients.

\section{Moderate certain-} ty
In general, the studies were of moderate quality, and the finding was seen across several studies and settings.
27. Some unsalaried LHWs expressed a strong wish for regular payment.

\section{Low certainty}

The studies were of moderate quality. However, the finding was only from two studies (Kenya, Uganda).
28. Some salaried LHWs were dissatisfied with their wages, believing that it did not reflect their abilities, their level of responsibility or their increase in skills as they acquired further training and education.

\section{Low certainty}

The studies were of moderate quality. However, the finding was only from four studies in UK, Canada, USA and South Africa.

\begin{abstract}
29. Some volunteer LHWs and other stakeholders expressed concern that payment would change the dynamics of the LHWclient relationship, threaten the LHWs' social status or lead recipients to question the LHWs' motives for delivering services. Some stakeholders underlined the importance of understanding what LHW motivations are in each context and the necessity of ensuring that the expectations of LHWs, programme managers and policy makers are in alignment.
\end{abstract}

\section{Low certainty}

The studies were of moderate quality. However, the finding was only from three studies in South Africa, Nepal and Australia.
30. Changes in tasks could influence expectations regarding incentives. For instance, while some LHWs were willing to work as volunteers when tasks could be done at their leisure, activities that demanded that they were present during labour and birth implied irregular and unpredictable working conditions, and led to demands for monetary incentives.
31. While regular salaries were not part of many programmes, other monetary and non-monetary incentives, including payment to cover out-of-pocket expenses and "work tools" such as bicycles, uniforms or ID badges, were greatly appreciated by LHWs.
Low certainty
The studies were of moderate quality. However, the finding was only from one study in Nepal.

32. Some LHWs who received payment through selling drugs and supplements encountered problems including an inflated idea of the profit they would be making; people buying drugs on credit purchase basis or being reluctant to buy drugs because of their perception that the LHWs got the drugs for free; and competition from other vendors.

\section{Moderate certain- In general, the studies were of moderate ty quality, and the finding was seen across several studies and settings.}

$\begin{array}{ll}\text { Low } & \text { The studies were of moderate quality. } \\ \text { certainty } & \text { However, the finding was only from two } \\ \text { studies in Bangladesh and Kenya. }\end{array}$

Low studies in Bangladesh and Kenya. 


\section{Table 7. Summary of qualitative findings, part 4 (Continued)}

33. Some LHWs referred to frustration when payment differed from region to region or across different types of institutions.
Low certainty
The studies were of moderate quality. However, the finding was only from two studies in Nepal and Ethiopia.
34. Some LHWs and other stakeholders complained that there were few systems in place through which they could voice their individual or collective complaints about incentives or other issues.
Low

certainty
The studies were of moderate quality. However, the finding was only from two studies (Iran, Nepal).

Table 8. Summary of qualitative findings, part 5

\begin{tabular}{|c|c|c|}
\hline Summary statement & Certainty in the evidence & $\begin{array}{l}\text { Explanation } \\
\text { of certainty } \\
\text { in the } \\
\text { evidence as- } \\
\text { sessment }\end{array}$ \\
\hline
\end{tabular}

\section{Lay health worker training, supervision and working conditions}

\begin{tabular}{lll}
\hline $\begin{array}{l}\text { 35. LHWs highlighted aspects of training } \\
\text { that they saw as positive including the use } \\
\text { of practical demonstrations, picture cards } \\
\text { and frequent refresher training. }\end{array}$ & $\begin{array}{l}\text { Low } \\
\text { certainty }\end{array}$ & $\begin{array}{l}\text { The studies were of moderate quality. However, } \\
\text { the finding was only from three studies in Gam- } \\
\text { bia, South Africa and Ethiopia. }\end{array}$
\end{tabular}

\begin{abstract}
36. In general, however, LHWs highlighted a number of weaknesses with current training, including schedules not flexible enough to respond to LHW turnover, poor quality and irrelevant training programmes and unskilled trainers.
\end{abstract}

Moderate certainty

In general, the studies were of moderate quality, and the finding was seen across several studies and settings.

\section{LHWs asked for more training in coun- selling and communication, a task which is often central to the role of the LHWs, but which they often found to be complex to perform.}

\section{Moderate certainty}

In general, the studies were of moderate quality, and the finding was seen across several studies and settings.

\begin{abstract}
38. Some LHWs wanted training in topics outside of their current role, including common health problems, birth complications, sexual abuse and domestic violence, substance abuse and housing difficulties. These requests appeared to reflect the LHWs' need to respond to the expressed needs of the community and to the circumstances they were confronted with in their work.
\end{abstract}

$\begin{array}{ll}\text { Low } & \text { The studies were of moderate quality. Howev- } \\ \text { certainty } & \text { er, the finding was only from four studies in USA, } \\ & \text { Thailand and Honduras. }\end{array}$

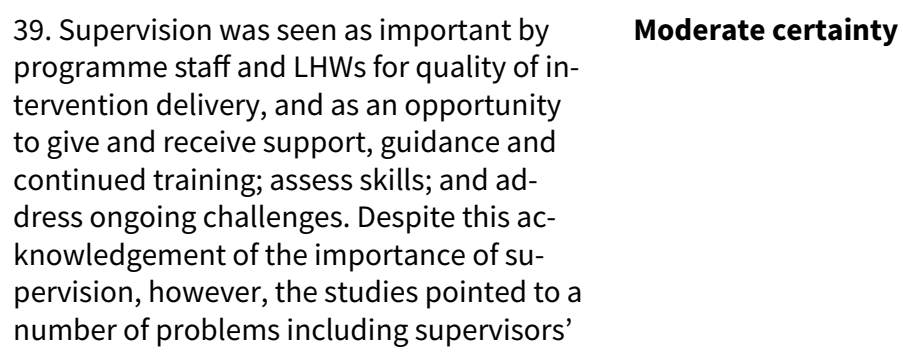
programme staff and LHWs for quality of intervention delivery, and as an opportunity to give and receive support, guidance and continued training; assess skills; and address ongoing challenges. Despite this acknowledgement of the importance of supervision, however, the studies pointed to a number of problems including supervisors'

\section{Moderate certainty}

In general, the studies were of moderate quality and the finding was seen across several studies and settings. 
Table 8. Summary of qualitative findings, part 5 (Continued)

lack of time, large distances, lack of transportation and lack of skills.

\begin{abstract}
40. A small number of studies described supervision that was perceived to be good. Here, supervisors displayed respect to the LHW; had a good understanding of the LHW's working conditions and personal circumstances; provided emotional and technical support; and carried out plentiful field visits.
\end{abstract}
Low
certainty
The studies were of moderate quality. However, the finding was only from a small number of stud- ies and settings.

$\begin{array}{lll}\begin{array}{l}\text { 41. In addition to formal supervision, some } \\ \text { LHWs also appreciated the opportunity to } \\ \text { share experiences with other LHWs }\end{array} & \begin{array}{l}\text { Low } \\ \text { certainty }\end{array} & \begin{array}{l}\text { The studies were of moderate quality. However, } \\ \text { the finding was only from two studies in USA and } \\ \text { Australia. }\end{array}\end{array}$

42. Both LHWs and supervisors in a number of studies expressed concern about the LHWs' workload and the distances they had to cover, and LHWs sometimes found it difficult to carry out all of their tasks because of this.
In general, the studies were of moderate quality, and the finding was seen across several studies and settings.

\section{Moderate certainty}

43. A few studies, mostly in LMICs, referred to poor working conditions, including inadequate lighting and small, dirty rooms, lack of supplies, too much paperwork, and high staff turnover.

Table 9. Summary of qualitative findings, part 6

\begin{tabular}{|c|c|c|}
\hline Summary statement & $\begin{array}{l}\text { Certainty in the cer- } \\
\text { tainty }\end{array}$ & $\begin{array}{l}\text { Explanation of certainty in the } \\
\text { evidence assessment }\end{array}$ \\
\hline \multicolumn{3}{|l|}{ Patient flow processes } \\
\hline $\begin{array}{l}\text { 44. LHWs in a number of studies were trained to refer patients with } \\
\text { complications on to health professionals. However, health profes- } \\
\text { sionals in one study were concerned that trained TBAs were over- } \\
\text { confident about their ability to manage danger signs or lacked the } \\
\text { knowledge to recognise such signs. Overconfidence was also sug- } \\
\text { gested by authors of another study as a reason for poor compliance } \\
\text { among LHWs who were meant to refer children with malaria on. }\end{array}$ & $\begin{array}{l}\text { Low } \\
\text { certainty }\end{array}$ & $\begin{array}{l}\text { The studies were of moderate } \\
\text { quality. However, the finding was } \\
\text { only from two studies in Malawi } \\
\text { and Gambia. }\end{array}$ \\
\hline $\begin{array}{l}\text { 45. The LHWs themselves and their recipients pointed to different } \\
\text { factors that made referral difficult to those highlighted by health } \\
\text { professionals. Some trained TBAs and recipients pointed out that } \\
\text { referral was made difficult by a lack of health professionals to refer } \\
\text { patients to. }\end{array}$ & $\begin{array}{l}\text { Low } \\
\text { certainty }\end{array}$ & $\begin{array}{l}\text { The studies were of moderate } \\
\text { quality. However, the findings } \\
\text { were only from two studies in Pak- } \\
\text { istan and Honduras. }\end{array}$ \\
\hline $\begin{array}{l}\text { 46. LHWs also pointed to clients' own reluctance to access care, } \\
\text { partly due to bad experiences with health professionals, fear of cae- } \\
\text { sarean sections, and concerns over cost. }\end{array}$ & Moderate certainty & $\begin{array}{l}\text { In general, the studies were of } \\
\text { moderate quality, and the finding } \\
\text { was seen across several studies } \\
\text { and settings. }\end{array}$ \\
\hline
\end{tabular}


Table 9. Summary of qualitative findings, part 6 (Continued)

47. Trained TBAs in some studies were also reluctant to refer women on because of the poor treatment and lack of cooperation the TBAs themselves experienced from health professionals.
Moderate certainty In general, the studies were of moderate quality, and the finding was seen across several studies and settings.
48. Other obstacles to referral were logistical factors, particularly the lack of transport necessary to move the woman to the clinic, but also lack of money to pay for transport or a telephone with which to call an ambulance.

49. In two studies, where LHWs were not TBAs, patients accompanied by LHWs were given preferential treatment by clinic staff.

\section{Moderate certainty}

In general, the studies were of moderate quality, and the finding was seen across several studies and settings.
Low certainty
The studies were of moderate quality. However, the findings were only from two studies in Nicaragua and Kenya.

\section{Service integration}

50. Some studies suggest that LHW programmes could be strengthened by a stronger integration into other services.
Low

certainty
The studies were of moderate quality. However, the finding was only from a small number of studies and settings.

\section{Social and cultural conditions}

51. Some studies described how social conditions, societal beliefs and values influenced LHW programme initiation, implementation or acceptance. Examples of this included differences in community organisation and cohesion, proximity to town and gender roles.
Low certainty

The studies were of moderate quality. However, the finding was only from a small number of studies and settings.

\section{APPENDICES}

\section{Appendix 1. MEDLINE search strategy}

MEDLINE In-Process \& Other Non-Indexed Citations and Ovid MEDLINE

\begin{tabular}{ll}
\hline 1. & Community Health Aides/ \\
\hline 2. & Home Health Aides/ \\
\hline 3. & Allied Health Personnel/ \\
\hline 4. & Voluntary Workers/ \\
\hline 5. & Home Nursing/ \\
\hline 6. & Peer Group/ \\
\hline 7. & Social Support/ \\
\hline 8. & (llayorvoluntaryorvolunteer or untrainedor unlicensedornonprofessional? or non profession-
\end{tabular}

8.

((lay or voluntary or volunteer? or untrained or unlicensed or nonprofessional? or non professional?) adj5 (worker? or visitor? or attendant? or aide or aides or support\$ or person $\$$ or helper? or 
carer? or caregiver? or care giver? or consultant? or assistant? or staff or visit\$ or midwife or midwives)).tw.

9.

10.

lay volunteer?.tw.

(paraprofessional? or paramedic or paramedics or paramedical worker? or paramedical personnel or allied health personnel or allied health worker? or support worker? or home health aide?).tw.

11. (trained adj3 (volunteer? or health worker? or mother?)).tw.

12.

13.

14.

15.

16.

17.

18.

19.

20

$$
21 .
$$

22.

23.

\begin{tabular}{ll}
\hline 24. & 22 and 23 \\
\hline 25. & or/1-21,24 \\
\hline 26. & limit 25 to english language \\
\hline 27. & limit 26 to "qualitative studies (specificity)" \\
\hline
\end{tabular}

\section{Appendix 2. CINAHL (EBSCO) search stategy}

\begin{tabular}{ll}
\hline$\#$ & Query \\
\hline S28 & S25 and S26 \\
& Limiters - Exclude MEDLINE records \\
\hline S27 & S25 and S26 \\
\hline
\end{tabular}

Barriers and facilitators to the implementation of lay health worker programmes to improve access to maternal and child health: a 

$\mathrm{S} 17$ or $\mathrm{S} 18$ or $\mathrm{S} 19$ or $\mathrm{S} 20$ or $\mathrm{S} 23$

Limiters - Language: English

$\mathrm{S} 1$ or $\mathrm{S} 2$ or $\mathrm{S} 3$ or $\mathrm{S} 4$ or $\mathrm{S} 5$ or $\mathrm{S} 6$ or $\mathrm{S} 7$ or $\mathrm{S} 8$ or $\mathrm{S} 9$ or $\mathrm{S} 10$ or $\mathrm{S} 11$ or $\mathrm{S} 12$ or $\mathrm{S} 13$ or $\mathrm{S} 14$ or $\mathrm{S} 15$ or $\mathrm{S} 16$ or $\mathrm{S} 17$ or $\mathrm{S} 18$ or $\mathrm{S} 19$ or $\mathrm{S} 20$ or $\mathrm{S} 23$

Limiters - Clinical Queries: Qualitative - Best Balance $\mathrm{S} 17$ or $\mathrm{S} 18$ or $\mathrm{S} 19$ or $\mathrm{S} 20$ or $\mathrm{S} 23$

\begin{tabular}{|c|c|}
\hline S23 & S21 and S22 \\
\hline S22 & $\begin{array}{l}\text { TI ( (care or aide or aides or nursing or support or intervention* or visit*) N3 (lay or volunteer* or } \\
\text { voluntary) ) OR AB ( (care or aide or aides or nursing or support or intervention* or visit*) N3 (lay or } \\
\text { volunteer* or voluntary) ) }\end{array}$ \\
\hline S21 & $\begin{array}{l}\text { TI ( home NO (care or aide or aides or nursing or support or intervention* or treatment }{ }^{\star} \text { or visit }{ }^{\star} \text { ) ) } \\
\text { OR AB ( home NO (care or aide or aides or nursing or support or intervention* or treatment }{ }^{\star} \text { or vis- }^{\star} \\
\text { it }^{\star} \text { ) ) }\end{array}$ \\
\hline S20 & $\begin{array}{l}\text { TI ( "church based" N3 (intervention* or program* or counsel*) ) OR AB ( "church based" N3 (inter- } \\
\text { vention* or program* or counsel*)) }\end{array}$ \\
\hline S19 & 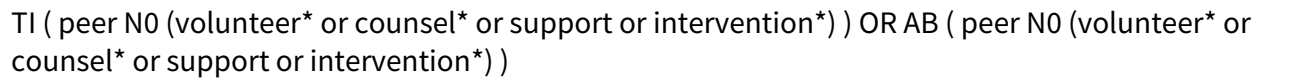 \\
\hline S18 & $\begin{array}{l}\text { TI ( doula or doulas or douladural* or monitrice* or linkworker* or "link worker" or "link workers" } \\
\text { or "barefoot doctor" or "barefoot doctors" or outreach ) OR AB ( doula or doulas or douladural* or } \\
\text { monitrice* or linkworker* or "link worker" or "link workers" or "barefoot doctor" or "barefoot doc- } \\
\text { tors" or outreach) }\end{array}$ \\
\hline S17 & $\begin{array}{l}\text { TI ( (birth or childbirth or labor or labour) N0 (attendant }{ }^{\star} \text { or assistant }{ }^{\star} \text { ) ) OR AB ( (birth or childbirth } \\
\left.\text { or labor or labour) N0 (attendant }{ }^{\star} \text { or assistant }{ }^{\star}\right) \text { ) }\end{array}$ \\
\hline S16 & $\begin{array}{l}\mathrm{TI} \text { ( community N3 (volunteer* or aide or aides or support) ) OR AB ( community N3 (volunteer* or } \\
\text { aide or aides or support) ) }\end{array}$ \\
\hline S15 & $\begin{array}{l}\text { TI ( (community or village*) N3 ("health worker" or "health workers" or "health care worker" or } \\
\text { "health care workers" or "healthcare worker" or "healthcare workers") ) OR AB ( (community or vil- } \\
\text { lage*) N3 ("health worker" or "health workers" or "health care worker" or "health care workers" or } \\
\text { "healthcare worker" or "healthcare workers") ) }\end{array}$ \\
\hline S14 & $\begin{array}{l}\text { TI ( trained N3 (volunteer* or "health worker" or "health workers" or mother*) ) OR AB ( trained N3 } \\
\text { (volunteer* or "health worker" or "health workers" or mother*)) }\end{array}$ \\
\hline S13 & $\begin{array}{l}\text { TI ( "lay volunteer" or "lay volunteers" or paraprofessional* or paramedic or paramedics or "para- } \\
\text { medical worker" or "paramedical workers" or "paramedical personnel" or "allied health person- } \\
\text { nel" or "allied health worker" or "allied health workers" or "support worker" or "support workers" } \\
\text { or "home health aide" or "home health aides" ) OR AB ( "lay volunteer" or "lay volunteers" or para- } \\
\text { professional* or paramedic or paramedics or "paramedical worker" or "paramedical workers" or } \\
\text { "paramedical personnel" or "allied health personnel" or "allied health worker" or "allied health } \\
\text { workers" or "support worker" or "support workers" or "home health aide" or "home health aides" ) }\end{array}$ \\
\hline S12 & 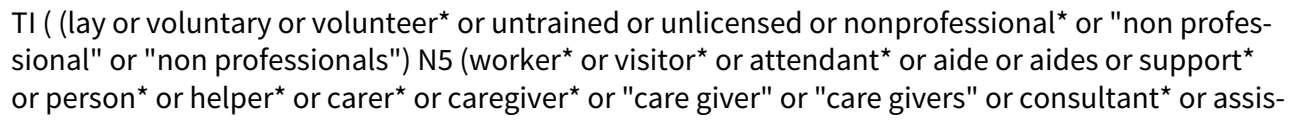 \\
\hline
\end{tabular}


tant ${ }^{\star}$ or staff or visit ${ }^{\star}$ or midwife or midwives) ) OR AB ( (lay or voluntary or volunteer ${ }^{\star}$ or untrained or unlicensed or nonprofessional* or "non professional" or "non professionals") N5 (worker* or visitor $^{\star}$ or attendant ${ }^{\star}$ or aide or aides or support ${ }^{\star}$ or person ${ }^{\star}$ or helper ${ }^{\star}$ or carer ${ }^{\star}$ or caregiver ${ }^{\star}$ or "care giver" or "care givers" or consultant* or assistant* or staff or visit* or midwife or midwives) )

\begin{tabular}{ll}
\hline S11 & (MH "Peer Group") \\
\hline S10 & (MH "Doulas") \\
\hline S9 & (MH "Lay Midwifery") \\
\hline S8 & (MH "Lay Midwives") \\
\hline S7 & (MH "Health Personnel, Unlicensed") \\
\hline S6 & (MH "Nursing Assistants") \\
\hline S5 & (MH "Allied Health Personnel") \\
\hline S4 & (MH "Home Nursing") \\
\hline S3 & (MH "Home Health Aides") \\
\hline S2 & (MH "Community Health Workers") \\
\hline S1 & (MH "Volunteer Workers") \\
\hline
\end{tabular}

\section{Appendix 3. British Nursing Index and Archive search strategy}

\begin{tabular}{ll}
\hline 1. & Voluntary Organisations/ \\
\hline 2. & Carers/ \\
\hline 3. & Health Care Assistants/ \\
\hline 4. & Health Visiting/ \\
\hline 5. & $\begin{array}{l}\text { ((lay or voluntary or volunteer? or untrained or unlicensed or nonprofessional? or non profession- } \\
\text { al?) adj5 (worker? or visitor? or attendant? or aide or aides or support\$ or person } \$ \text { or helper? or } \\
\text { wives)).tw. }\end{array}$ \\
\hline 6. & \begin{tabular}{l} 
lay volunteer?.tw. \\
\hline 7.
\end{tabular} \\
\hline (paraprofessional? or paramedic or paramedics or paramedical worker? or paramedical personnel \\
\hline 9. & or allied health personnel or allied health worker? or support worker? or home health aide?).tw. \\
\hline 10. & (trained adj3 (volunteer? or health worker? or mother?)).tw. \\
\hline
\end{tabular}


(Continued)

11.

((birth or childbirth or labor or labour) adj (attendant? or assistant?)).tw.

\begin{tabular}{|c|c|}
\hline 12. & (doula? or douladural? or monitrice?).tw. \\
\hline 13. & (peer adj (volunteer? or counsel\$ or support or intervention?)).tw. \\
\hline 14. & (church based adj3 (intervention\$ or program\$ or counsel\$)).tw. \\
\hline 15. & (linkworker? or link worker?).tw. \\
\hline 16. & barefoot doctor?.tw. \\
\hline 17. & outreach.tw. \\
\hline 18. & (home adj (care or aide or aides or nursing or support or intervention? or treatment? or visit\$)).tw. \\
\hline 20. & 18 and 19 \\
\hline 21. & or/1-17,20 \\
\hline 22. & "interviews and interviewing"/ \\
\hline 23. & 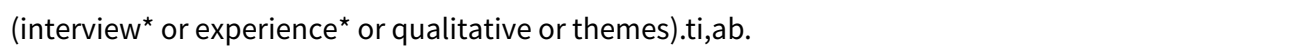 \\
\hline 24. & 22 or 23 \\
\hline 25. & 21 and 24 \\
\hline
\end{tabular}

WHAT'S NEW

\begin{tabular}{lll}
\hline Date & Event & Description \\
\hline 1 March 2019 & Amended & Minor error corrected in the title \\
\hline
\end{tabular}

\section{H I S T O R Y}

Protocol first published: Issue 2, 2013

Review first published: Issue 10, 2013

\begin{tabular}{lll}
\hline Date & Event & Description \\
\hline 5 November 2015 & Amended & $\begin{array}{l}\text { Review transferred to qualitative review template and some fig- } \\
\text { ures converted to tables }\end{array}$ \\
\hline
\end{tabular}




\section{CONTRIBUTIONS OF AUTHORS}

CG, SL, and CC conceptualised the review. CG, CC, BC, AS, SL, JN and AR designed the approach and prepared the protocol. Marit Johansen developed the search strategy. CG, CC, BC and AS actively participated in all stages of the review (conducting the search, obtaining data, data extraction, data synthesis, and review preparation). SL, JN and AR contributed to the interpretation of the evidence, development of the logic model, and editing of the review.

\section{DECLARATIONS OF INTEREST}

SL is an editor for the Cochrane Effective Practice and Organisation of Care Review Group. CG and SL are editors for the Cochrane Consumers and Communication Review Group. JN is co-convener of the Cochrane Qualitative and Implementation Methods Group. CG and SL coauthored one of the studies that was included in this synthesis. The other review authors have no conflicts of interest.

\section{SOURCES OF SUPPORT}

\section{Internal sources}

- No sources of support supplied

\section{External sources}

- Alliance for Health Policy and Systems Research, Switzerland.

Implementation Research Platform: WHO-AHPSR grant 2011/138613-2

- The Norwegian Agency for Development Cooperation (Norad), Norway.

\section{DIFFERENCES BETWEEN PROTOCOLANDREVIEW}

None. As is usual with qualitative syntheses, the design, methods and processes of the review were articulated once the pool of evidence was known.

\section{INDEX TERMS}

\section{Medical Subject Headings (MeSH)}

${ }^{\star}$ Child Health Services; *Community Health Workers [education] [psychology] [supply \& distribution]; *Health Services Accessibility; *Maternal Health Services; Attitude; Patient Acceptance of Health Care [psychology]; Program Evaluation; Qualitative Research; Salaries and Fringe Benefits

\section{MeSH check words}

Adult; Child; Female; Humans 